\title{
MAPEAMENTO DE GENES DE RESISTÊNCIA A MANCHA DE Phaeosphaeria EM MILHO
}

\section{MARIA TERESA GOMES LOPES}

Engenheiro Agrônomo

Orientador: Prof. Dr. LUIS EDUARDO ARANHA CAMARGO

Tese apresentada à Escola Superior de Agricultura "Luiz de Queiroz", Universidade de São Paulo, para obtenção do título de Doutor em Agronomia, Área de Concentração: Genética e Melhoramento de Plantas.

\section{PIRACICABA}

Estado de São Paulo - Brasil

Janeiro - 2003 


\section{ERRATA}

MAPEAMENTO DE GENES DE RESISTÊNCIA A MANCHA DE Phaeosphaeria EM MILHO

\begin{tabular}{|c|c|c|c|c|}
\hline Página. & item & linha & onde se lê & leia-se \\
\hline 25 & 3.1 .4 & $2^{\mathrm{D}}$ Par. $2^{\mathrm{a}} \mathrm{L}$ & $\ldots \beta\left(X^{\prime} Y\right)^{\vdots 1} X^{\prime} Y$, do sistema $\left(y=X^{\prime} \beta\right)$ de $\ldots$ & $\ldots \beta\left(X^{\prime} X\right)^{-1} X^{\prime} Y$ do sistema $(Y=X \beta+\varepsilon)$ de $\ldots$ \\
\hline 27 & 3.1 .4 & $2^{\circ}$ Par. $2^{\mathrm{a}} \mathrm{L}$. & $\ldots \beta\left(X^{\prime} Y\right)^{-1} X^{\prime} Y$ do sistema $\left(y=X^{\prime} \beta\right)$ de...' & $\therefore \beta\left(X^{\prime} X\right)^{-1} X^{\prime} Y$ do sistema $(Y=X \beta+\varepsilon)$ de $\ldots$ \\
\hline Página. & item & Coluna & onde se lê & leia-se \\
\hline 28 & 3.1 .4 & $\begin{array}{l}\text { Matriz X. } \\
\text { Coluna } 5\end{array}$ & $\ldots-\ldots$ & $\ldots+\ldots$ \\
\hline 28 & 3.1 .4 & $\begin{array}{l}\text { Matriz X. } \\
\text { Coluna } 5\end{array}$ & + & $\ldots-\ldots$ \\
\hline 51 & 4.1 & $\begin{array}{l}\text { Tabela } 7 \\
\text { Coluna } 1\end{array}$ & Na primeira coluna :.. & $\begin{array}{l}\text { Conforme coluna } 1 \text { da Tabela } 3 \text { da página } \\
29\end{array}$ \\
\hline
\end{tabular}


Dados Internacionais de Catalogação na Publicação (CIP) DIVISĀo DE BIBLIOTECA E DOCUMENTAÇĀO - ESALQ/USP

\section{Lopes, Maria Teresa Gomes}

Mapeamento de genes de resistência a mancha de Phaeosphaeria em milho / Maria Teresa Gomes Lopes. - - Piracicaba, 2003.

$117 \mathrm{p}$.

Tese (doutorado) - Escola Superior de Agricultura Luiz de Queiroz, 2003. Bibliografia.

1..Mab̀cha-foliar 3. Mapeamento genético 3. Melhoramento genético vegetal 4. Milho 5. Resistência a doença I. Título

CDD 633.15 
Aos meus pais:

Geraldo (com saudades).

Maria Imaculada.

Ofereço

Ao meu esposo:

. Ricardo Lopes.

Por nosso amor e carinho

Dedico 


\section{AGRADECIMENTOS}

A Deus pela força e paciência concedidas para concretizar este trabalho.

À Escola Superior de Agricultura "Luiz de Queiroz" - (ESALQ), em especial ao Programa de Pós-graduação em Genética e Melhoramento de Plantas, pela oportunidade de realizar este curso.

À Fundação de Amparo a Pesquisa do Estado de São Paulo - FAPESP, pela concessão da bolsa de estudo e o auxílio financeiro a pesquisa.

Ao Prof. Dr. Luis Eduardo Aranha Camargo pela orientação, confiança, sugestões e apoio durante todas as etapas da realização deste trabalho. Em especial pela oportunidade de realizar um trabalho gratificante e enriquecedor à minha formação profissional.

À profa. Dra. Maria Lucia Carneiro Vieira pelo incentivo, contribuições a este trabalho, por tanta gentileza e atenção durante a minha permanência no Laboratório de Biologia Celular e Molecular de Plantas (ESALQ-USP).

Aos professores do Departamento de Genética da ESALQ-USP pelos ensinamentos e colaboração ao desenvolvimento deste trabalho.

A meu esposo, Ricardo Lopes, pelo companheirismo, incentivo, e colaboração em todas as etapas de realização deste trabalho. 
Ao Dr. Heyder Diniz Silva, professor da Universidade Federal de Uberlândia, pelas discussões sobre o tema deste trabalho e colaboração com valiosas sugestões.

Ao Dr. Herberte Pereira da Silva e empresa DowAgroSciences pelo fornecimento do material vegetal e pelo auxílio na condução dos experimentos de campo.

Aos amigos, Kátia R. Brunelli, Jorge O. Gieco, Rodrigo R. Matiello e Maria Rita Campos, pela ajuda em muitos momentos dificeis.

Aos colegas do Laboratórios de Genética Molecular (ESALQ-USP) Regina, Kátia, Célia, Rodrigo, Jorge, Adriane, Mariana, Ana Paula, Viviane, Camila, Maila, Osmar, Ademir, Alice, Jaqueline, Maeli, Cláudia, Alessandra, Cristina, Daniela, Giovana, Vanoli, Paulo, Maurício; e do Laboratório de Biologia Celular e Molecular de Plantas (ESALQ-USP) Elizabete, Juliano, Mariza, Ricardo, Luis Ricardo, Frederico, Maria Rita, Carlos Oliveira, Luciana Rossini, Monalisa, Luciana Barbosa, Adriano, Michel, por tanto apoio e pelos momentos de convivio e crescimento compartilhados.

Aos estudantes e funcionários dos Departamentos de Genética e de Entomologia, Fitopatologia e Zoologia Agrícola da ESALQ-USP pela atenção e incentivo.

A todas as pessoas que direta ou indiretamente contribuíram para a realização deste trabalho. 


\section{SUMÁRIO}

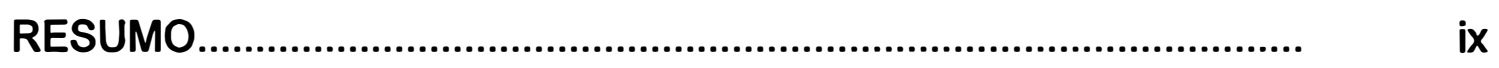

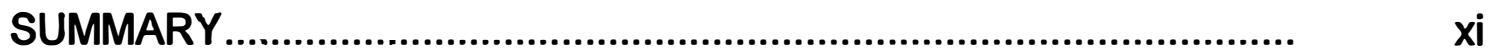

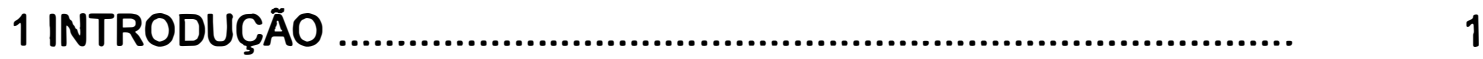

2 REVISÃO DE LITERATURA.........................................................

2.1 A mancha de Phaeosphaeria...................................................... 3

2.1.1 Importância econômica e distribuição geográfica.......................... 3

2.1.2 Etiologia e sintomatologia......................................................... 4

2.1.3 Avaliação da severidade da mancha de Phaeosphaeria e época de avaliação.............................................................................

2.1.4 Resistência genética a mancha de Phaeosphaeria....................... 8

2.2 Marcadores moleculares............................................................. 9

2.2.1 Marcadores microssatélites (SSR)...............................................

2.2.2 Marcadores AFLPs.................................................................

2.3 Mapeamento genético.............................................................

2.3.1 A análise de grupos segregantes e de indivíduos extremos para resistência......................................................................................

2.3.2 Análises estatísticas para detecção de QTLs.............................. 14

2.4 Genes de resistência a doenças em milho...................................... 17

3 MATERIAL E MÉTODOS.......................................................... 22

3.1 Análise de médias de gerações para resistência à mancha de Phaeosphaeria em três linhagens tropicais de milho........................... 22

3.1.1 Material vegetal................................................................. 22

3.1.2 Avaliação da resistência à mancha de Phaeosphaeria................ 23

3.1.3 Análises estatísticas.............................................................. 
3.1.4 Estimativa de efeitos gênicos.

3.2 Mapeamento de locos de resistência quantitativa à mancha de Phaeosphaeria

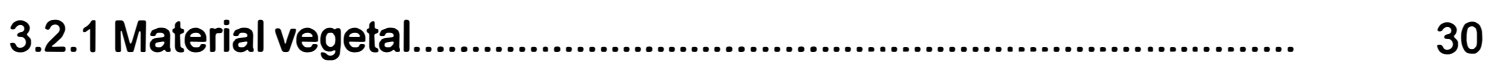

3.2.2 Avaliação da resistência......................................................... 30

3.2.3 Genotipagem com marcadores moleculares.............................. 31

3.2.3.1 Extração e quantificação do DNA........................................... 31

3.2.3.2 Genotipagem com marcadores microssatélites....................... 32

3.2.3.3 Genotipagem com marcadores AFLPs................................. 34

3.2.4 Análises estatísticas............................................................ 40

3.2.4.1 Análises de variância.......................................................... 40

3.2.4.2 Testes de segregação mendeliana.......................................... 41

3.2.5 Identificação de marcadores ligados a QRLs com análise de regressão linear múltipla................................................................. 42

3.2.6 Mapeamento de QRLs utilizando a metodologia de intervalo 43 composto (MIC)

4 RESULTADOS E DISCUSSÃO

4.1 Análise de médias de gerações.

4.2 Mapeamento de genes de resistência à mancha de Phaeosphaeria em milho.

4.2.1 Avaliação de progênies $F_{3}$ de milho para resistência à mancha de Phaeosphaeria.

4.2.2 Análise de marcadores microssatélites........................................ 60

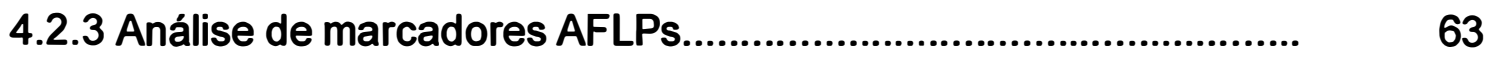

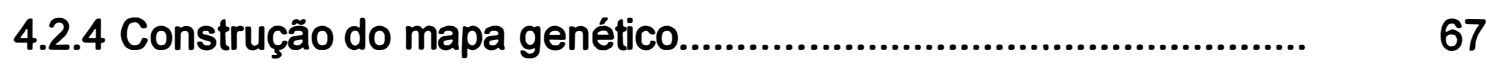

4.2.5 Identificação de marcadores moleculares associados a QRLs usando regressão linear múltipla

4.2.6 Mapeamento de QRLs utilizando a metodologia do intervalo composto (MIC).

4.2.7 Considerações finais. 


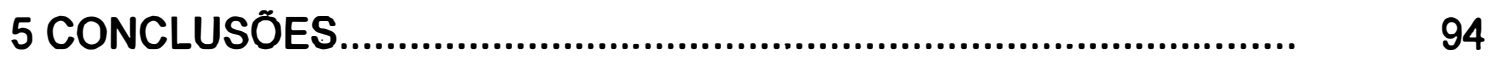

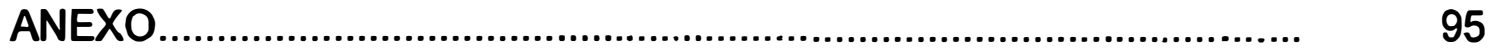

REFERÊNCIAS BIBLIOGRÁFICAS......................................... 102 


\title{
MAPEAMENTO DE GENES DE RESISTÊNCIA A MANCHA DE Phaeosphaeria EM MILHO
}

\author{
Autora: MARIA TERESA GOMES LOPES \\ Orientador: Prof. Dr. LUIS EDUARDO ARANHA CAMARGO
}

\section{RESUMO}

O objetivo do presente trabalho foi estimar o modo de herança da resistência a mancha de Phaeosphaeria em milho através da análise de média de gerações e identificar locos de resistência quantitativa ( $Q R L)$ por meio de marcadores moleculares. Uma análise de média de gerações foi realizada para duas populações descendentes dos cruzamentos entre duas linhagens resistentes (DAS72 e DAS95) com uma suscetível (DAS21). A avaliação foi realizada utilizando-se escala diagramática, 30 dias após o florescimento. As médias de severidade da doença dos genitores e das gerações $F_{1}, F_{2}, R C P_{1}$ e $\mathrm{RCP}_{2}$ foram analisadas segundo o modelo de Mather e Jinks (1971). Os resultados evidenciaram a importância dos efeitos genéticos aditivos comparado aos dominantes em ambas populações. A variação genética média devida a efeitos aditivos foi de $73 \%$ e $74 \%$ em cada população. A resistência à mancha de Phaeosphaeria apresentou-se ainda como uma característica de alta herdabilidade no sentido amplo (71\% e $63 \%$, respectivamente para as populações oriundas de DAS95 $\times$ DAS21 e DAS72 x DAS21) e oligogênia. 0 mapeamento de QRLs foi realizado com base na análise de 118 famílias $F_{3}$, provenientes do cruzamento entre DAS95 x DAS21, avaliadas em duas épocas de semeadura com três repetições cada. A severidade da doença foi avaliada 
no florescimento, 15 e 30 dias após este. A partir das avaliações pontuais, calculou-se a AUDPC (área abaixo da curva de progresso da doença) para cada família. Análises de ligação entre marcadores e QRLs foram efetuadas por regressão linear múltipla (RLM) e por mapeamento por intervalo composto (MIC). A proporção da variação fenotípica em resistência devida a associação de QRLs com marcadores para avaliações pontuais e AUDPC dos dois experimentos e análise conjunta dos mesmos, variou de $33 \%$ a $45 \%$, segundo a análise de RLM. Considerando as três avaliações individuais e a AUDPC, foram identificados 10 marcadores ligados a QRLs no primeiro experimento, 9 no segundo e 9 na análise conjunta, em seis cromossomos distintos. Um QRL foi identificado ligado a um marcador não alocado a nenhum cromossomo. Foram identificados QRLs que apresentaram interação com o ambiente, ressaltando a importância de avaliar populações em diferentes ambientes. Através do método do mapeamento por intervalo composto, foram mapeados QRLs em 10 intervalos, sendo 2 no cromossomo 1, 2 no cromossomo 2, 3 no cromossomo 4, 1 no cromossomo 5, 1 no cromossomo 6 e 1 no cromossomo 9. Foram identificados alelos de resistência em ambos os genitores, embora a maior contribuição para resistência tenha sido a do genitor resistente. 


\title{
MAPPING OF RESISTANCE GENES TO Phaeosphaeria LEAF SPOT IN MAIZE (Zea mays L.)
}

\author{
Author: MARIA TERESA GOMES LOPES \\ Adviser: Prof. Dr. LUIS EDUARDO ARANHA CAMARGO
}

\section{SUMMARY}

The objective of the present work was to estimate the mode of inheritance of resistance to Phaeosphaeria leaf spot of maize through generation mean analysis and to map quantitative resistance loci (QRL) with molecular markers. The analysis of generations was carried out for two populations derived from crossings of two resistant lines (DAS72 and DAS95) with a susceptible one (DAS21). Disease severity was evaluated 30 days after flowering using a diagrammatic scale. The mean disease severity of the paternal, $F_{1}, F_{2}, B C P_{1}$ and $B C P_{2}$ generations were analyzed according to the model of Mather and Jinks (1971). Results evidenced the importance of additive genetic effects compared to the dominant ones in both populations. The genetic variation due to additive effects accounted for $73 \%$ and $74 \%$ of the total genetic variance in each population. Resistance to Phaeosphaeria leaf spot was highly inheritable in the broad sense ( $71 \%$ and $63 \%$, respectively for the populations originated from DAS95 $\times$ DAS21 and DAS72 $\times$ DAS21) and oligogenic. Mapping of QRLs was accomplished based on the analysis of $118 F_{3}$ families derived from DAS95 $\times$ DAS21, evaluated in two field trials with three replications each. Disease severity was evaluated at the flowering time and 15 and $\mathbf{3 0}$ days after. These evaluations were used to calculate the AUDPC (area under the curve of disease progress) for each family. Linkage analyses between markers and 
QRLs were made using multiple linear regression (MLR) and composite interval mapping (CIM). The proportion of the phenotypic variation in resistance due to the association of QRLs with markers for each evaluation and AUDPC of the two experiments as well as for the mean values of both experiments varied from 33 $\%$ to $45 \%$, according to MLR analysis. Considering the three individual evaluations and AUDPC, 10 markers were found linked to QRLs in the first experiment, 9 in the second and 9 in the joint analysis in six different chromosomes. A QRL was identified linked to a marker not allocated to any chromosome. Evidences of QRLs $x$ environment interactions emphasized the importance of evaluating populations in different environments. The results of CIM analysis identified QRLs in 10 intervals, 2 in chromosome 1, 2 in chromosome 2, 3 in chromosome 4, 1 in chromosome 5, 1 in chromosome 6 and 1 in chromosome 9. Resistance alleles were identified in both genitors, although alleles from the resistant genitor contributed most to resistance. 


\section{INTRODUÇÃO}

A mancha de Phaeosphaeria ou pinta branca é considerada, no Brasil, a principal doença do milho, tanto pelos prejuízos que tem causado aos cultivares suscetiveis, como pela sua ampla distribuição. Pode ser encontrada em todas as regiões brasileiras onde o milho é cultivado (Silva, 2002). Sua ocorrência foi relatada ainda em muitas outras áreas tropicais e subtropicais do mundo (Carson et al., 1991; Fantin, 1994; Hennings, 1902; Rane et. al., 1965 e Shurtleff, 1992).

O milho possui uma grande diversidade genética para resistência a patógenos, o que viabiliza a utilização do controle genético para o manejo de suas doenças (Balmer \& Pereira, 1987; Futrel, 1975 e Silva, 2001). Embora a mancha de Phaeosphaeria seja de reconhecida importância, é recente a atenção à obtenção de informações genéticas para resistência a esta doença. Estudos mostram que a resistência apresenta-se como uma característica quantitativa, sendo a ação gênica aditiva de maior importância na herança do caráter quando comparada a ação gênica dominante (Carson et al., 1996; Carson, 2001; Pegoraro et al., 2000 e Silva, 2002). Apenas Das et al. (1989a e 1989b) relatam maior importância da ação gênica dominante no controle da resistência a este patógeno.

Em um programa de melhoramento, o conhecimento do modo de herança da resistência é um quesito básico para combinar eficientemente os genitores e obter populações ou híbridos superiores. A análise genética desta característica, por outro lado, pode ser grandemente facilitada aliando-se o uso de marcadores moleculares a estudos clássicos, como a análise de média de gerações. Com o mapeamento de QRLs (locos de resistência quantitativa), os locos de resistência parcial podem ser individualizados e tratados como fatores 
mendelianos, sendo possível estudar o efeito dos mesmos na manifestação fenotípica da resistência (Young, 1996). A partir da identificação de marcadores moleculares fortemente ligados a QTLs (locos de característica quantitativa), os programas de melhoramento poderão ser assistidos por esses marcadores e QTLs de diversos pais doadores poderão ser introduzidos em genótipos de interesse, facilitando e acelerando a obtenção e lançamento de híbridos superiores. Deste modo, o uso da genética quantitativa clássica associada a estudos envolvendo marcadores moleculares pode minimizar as dificuldades encontradas na identificação, seleção e transferência de genes de resistência.

Os objetivos desse trabalho foram: (i) estudar o modo de herança e o número provável de genes de resistência a mancha de Phaeosphaeria; (ii) estimar o tipo e a magnitude da ação gênica envolvida; (iii) identificar marcadores moleculares ligados aos genes de resistência e (iv) definir as posições genômicas destes genes mediante análise de cosegregação com marcadores moleculares. 


\section{REVISÃO DE LITERATURA}

\subsection{A mancha de Phaeosphaeria}

\subsubsection{Importância econômica e distribuição geográfica da doença}

O milho (Zea mays L.) é uma das principais culturas agrícolas no Brasil e no mundo. Apresenta grande importância sócio-econômica, não só pela grande área que ocupa, mas também por todo complexo industrial que gira em torno do seu cultivo, gerando empregos e contribuindo como fonte de carboidratos nas dietas humana e animal. $O$ Brasil encontra-se em terceiro lugar na produção deste cereal, atrás somente dos EUA e China. Na safra 2001 cerca de 12 milhões de hectares foram plantados e mais de 33 milhões de toneladas colhidas (Fonte: Fonte: FAO - url: http:/lapps.fao.org). De 1990 a 2000 , O Brasil teve sua produção de milho acrescida em $37 \%$ devido, principalmente, a introdução de híbridos mais produtivos e práticas culturais adequadas. Outros fatores importantes foram o aumento do plantio na época da "safrinha" e o avanço da cultura para novas regiões do Centro-Oeste (Fernandes e Oliveira, 1997).

A importância das doenças foliares do milho no Brasil sempre foi pequena devido ao eficiente controle conseguido com híbridos resistentes. Mesmo sem apresentar resistência completa, os híbridos cultivados apresentavam severidade de doenças foliares sempre abaixo do limiar de dano econômico. A partir da década de 90 , no entanto, com a expansão da cultura, a importância das doenças aumentou, sendo que algumas passaram a provocar perdas consideráveis. Dentre estas, sobreleva-se a mancha de Phaeosphaeria ou pinta branca, que é considerada atualmente a principal doença do milho, tanto pelos prejuízos que tem causado aos cultivares suscetíveis, como pela 
sua ampla distribuição. Há relatos de perdas severas, com reduções de até $60 \%$ na produtividade de híbridos suscetiveis (Fernandes \& Oliveira, 1997). Anteriormente, a incidência da doença era expressiva somente após a maturação fisiológica. No entanto, em plantios recentes, vem sendo observada em plantas jovens, levando-as à seca prematura pela intensa redução da área fotossintética, acarretando perdas significativas na produção de milho (Silva, 2002). Para a maioria dos genótipos cultivados, os sintomas são mais severos após o pendoamento e aparecem primeiro nas folhas inferiores, progredindo rapidamente em direção ao ápice da planta (Sawazaki et al., 1997).

A crescente importância em incidência e severidade da mancha de Phaeosphaeria pode ser explicada, aparentemente, pelos fatores que contribuíram para o crescimento da produção, como o deslocamento da cultura para novas regiões e pelo aumento do plantio da "safrinha" (Fernandes e Oliveira, 1997). Von Pinho (1998) atribuiu essa importância às condições climáticas favoráveis e à ausência de cultivares resistentes ou com nível adequado de resistência. Estudos visando avaliar níveis de resistência de cultivares no estado de São Paulo demonstraram que na presença de alta umidade relativa, fator preponderante para o desenvolvimento da doença, a maioria dos híbridos comerciais são suscetiveis à doença (Sawazaki et al., 1997).

A ocorrência da mancha de Phaeosphaeria foi relatada ainda em muitas áreas tropicais e subtropicais do mundo, como nos E.U.A, África do Sul, Ásia e América Central (Carson et. al., 1991; Fantin, 1994; Hennings, 1902; Rane et. al., 1965 e Shurtleff, 1992;).

\subsubsection{Etiologia e sintomatologia}

O agente causal da mancha de Phaeosphaeria foi inicialmente relatado, no Brasil, por Hennings (1902), como sendo Phaeosphaeria maydis. No entanto, os postulados de Koch somente foram satisfeitos aproximadamente meio século após, por Rane et al. (1965). Embora os resultados destes autores 
tenham sido posteriormente corroborados por Fantin \& Balmer (1997), ainda hoje há uma certa controvérsia sobre a etiologia da doença, principalmente devido à dificuldade em se reproduzir sintomas a partir de inoculações com esporos do fungo. Paccola-Meirelles et al. (2001), por exemplo, não detectaram a presença de $P$. maydis em tecido doente após análises citológicas de lesões em estádio inicial. Ao contrário, os autores isolaram a bactéria Pantoea ananas (sinonímia Enwinia ananas) e obtiveram sucesso na reprodução dos sintomas após inoculação com a mesma, sugerindo o envolvimento deste organismo ao menos na fase inicial da doença. Assim, segundo os autores, estes resultados indicam que o fungo não é o patógeno primário desta doença, como proposto originalmente, e que o mesmo se estabelece após a infecção pela bactéria.

As lesões da mancha de Phaeosphaeria em milho podem ser classificadas em quatro estádios de desenvolvimento: (1) lesões aquosas verde-escuros, (2) lesões acinzentadas, (3) lesões necróticas que não apresentam estruturas reprodutivas (picnídios e pseudotécios) de $P$. maydis (4) lesões necróticas com estruturas reprodutivas de $P$. maydis. $O$ isolamento do fungo foi associado somente a lesões nos estádios 3 e 4, e as frequiências de isolamento, $11,5 \%$ e $10,6 \%$, respectivamente, foram considerada baixas por Paccola-Meirelles et al. (2001), fato que corrobora com a hipótese que $P$. maydis é patógeno secundário da doença.

Estudos sobre a influência das condições climáticas na ocorrência de lesões foliares indicam condições ótimas de temperatura e umidade relativa iguais ou superiores a $14^{\circ} \mathrm{C}$ e $60 \%$, com ocorrência conjunta ou individual. Dentre as variáveis climáticas medidas, a temperatura minima do ar e a umidade relativa noturna foram as que melhor se correlacionaram com a incidência da doença (Fernandes \& Sans, 1994, citados por Silva, 2002). 
2.1.3 Avaliação da severidade da mancha de Phaeosphaeria e época de avaliação

Para quantificar doenças foliares, a variável severidade, expressa pela porcentagem da área de tecido coberto por sintomas, é apontada como a mais apropriada (Bergamin Filho \& Amorim, 1996). A avaliação da severidade pode ser feita mediante chaves descritivas, escalas diagramáticas e análises de imagens por computador (Amorim, 1995; Bergamin Filho \& Amorim, 1996). Nas avaliações dessas doenças predominam a utilização de escalas diagramáticas, por serem método mais simples e de fácil execução. No Brasil, a escala diagramática mais utilizada para avaliação da mancha de Phaeosphaeria é a da Agroceres (1996). A avaliação da severidade da doença com o auxílio de escala diagramática pode ser realizada na planta inteira ou na folha posicionada abaixo do ponto de inserção da espiga principal. Para avaliação da mancha de Phaeosphaeria, o método de avaliação da severidade da doença na planta inteira mostrou-se mais prático e melhor ajustado (Silva, 2002).

A partir da avaliação da severidade em dado momento ou estádio fenológico, é possível fazer inferências sobre a resistência/suscetibilidade do genótipo somente para o referido momento da avaliação. $O$ estádio fenológico sugerido como ideal para avaliação de doenças em genótipos de milho é o estádio fenológico 7 , devido à maior incidência das doenças nesta fase da cultura (Agroceres, 1996). No entanto, a mancha de Phaeosphaeria é observada em vários estádios fenológicos, sendo a sua maior incidência a partir do florescimento (estádio 5). Assim, a melhor representação da resistência da planta é dada pelo seu desempenho ao longo de uma epidemia, a qual pode ser graficamente ilustrada pela curva de progresso da doença, que representa a quantidade de doença observada em função do tempo. Através desta curva, as interações entre patógeno, hospedeiro e ambiente podem ser caracterizadas e comparadas quantitativamente por meio da variável AUDPC (AUDPC - Area Under the Disease Progress Curve) (Bergamin Filho, 1995), que nada mais é do que a quantidade de tecido doente ao longo do tempo. Estudos genéticos 
utilizando a AUDPC oferecem maior segurança nas inferências sobre a epidemia quando comparados a estudos baseados em uma única avaliação, que muitas vezes não são representativas da resistência geral da planta observada durante o desenvolvimento da doença (Campbell \& Madden, 1990).

Um exemplo de estudo em que se utilizou AUDPC para avaliar resistência a doenças em milho é descrito por Parlevliet (1979). O autor relata que esta variável resultou em uma avaliação mais estável com menor influência da época de avaliação e das flutuações ambientais para o patossistema ferrugem comum-milho.

A determinação dos niveis de severidade da mancha de Phaeosphaeria, em diferentes épocas de semeadura e localidades, permite a melhor discriminação de genótipos. Fernandes et al. (1995) relataram o aumento da doença a partir de setembro e a sua maior incidência nos meses de dezembro a fevereiro. $O$ aumento da severidade da doença, que ocorre com o avanço da época de semeadura, provavelmente é devido à sobreposição de cultivos que leva ao acúmulo de inóculo no campo (Godoy et al., 1998). Pegoraro et al. (1998), por exemplo, avaliaram cinco épocas de semeadura, sendo a primeira em setembro e a última em janeiro, e verificaram que quando a semeadura do milho ocorre mais tardiamente, há um aumento da incidência da doença, devido a ocorrência de temperatura e umidade mais adequadas para o desenvolvimento do patógeno. A comparação por esses autores permitiu obter um referencial sobre a variação da severidade da mancha de Phaeosphaeria em função de locais e épocas. Tais comparações tornam-se mais seguras com a utilização de curvas de progresso da doença, considerando-se que avaliações especificas (pontuais) realizadas com poucos dias de diferença (em estádios fenológicos diferentes), em uma segunda época ou outro local, podem artificialmente acusar uma interação genótipo $x$ ambiente significativa. 


\subsubsection{Resistência genética a mancha de Phaeosphaeria}

Ao longo do processo evolutivo, as plantas desenvolveram mecanismos sofisticados para resistir aos patógenos. Em nível celular, ocorre o reconhecimento do patógeno e, em função disto, uma elaborada resposta de defesa por parte do hospedeiro. A resistência genética pode ser qualitativa ou quantitativa. A primeira é geralmente específica para certos genótipos do patógeno, geralmente controlada por um ou poucos genes dominantes ou recessivos, e completa. Já a resistência quantitativa, por sua vez, é o resultado da ação combinada de vários genes e geralmente é não-específica. Expressase no campo reduzindo a eficiência do inóculo, a colonização, multiplicação do patógeno e a quantidade de unidades infectivas. Esse tipo de resistência é influenciado pelo ambiente, pelo vigor da planta e tende a aumentar com a idade da planta hospedeira. Caracteriza-se por apresentar uma variação contínua em uma população segregante. É geralmente incompleta, porém duradoura (Robinson, 1987, citado por Silva, 2002).

Estudos relacionados ao conhecimento da natureza e da magnitude dos efeitos gênicos que controlam a resistência são importantes para direcionar os trabalhos de introdução de genes em germoplasmas suscetíveis e maximizar a exploração da variabilidade genética. Há poucos trabalhos sobre a herança da resistência à $P$. maydis em milho. Das et al. (1989a e 1989b) relatam maior importância da ação gênica dominante comparada a ação gênica aditiva. Lima et al. (1998), Paterniani et al. (1998), Pegoraro et al. (2000) e Silva (2002) obtiveram estimativas de maior contribuição dos efeitos genéticos aditivos, embora efeitos genéticos dominantes também tenham sido encontrados. A resistência neste patossistema tem sido relatada ainda como caráter de alta herdabilidade (Carson, 2001; Pegoraro et al., 2000 e Silva, 2002).

As informações obtidas pelos métodos clássicos de melhoramento sobre herança da resistência podem ser complementadas por mapeamento de genes com o uso de marcadores moleculares. $O$ trabalho de Carson et al. (1996) de mapeamento de QTL utilizando marcadores RFLPs (polimorfismos de 
comprimento dos fragmentos de restrição) em linhagens recombinantes derivadas do cruzamento B73 x Mo17, mostrou que a resistência a mancha de Phaeosphaeria é controlada por mais de seis QTLs.

\subsection{Marcadores moleculares}

\subsubsection{Marcadores microssatélites (SSR)}

Marcadores baseados em regiões de microssatélites, também denominados SSR (seqüências simples repetidas), foram utilizados inicialmente em humanos por Litt e Luty (1989). Microssatélites consistem em seqüências curtas de nucleotídeos, geralmente de 2-10 pb, denominadas motivos, que se repetem em tandem no genoma e são flanqueados por seqüências não repetidas. As regiōes flanqueadoras de SSRs podem ser usadas como molde para construção de oligonucleotídeos, normalmente variando de 18 a 30, os quais são úteis para amplificação do loco microssatélite pela reação em cadeia por polimerase (PCR). Esses marcadores podem ser visualizados em géis de agarose e poliacrilamida após sua amplificação. Microssatélites têm sido identificados em um grande número de espécies vegetais e caracterizados como uma das melhores opções para o mapeamento genético (Milach, 1998). Ocorrem de maneira relativamente dispersa nos cromossomos do milho, são co-dominantes e apresentam um satisfatório grau de polimorfismo (Chin et al., 1996; Senior et al., 1996).

\subsubsection{Marcadores AFLPs}

Marcadores AFLP ("amplified fragment length polymorphism" ou "polimorfismo de comprimento de fragmentos amplificados") envolvem digestão do DNA genômico com combinações de enzimas de restrição de corte raro (reconhecem sítios de 6-8 bases, ex.: EcoRI, Hindlll e Pstl) e corte freqüente (reconhecem sítios de 4 bases, ex. Msel e Taql), que geram fragmentos com extremidades denominadas protuberantes ou coesivas. A estas são ligados 
adaptadores específicos e, uma vez que as seqüências dos adaptadores e dos sítios de restrição são conhecidas, iniciadores ("primers") específicos complementares a essas seqüências são utilizados para amplificação dos fragmentos de restrição. Este procedimento é realizado em duas etapas, sendo a primeira denominada pré-seletiva, onde um subconjunto de fragmentos é amplificado com "primers" apresentando um nucleotídeo arbitrário na extremidade 3'. Posteriormente é feita uma seleção mais intensiva dos fragmentos pré-amplificados, sendo adicionados nucleotídeos arbitrários na extremidade 3' dos "primers". A resolução dos fragmentos amplificados é realizada em gel de poliacrilamida (Vos et al., 1995) e a visualização dos mesmos pode ser feita mediante coloração do gel com nitrato de prata, através de autoradiografia, com marcação prévia dos "primers" com radioisótopos, ou pelo método semi-atomatizado com marcação de "primers" com fluorescência (Ferreira e Grattapaglia, 1996).

Quando ainda não existem informações da análise de marcadores AFLP na espécie, o ideal é que seja realizado um teste preliminar com diferentes combinações de enzimas e nucleotídeos seletivos utilizados nos terminais 3' dos iniciadores. De acordo com Janssen et al. (1996), a combinação EcoRI/Msel geralmente é mais adequada para genomas pobres em $G+C$, Hindlil/Msel para genomas com conteúdo de $G+C$ em torno de 40$50 \%$ e Taql para genomas ricos em G+C. Para o genoma do milho, Castiglioni et al. (1999) mostraram que fragmentos Pstl/Msel distribuem-se mais aleatoriamente nos cromossomos quando comparados com os fragmentos EcoRI/Msel. Marcadores Pstl/Msel apresentaram localização preferencial em regiöes cromossômicas teloméricas hipometiladas, enquanto que fragmentos EcoRI/Msel posicionaram-se principalmente em regiōes centroméricas.

A técnica AFLP gera um número elevado de marcadores por gel, o que permite uma rápida saturação de mapas genéticos (Castiglioni et al., 1999; Vuylsteke et al., 1999). Esta técnica pode gerar muitos marcadores dispersos por todo o genoma, o que a torna uma técnica importante para o mapeamento 
de QTLs de características de importância agronômica em plantas, tais como resistência a doenças (Lehmensiek, et al., 2001; Van der Voort et al., 1999 e Xu et al., 1999). AFLPs também são utilizados em estudos de taxonomia e diversidade genética em bactérias, fungos, animais e plantas (Müeller e Wolfenbarger, 1999).

\subsection{Mapeamento genético}

A ligação física entre um oligogene e um monogene permite que os efeitos fenotípicos do oligogene possam ser indiretamente estudados com base no efeito do seu gene vizinho (Thoday, 1961). Com base nesta simples porém revolucionária idéia, marcadores moleculares passaram a ser amplamente utilizados para o mapeamento de locos de características quantitativas, ou QTLs (quantitative trait loci). Nos últimos anos, o número de associações entre marcadores e QTLs de importância econômica aumentou significativamente devido aos aprimoramentos nas técnicas de marcadores moleculares, que hoje permitem a obtenção de mapas genéticos saturados em um curto espaço de tempo e a um relativo baixo custo.

Para o sucesso do mapeamento genético, as etapas mais importantes são: a) escolha cuidadosa dos genitores; b) obtenção de uma população segregante $e$; $c$ ) avaliação fenotípica precisa na população segregante. $O$ maior contraste entre os genitores para a característica fenotípica a ser estudada permite uma segregação mais facilmente detectável na população segregante, que por sua vez, proporciona maior precisão nas avaliações fenotípicas. A população segregante garante desequilíbrio de ligação entre os locos segregantes. Na presença desse, alelos de locos marcadores ligados a poligenes ocorrem em condições diferentes da distribuição independente, o que permite a deteç̧ão destes últimos.

Em populações de mapeamento, a máxima informação genética é alcançada com a utilização de indivíduos de uma geração $F_{2}$, resultante do cruzamento entre duas linhagens homozigotas contrastantes para a 
característica em estudo. A grande vantagem da utilização deste delineamento reside no fato de que os indivíduos da geração $F_{2}$ são formados por dois gametas que têm seus locos em desequilíbrio de ligação, e não por um único, como no caso de indivíduos obtidos por retrocruzamento. Assim, um único indivíduo $F_{2}$ apresenta 0 dobro da informação genética comparado a um indivíduo obtido por retrocruzamento. A utilização de geração $F_{2}$, portanto, reduz consideravelmente o esforço necessário em termos de avaliação genotípica (Coelho, 2000). Este delineamento é um dos mais comumente utilizados no mapeamento genético em espécies vegetais.

$O$ uso de populações $F_{2}$ tem como inconveniente o fato de que os indivíduos que são utilizados para o mapeamento são únicos, o que pode ser um entrave em situações onde a avaliação de um determinado caráter exige ensaios em vários locais (Coelho \& Silva, 2002) ${ }^{1}$. Uma estratégia que tem sido utilizada para solucionar tal problema é a avaliação de famílias $F_{3}$, o que possibilita a avaliação fenotípica com repetições e em vários ambientes.

No mapeamento genético, podem ser utilizados ainda outros delineamentos como: populações obtidas de retrocruzamentos, linhagens puras recombinantes, linhagens duplo-haplóides e cruzamentos entre indivíduos heterozigotos. As populações obtidas por retrocruzamentos são facilmente produzidas a partir de linhagens de diversas espécies e utiliza o desequilíbrio de ligação presente nos gametas produzidos pelos indivíduos da geração $F_{1}$. Linhagens puras recombinantes utilizam o desequilíbrio de ligação que permanece em um conjunto de linhagens puras derivadas por autofecundações sucessivas de indivíduos $F_{2}$ utilizados no mapeamento genético. Neste caso, no entanto, Tanksley (1993) enfatiza que devido ao maior número de gerações de recombinação deste delineamento, o desequilíbrio é menor do que o encontrado em populações $F_{2}$ e de retrocruzamentos. $A$ utilização de linhagens duplo-haplóides é uma alternativa que reúne as vantagens do delineamento de

\footnotetext{
${ }^{1}$ COELHO, A.S.G.; SILVA, H.D. Construçäo de mapas genéticos e mapeamento de QTL's. Piracicaba, 2002. 65p. (apostila).
} 
linhagens puras recombinantes e a informação do delineamento de retrocruzamentos. Os genótipos são completamente homozigotos correspondentes aos gametas originados por indivíduos $F_{1}$. A análise de progênies de cruzamentos entre indivíduos heterozigotos é utilizada onde é difícil a obtenção em linhagens endogâmicas seja pelo tempo longo de geração seja pela ocorrência de depressão por endogamia. A informação contida nos locos segregantes desse delineamento é utilizada para detectar o desequilíbrio de ligação. Uma descrição detalhada desses delineamentos pode ser encontrada em Coelho \& Silva (2002) ${ }^{1}$.

\subsubsection{A análise de grupos segregantes e de indivíduos extremos para a resistência}

Grupos ou "bulks" segregantes (BSA) podem ser empregados em uma etapa inicial das análises de mapeamento para reduzir o número de locos marcadores a serem analisados na população segregante. A técnica consiste na identificação de polimorfismos entre dois "bulks" de DNA constituídos a partir de indivíduos de uma população segregante pertencentes aos extremos do espectro fenotípico da característica sob estudo. Espera-se que indivíduos de um mesmo "bulk" sejam monomórficos para locos marcadores ligados a genes que controlam o fenótipo utilizado para a composição dos "bulks", porém polimórficos para aqueles não ligados. Assim, os dois "bulks" resultantes devem diferir entre si apenas para regiōes ligadas a genes, sendo monomórficos para todas as outras regiões.

Esse método simplifica a identificação de marcadores ligados a genes de interesse, pois não é preciso analisar toda a população segregante para a sua identificação. Os marcadores que se mostrarem polimórficos entre os "bulks" são verificados em toda a população para a confirmação da ligação e

\footnotetext{
${ }^{1}$ COELHO, A.S.G.; SILVA, H.D. Construçāo de mapas genéticos e mapeamento de QTL's. Piracicaba, 2002. 65p. (apostila).
} 
determinação da distância genética entre o marcador e o gene estudado. 0 método BSA foi usado, com sucesso, na identificação de genes de resistência a patógenos, em várias culturas, como míldio em alface (Michelmore et al., 1991), Pseudomonas syringae em tomate (Martin et al., 1991), Phaeoisariopsis griseola em feijão (Carvalho et al., 1998), nematóide do cisto em soja (Shuster, 1999) e Cercosporiose em milho (Lehmensiek et al., 2001), entre outros exemplos.

A detecção de QTLs de efeito reduzido através da utilização da técnica de BSA pode não ser tão eficiente. Neste caso, a análise requer a utilização populações segregantes com número maior de indivíduos de modo a propiciar uma classificação fenotípica eficiente dos representantes de cada "bulk" (Brunelli, 2002 e Lynch \& Walsh, 1998).

Para aumentar a probabilidade da detecção de QTLs, é importante a utilização de marcadores que permitam uma boa cobertura do genoma. A técnica AFLP permite a obtenção de grande número de locos por reação, sendo portanto adequada para uma rápida saturação do genoma. Com a utilização de uma determinada combinação de iniciadores AFLPs em "bulks" de DNA marcas polimórficas podem ser encontradas entre os "bulks", possibilitando direcionar as análises de marcadores ligados a locos de interesse na população de mapeamento e, ao mesmo tempo, amostrar outras regiões do genoma, aumentando a possibilidade de detectar QTLs que porventura não tenham sido detectados pela análise de BSA.

\subsubsection{Análises estatísticas para detecção de QTLs}

Para o mapeamento de QTLs, é necessária a construção de mapas genéticos consistentes, com marcadores espaçados adequadamente entre si e em quantidade suficiente para garantir uma boa cobertura genômica. Os vários exemplos de mapas de ligação em milho disponiveis na literatura constituem importantes pontos referenciais para a realização de outros estudos, principalmente no que concerne o tipo de marcador a ser utilizado e o número 
necessário desses para que o mapeamento de QTLs tenha êxito (AjmoneMarsan et.al., 1994; Ajmone-Marsan et.al., 2001; Beavis \& Grant, 1991; Burr et. al, 1988; Castiglione et. al. 1999; Coe et al., 1987; Davis et. al., 1999; Veldboom et al., 1994 e Vuylsteke et al., 1999). A utilização de microssatélites associada a de AFLPs é uma estratégia que vem sendo utilizada na construção de mapas genéticos de alta saturação (Vuylsteke et al., 1999 e Ajmone-Marsan et.al., 2001). Deste modo, a localização cromossômica dos locos AFLPs é facilitada, uma vez que o posicionamento genômico da grande maioria dos locos microssatélites já é conhecida.

As análises estatísticas para a deteç̧ão de QTLs vêm passando por considerável aprimoramento. A associação entre um marcador e um QTL pode ser avaliada utilizando uma, duas ou mais marcas simultaneamente. $\mathrm{Na}$ análise de marcas simples, a distribuição dos valores do caráter é examinada separadamente para cada loco marcador. As análises de marcas simples não apresentam aspectos computacionais complicados e não requerem conhecimento prévio da posição dos marcadores no genoma. Tanksley (1993) ressalta como desvantagem deste método o fato de que quanto maior a distância entre o QTL e o marcador, menor é a probabilidade em detectá-lo estatisticamente. Já Lynch \& Walsh (1998) relatam que não é possivel distinguir um QTL de pequeno efeito, situado muito próximo ao marcador, de um QTL de grande efeito, situado mais longe. Ambos autores também relatam que não existe independência entre os testes de hipóteses para ligação, o que não permite a obtenção de uma posição precisa do QTL. Estes problemas, embora limitantes, podem ser minimizados quando um número grande de marcadores segregantes é utilizado perfazendo uma cobertura completa do genoma, com marcas distribuídas em intervalos de aproximadamente $15 \mathrm{cM}$ (Tanksley, 1993).

O mapeamento por intervalo é uma extensão do método de máxima verossimilhança para marcas simples. Baseia-se na análise de freqüências conjuntas de um par de marcas adjacentes e um QTL pontual, flanqueado por essas duas marcas (Lander \& Botstein, 1989). O maior benefício da análise por 
intervalo sobre a análise por marcas simples ocorre quando a distância entre os marcadores está entre 20 a $35 \mathrm{cM}$. Nestas condições, provavelmente existirão algumas permutas entre os marcadores e o QTL, que podem ser compensadas pela análise por intervalo. Quando a densidade de marcadores é alta $(<15 \mathrm{cM})$, as análises por ponto ou intervalo dão resultados praticamente idênticos. Quando os locos marcadores são muito distantes (> $35 \mathrm{cM}$ ), constantemente a análise por intervalo se mostra ineficiente para detectar QTL no intervalo entre dois locos marcadores (Stuber et al., 1992, citados por Melo, 2000).

A técnica denominada mapeamento por intervalo composto resume em um único modelo as técnicas de mapeamento por intervalo e regressão múltipla, visando eliminar as influências de outros QTLs sobre o intervalo considerado (Jansen, 1993; Zeng,1993 e Zeng 1994). A abordagem utiliza em seus procedimentos uma composição das técnicas de regressão com o método da máxima verossimilhança (Jansen, 1993 e Zeng, 1993). O mapeamento por intervalo composto não é capaz de eliminar a interferência de QTLs localizados em intervalos adjacentes, por exemplo, se entre os marcadores ordenados na seqüência $M_{1} M_{2} M_{3} M_{4}$ houver um QTL entre $M_{2}$ e $M_{3}$ e outro entre $M_{3}$ e $M_{4}$, a metodologia não impede que o QTL entre $M_{2}$ e $M_{3}$ interfira na estimação dos efeitos do QTL entre $M_{3}$ e $M_{4}$, e vice-versa (Bearzoti, 2000). No entanto, em mapas saturados a probabilidade de ocorrência deste fenômeno é muito baixa (Melo, 2000 e Coelho \& Silva, 2002 ${ }^{1}$ ).

Existe um grande número de interações epistáticas envolvendo dois, três ou mais locos no caso de caracteres poligênicos. Nos estudos de genética quantitativa, a variância genética atribuída a epistasia tem sido freqüentemente referida como interação genótipo $x$ genótipo. No passado, raramente era possivel determinar se tais interações ocorriam entre poligenes específicos ou ainda medir exatamente a natureza desta interação. Tanksley (1993) relata que

\footnotetext{
${ }^{1}$ COELHO, AS.G.; SILVA, H.D. Construção de mapas genéticos e mapeamento de QTL's. Piracicaba, 2002.
} 65p. (apostila). 
a disponibilidade de mapas e de QTLs individualmente caracterizados por marcadores moleculares aumentou as possibilidades de detectar e caracterizar as interações entre QTLs específicos. A metodologia de mapeamento por intervalos múltiplos, apresentada por Kao et al. (1999), pode proporcionar um aumento na precisão e no poder da detecção de QTLs, além de permitir a estimativa e análise dos efeitos epistáticos entre QTLs. Segundo Melo (2000), esse é um método múltiplo, pois simultaneamente busca estimativas de número, posições, efeitos e interações entre diferentes QTLs. As vantagens dessa metodologia são: maior eficiência e precisão na identificação de QTLs e de seus padrões epistáticos com conseqüente aumento da eficiência da seleção assistida por marcadores.

\subsection{Genes de resistência a doenças em milho}

A utilização dos marcadores moleculares possibilitou a construção de mapas genéticos com maior saturação e contribuiu positivamente para a localização de locos de resistência quantitativa ou QRL (quantitative resistance loci). Um exemplo a ser considerado é a utilização de marcadores AFLPs na construção de um mapa de ligação por Castiglioni, et al. (1999), que relataram um mapa com $2.057 \mathrm{cM}$, sendo $440 \mathrm{cM}$ maior que o mapa obtido a partir de marcadores RFLPs por Ajmone-Marsan et al. (1995). Os autores relatam que marcadores AFLPs constituem poderosa ferramenta a ser utilizada no mapeamento de genes controladores de características de importância econômica.

O milho é considerado um modelo no desenvolvimento e avaliação de marcadores moleculares. Seus cromossomos estão subdivididos em "bins", ou seja, regiões de cerca de $20 \mathrm{cM}$ delimitadas por marcadores RFLPs de posição conhecida (McMullen \& Sincox, 1995a). A posição de um determinado gene é dada por uma combinação numérica referente a sua localização, onde o primeiro número se refere ao grupo de ligação ao qual o "bin" pertence e o segundo, à posição relativa do "bin" dentro do grupo de ligação. Embora a 
relação entre a distância genética do conjunto haplóide do milho e a distância física seja da ordem de $2140 \mathrm{kpb} / \mathrm{cM}$, podendo ainda apresentar variação entre diferentes regiões do genoma (Lynch \& Walsh, 1998), a caracterização em "bins" é muito útil, principalmente por facilitar a comparação das informações genética da espécie. Podemos, portanto, utilizar este tipo de identificação para relacionar a diversidade de genes de resistência e QRLs a diferentes patógenos que foram mapeados em milho nos últimos anos (Quadro1).

As informações geradas pelo mapeamento de genes de resistência em milho encontradas na literatura contemplam quase que exclusivamente genótipos originados de populações desenvolvidas em clima temperado. Para genótipos de origem tropical é recente a mobilização de pesquisadores em identificar genes de resistência utilizando marcadores moleculares. Uma análise conjunta da posição de QRLs e genes de resistência a doenças no genoma do milho fortalece a evidência de uma organização dos mesmos em "clusters". Existem caracterizadas, até o momento, seis dessas regiões: (1) "bin" 1.04, (2) "bin" 3.04, (3) cromossomo 4, (4) "bin" 6.01, (5) cromossomo 8 e (6) no braço longo do cromossomo 10 . Tais agregamentos incluem genes para resistência a diversos patógenos (McMullen \& Sincox, 1995b). A descrição dos "clusters", aqui realizada, é adaptada de McMullen \& Sincox (1995b): O primeiro "cluster" de resistência situa-se na região 1.4, perto do centrômero, e abriga os gene de resistência $m s v 1$ a "maize streak vírus" e $h m 1$, que confere resistência a raça 1 de Cochiobolus carbonum. Ainda perto destes genes encontram-se QRLs para Cercospora e Giberella. $O$ segundo "cluster" está no cromossomo 3, em região centromérica, e inclui os genes de resistência mv1 ("maize mosaic virus"), wsm2 ("Wheat streak mosaic virus") e RP3 (Puccinia sorghi.), além de um QRL para resistência a Giberella. $O$ terceiro "cluster" encontra-se no braço curto do cromossomo 4, sendo composto pele gene rp4 (Puccinia sorghi) e QRLs para resistência a Helminthosporium, Cercospora e Giberella. O quarto "cluster" é composto por três genes de resistência mapeados no "bin" 6.01: $m d m 1$ ("maize dwarf mosaic virus"), wsm1 ("Wheat streak mosaic virus") e rhm1 
(Helminthosporium). O quinto "cluster" encontra-se no braço longo do cromossomo 8 e inclui Ht2 e Htn1 (Exserohilum) e QRLs para resistência a Helminthosporium e Cercospora. Finalmente, a sexta região localiza-se no braço longo do cromossomo 10 e apresenta os genes de resistência wsm3 ("Wheat streak mosaic virus") e QTLs para resistência a Cercospora e Giberella.

McMullen \& Sincox (1995a) relatam a possibilidade de existir um significado funcional dando suporte disposição agregada de genes de resistência. Existe a possibilidade de tais agregamentos representarem famílias gênicas envolvidas na transdução de sinais ou em algum outro passo na cascata de eventos que leva a uma interação auto-incompatível entre o hospedeiro e o patógeno. 


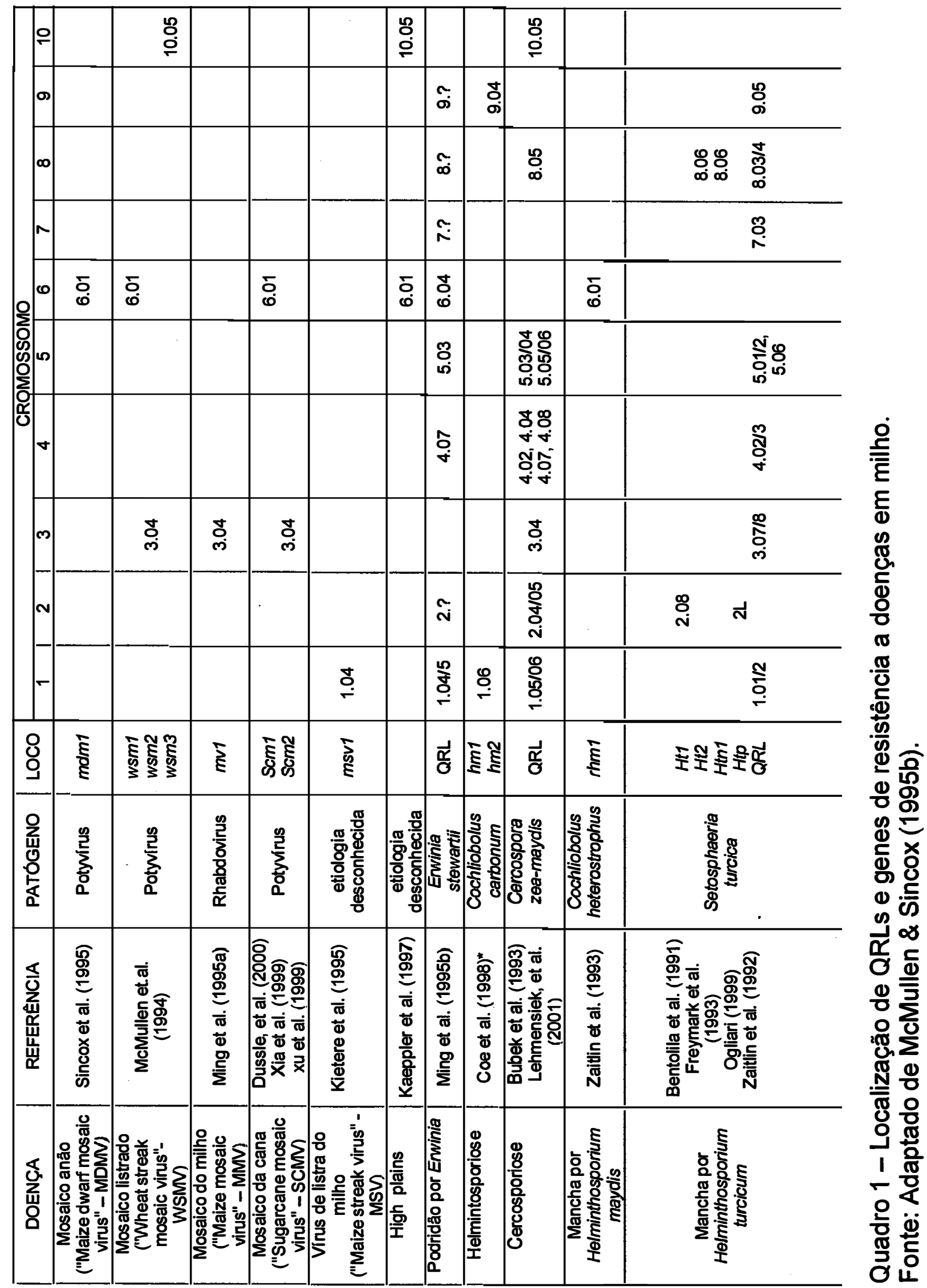




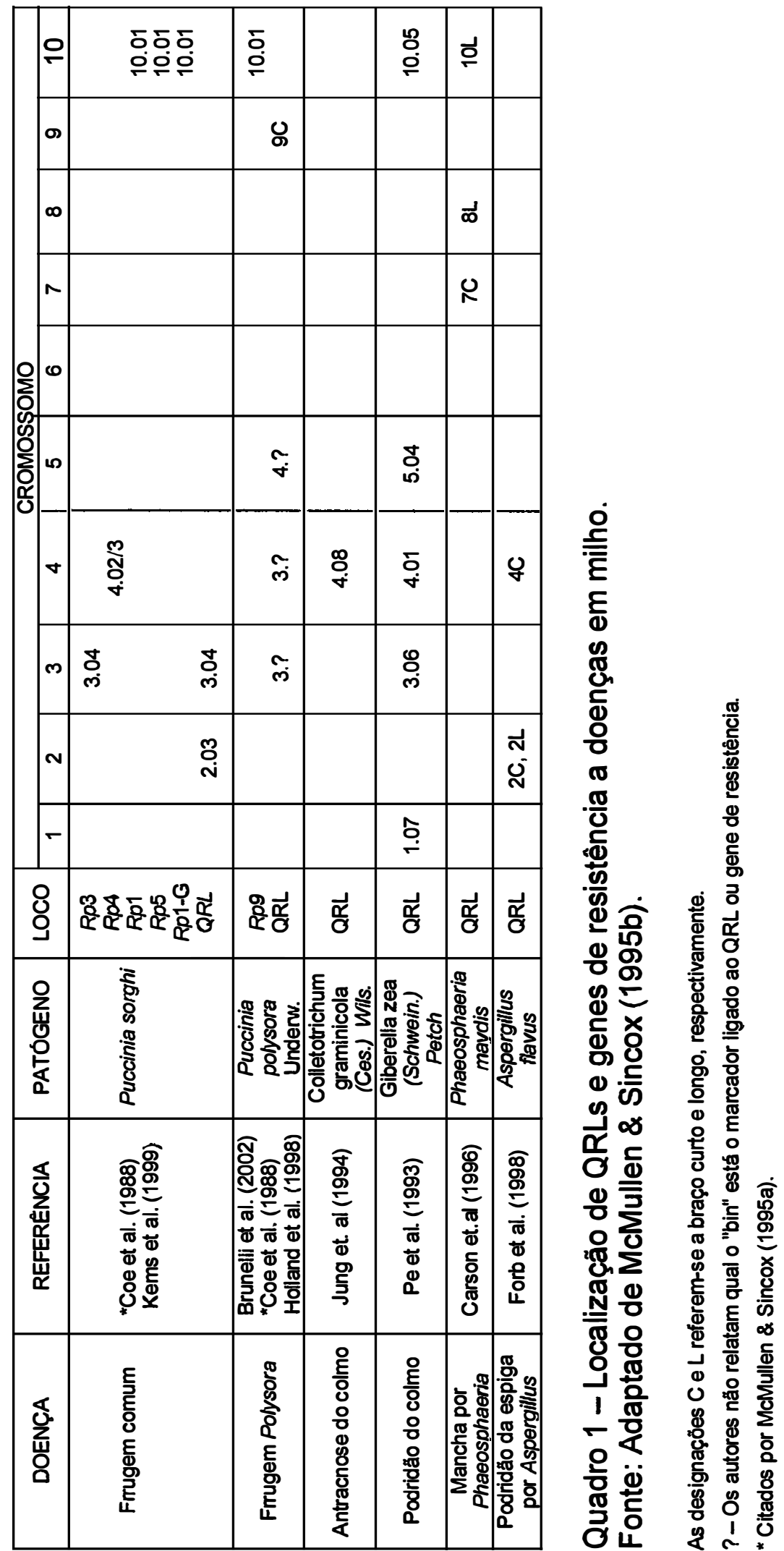




\section{MATERIAL E MÉTODOS}

3.1 Análise de médias de gerações para resistência à mancha de Phaeosphaeria em três linhagens tropicais de milho

\subsubsection{Material vegetal}

As três linhagens utilizadas no presente estudo (DAS21, DAS95 e DAS72) pertencem ao programa de melhoramento da Sementes DowAgroSciences Ltda. Silva (2002) relata que estas foram obtidas por meio de, no mínimo, sete autofecundações sucessivas a partir de populações tropicais. A linhagem DAS21 é precoce, de grãos semiduros alaranjados, oriunda da população Suwan DMR, considerada suscetível a mancha de Phaeosphaeria. A população Suwan DMR é uma população desenvolvida na Tailândia a partir da seleção de materiais tropicais de grãos duros do Caribe e materiais dentados Tuxpeño, que foi lançada como Thai Composite 1 após vários ciclos de seleção recorrente. A este material foram incorporadas duas fontes de resistência à Peronosclerospora sorghi das Filipinas (DMR 1 e DMR 5). No Brasil, corresponde à população CMS 05 , que é utilizada e distribuída pelo Centro Nacional de Pesquisa de Milho e Sorgo (CNPMS) da Empresa Brasileira de Pesquisa Agropecuária (EMBRAPA).

A linhagem DAS72 é moderadamente resistente a mancha de Phaeosphaeria. É precoce e de grãos semiduros alaranjados, oriunda de um sintético de base genética restrita. Esse sintético foi obtido a partir de um grupo de linhagens endogâmicas de uma população Amarillo Dentado e de uma população tropical do Caribe de grãos duros. Ambas as populações são amplamente utilizadas nos programas públicos e privados da Ásia. A linhagem DAS95, altamente resistente à mancha de Phaeosphaeria, precoce, de grãos 
duros alaranjados, é oriunda de um sintético constituído de linhagens provenientes de materiais tropicais "flints".

Populações oriundas dos cruzamentos DAS95 x DAS21 e DAS72 x DAS21 foram obtidas na estação experimental da Sementes DowAgroSciences Ltda, no ano agrícola de 1998/99, em Cravinhos-SP. Para a obtenção dos $F_{1}$ 's, linhas de $5 \mathrm{~m}$ de cada linhagem resistente, contendo 25 plantas cada, foram instaladas lado a lado e as plantas cruzadas com a linhagem suscetivel DAS21. As gerações $F_{2}$ foram obtidas por autofecundação das plantas $F_{1}$ 's, ao passo que os retrocruzamentos $\left(\mathrm{RCP}_{1}\right.$ e $\left.\mathrm{RCP}_{2}\right)$ foram obtidos pelos cruzamentos dos respectivos híbridos $F_{1}$ com as linhagens genitoras correspondentes.

\subsubsection{Avaliação da resistência à mancha de Phaeosphaeria}

Dois ensaios foram instalados na Estação Experimental da Sementes DowAgroSciences Ltda, em Indianópolis (MG), em 10/10/2000 e 02/12/2000. 0 delineamento experimental utilizado foi o de blocos casualizados com três repetições, sendo as parcelas constituídas pelas gerações. Em cada repetição, cada parcela foi representada por uma fileira de $5 \mathrm{~m}$ para as gerações $P_{1}, P_{2}$ e $F_{1}$, duas fileiras de $5 \mathrm{~m}$ para as gerações $R C P_{1}$ e $R C P_{2}$ e quatro fileiras de $5 \mathrm{~m}$ para a geração $F_{2}$, sendo cada fileira constituída de 25 plantas com espaçamento de $0,20 \mathrm{~m}$ entre plantas e $0,80 \mathrm{~m}$ entre fileiras. $O$ híbrido suscetivel DAS8420 foi utilizado como bordadura em ambos os experimentos. As avaliações da severidade da mancha de Phaeosphaeria foram realizadas $\mathbf{3 0}$ dias após o florescimento, considerando-se a planta inteira, através da escala diagramática da Agroceres (1996) (Tabela 1). 
Tabela 1. Escala de notas usada para a avaliação da severidade da mancha de Phaeosphaeria em milho.

\begin{tabular}{cc}
\hline Nota & Area foliar infectada (\%) \\
\hline 1 & 0 \\
2 & 1 \\
3 & 1 a 10 \\
4 & 10 a 20 \\
5 & 20 a 30 \\
6 & 30 a 40 \\
7 & 40 a 60 \\
8 & 60 a 80 \\
9 & $>80$ \\
\hline
\end{tabular}

\subsubsection{Análises estatísticas}

Análises de variância para a variável AUDPC foram realizadas para cada época de plantio segundo o modelo:

$$
Y_{i j}=m+r_{j}+t_{i}+e_{i j}, \text { sendo: }
$$

$Y_{i j}$ : média do tratamento i na repetição j;

$m$ : média geral do experimento, $E(m)=m$ e $E(m)^{2}=m^{2}$;

$r_{j}$ : efeito da repetição $j(j=1,2,3), E\left(r_{j}\right)=0$ e $E\left(r_{j}\right)^{2}=\sigma_{r}^{2}$;

$t_{i}$ : efeito do tratamento $i(i=1,2, \ldots .11), E\left(t_{i}\right)=0$ e $E\left(t_{i}\right)^{2}=t_{i}^{2}$;

$\mathrm{e}_{\mathrm{ij} \text { : }}$ erro experimental associado à parcela i dentro da repetição j, aleatório e distribuído de forma normal e independente, isto é: $E\left(e_{i j}\right)=0$ e $E\left(e_{i j}\right)^{2}=\sigma_{e}{ }^{2}$;

A fim de realizar as análises conjuntas, verificou-se a conformidade ao critério da homogeneidade de variâncias ( $>$ QMR/<QMR inferior'a 7) (GOMES, 1990). A análise de variância conjunta para a variável AUDPC (considerando as duas épocas de plantio), foi realizada utilizando o seguinte modelo:

$$
Y_{i j g}=m+r_{j(g)}+t_{i}+d_{g}+(t d)_{i g}+e_{i j g}, \text { sendo: }
$$

$Y_{\mathrm{ijg}}$ : média do tratamento i na repetição j, na época $\mathrm{g}$;

$m$ : média geral do experimento, $E(m)=m$ e $E(m)^{2}=m^{2}$;

$r_{j(g)}$ : efeito da repetição $j(j=1,2,3)$ dentro da época $g, E\left(r_{j(g)}\right)=0$ e $E\left(r_{j(g)}\right)^{2}=\sigma_{r}^{2}$; 
$t_{i}$ : efeito do tratamento $i(i=1,2, \ldots .11), E\left(t_{i}\right)=0$ e $E\left(t_{i}\right)^{2}=t_{i}{ }^{2}$;

$d_{g}$ : efeito do época $g(g=1,2), E\left(d_{g}\right)=0$ e $E\left(d_{g}\right)^{2}=d_{g}{ }^{2}$;

(td) $)_{\text {ig: }}$ efeito da interação entre o tratamento i e a época $g, E\left[(t d)_{i g}\right]=0$ e $E$ $\left.[(\mathrm{td}))_{\mathrm{ig}}\right]^{2}=\sigma_{\mathrm{td}}^{2}$

$e_{i j g}$ : erro efetivo associado ao tratamento $i$, na repetição $j$, para a época $g$, aleatório e distribuído de forma normal e independente, isto é: $E\left(e_{i j g}\right)=0$ e $E\left(e_{i j g}\right)^{2}=\sigma_{e}{ }^{2}$;

\subsubsection{Estimativa de efeitos gênicos}

As médias das gerações $P_{1}$ (DAS72 e DAS95); $P_{2}$ (DAS21); $F_{1} ; F_{2}$; $R C P_{1}$ e $R C P_{2}$ foram analisadas segundo o modelo de Mather \& Jinks (1971) $Y_{k}=m+w_{1} a+w_{2} d+\theta_{k}$, no qual $Y$ é a média da geração $k, m$ é a média geral, a representa o efeito aditivo, $d$ o efeito genético dominante, $w_{1}$ e $w_{2}$ as relativas contribuições destes efeitos para cada média da geração e $\theta k$ os desvios do modelo para cada família.

As estimativas dos parâmetros $\hat{\mu}, \hat{a}$ e $\hat{d}$ do modelo foram obtidas pela resolução da equação $\beta=\left(X^{\prime} Y\right)^{-1} X^{\prime} Y$ do sistema $\left(y=X^{\prime} \beta\right)$ de Mather \& Jinks (1971), como apresentado a seguir, sendo $Y$ o vetor das médias observadas das gerações para cada família, $X$ a matriz dos coeficientes e $\beta$ o vetor dos parâmetros.

$\mathrm{X}=\left|\begin{array}{ccc}1 & -1 & 0 \\ 1 & 1 & 0 \\ 1 & 0 & 1 \\ 1 & 0 & 1 / 2 \\ 1 & -1 / 2 & 1 / 2 \\ 1 & 1 / 2 & 1 / 2\end{array}\right| \hat{\beta}=\left|\begin{array}{c}\hat{\mu} \\ \hat{a} \\ \hat{d} \\ \mathrm{P}_{2} \\ \mathrm{~F}_{1} \\ \mathrm{~F}_{2} \\ \mathrm{RC}_{1} \\ \mathrm{RC}_{2}\end{array}\right|$


A resolução do sistema leva às estimativas dos parâmetros e somas de quadrados.

$$
\begin{aligned}
& \hat{\mu}=(1 / 17)\left(7 \mathrm{~T}_{1}-10 \mathrm{~T}_{3}\right) \\
& \hat{a}=(2 / 5) \mathrm{T}_{2} \\
& \hat{d}=(1 / 17)\left(24 \mathrm{~T}_{3}-10 \mathrm{~T}_{1}\right)
\end{aligned}
$$

A análise da variância para estudo das médias de gerações pelo método dos quadrados mínimos foi feita de acordo com Miranda Filho (1991) conforme Tabela 2.

sendo:

$$
\begin{aligned}
& T_{1}=P_{1}+P_{2}+F_{1}+F_{2}+R C_{1}+R C_{2} \\
& T_{2}=\left(P_{2}-P_{1}\right)+1 / 2\left(R C_{2}-R C_{1}\right) \\
& T_{3}=F_{1}+1 / 2\left(F_{2}+R C_{1}+R C_{2}\right)
\end{aligned}
$$

A estimativa da soma de quadrados do erro (SQErro) foi obtida do resultados das análises de variância individual dos experimentos em blocos para a análise de todas as gerações (item:3.1.3). 
Tabela 2. Estimativas das somas de quadrado dos parâmetros para análise de média de gerações.

\begin{tabular}{ccc}
\hline Fonte de variação & G.L. & Estimativas das Somas de Quadrados \\
\hline Gerações & 6 & $\sum_{\mathrm{i}} \mathrm{Y}_{\mathrm{i}}{ }^{2}$ \\
Parâmetros $(\hat{\mu}, \hat{a}, \hat{d})$ & 3 & $(1 / 85)\left(35 \mathrm{~T}_{1}{ }^{2}+34 \mathrm{~T}_{2}{ }^{2}+120 \mathrm{~T}_{3}{ }^{2}-100 \mathrm{~T}_{1} \mathrm{~T}_{3}\right)$ \\
Aditivo $(\hat{a})$ & 1 & $(2 / 5) \mathrm{T}_{2}{ }^{2}$ \\
Dominante $(\hat{d})$ & 1 & $(1 / 102)\left(5 \mathrm{~T}_{1}-12 \mathrm{~T}_{3}\right)^{2}$ \\
Desvios & 3 & $\mathrm{SQ} \mathrm{total}-\mathrm{SQ} \hat{\mu}, \hat{a}, \hat{d}$ \\
Erro & 20 & $\mathrm{SQ} \mathrm{Erro}$
\end{tabular}

O estudo dos parâmetros propostos por Mather \& Jinks (1971) foi realizado também através da análise conjunta considerando as médias das gerações $P_{1}$ (DAS72 e DAS95); $P_{2}$ (DAS21); $F_{1} ; F_{2} ; R C P_{1}$ e $R C P_{2}$ de cada ambiente (L). Foi utilizado o modelo: $Y_{k j}=m+w_{1 k j a} j+w_{2 k j} d+l j+w_{1 k j a l}+w_{2 k j} d l+$ $\theta_{\mathrm{kj}}$, no qual $\mathrm{Y}$ é a média da geração $\mathrm{k}$ no ambiente $\mathrm{j}$ para uma determinada família, $\mathbf{m}$ é a média geral, a representa o efeito aditivo, $\mathbf{d}$ o efeito genético dominante, $\mathbf{w}_{\mathbf{1}} \mathbf{e} \mathbf{w}_{\mathbf{2}}$ as relativas contribuições destes efeitos para cada média da geração, I o efeito de ambiente, al interação do efeito aditivo com ambiente, dl interação do efeito dominante com ambiente e $\theta_{\mathbf{k j}}$ os desvios do modelo.

As estimativas dos parâmetros foram obtidas pela resolução da equação $\beta=\left(X^{\prime} Y\right)^{-1} X^{\prime} Y$ do sistema $\left(y=X^{\prime} \beta\right)$, a seguir, e a análise de variância conjunta para esse modelo foi conduzida como apresentado na Tabela 3, conforme Reginato Neto (1998). 


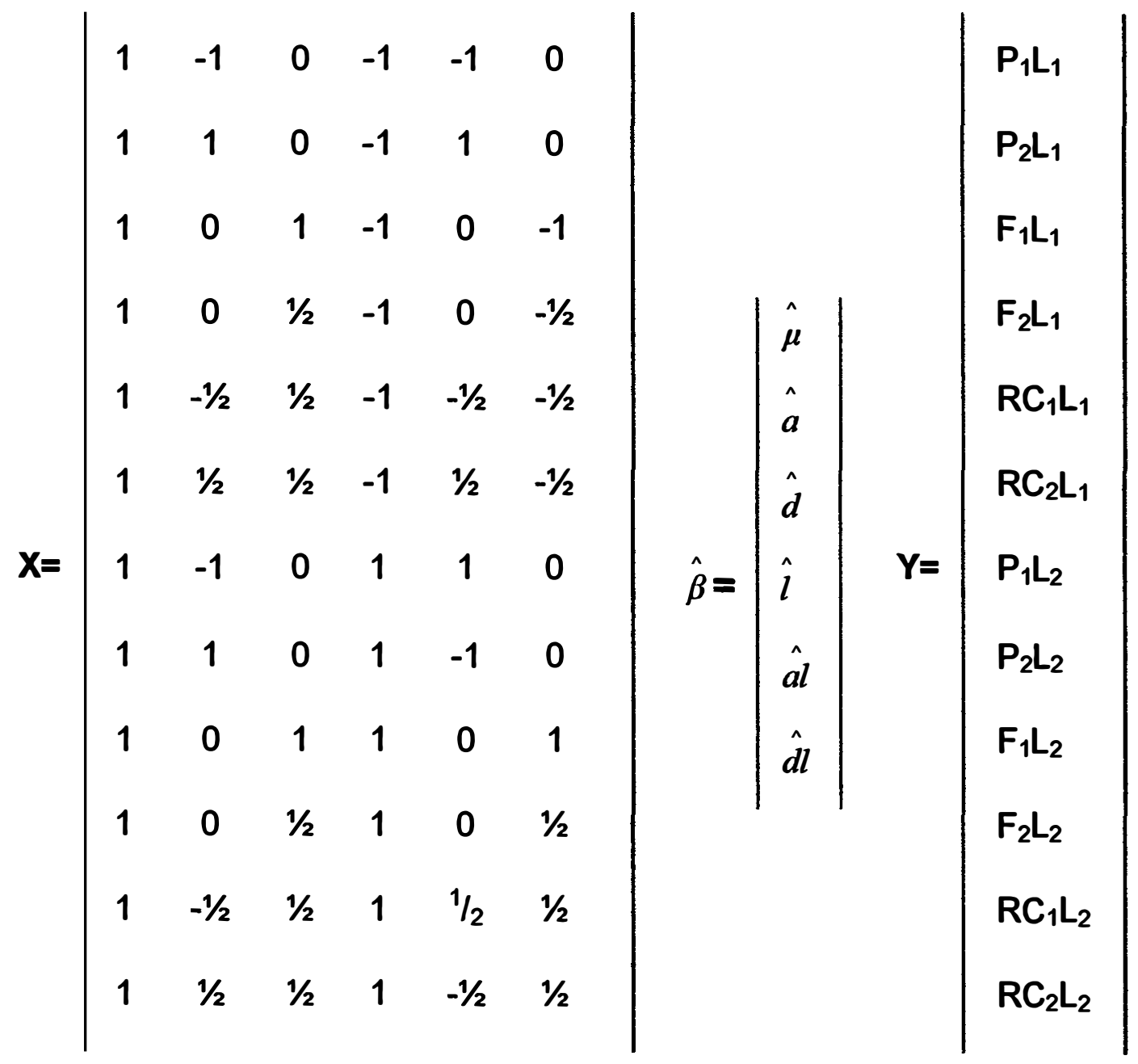

A estimativa da soma de quadrados do erro (SQErro) foi obtida do resultados das análises de variância conjunta dos experimentos em blocos para a análise de todas as gerações (item:3.1.3).

Estimativas da herdabilidade no sentido amplo foram calculadas pela fórmula $\left(\sigma_{F 2}^{2}-\sigma_{e}^{2}\right) / \sigma_{F 2}^{2}$, na qual $\sigma_{F 2}^{2}$ é a variância fenotípica dos indivíduos na geração $F_{2}$ e $\sigma_{e}^{2}$ é a variância ambiental entre indivíduos do mesmo genótipo, estimada através do agrupamento da soma de quadrados e dos graus de liberdade das linhagens genitoras e da geração $F_{1}$.

Estimativas do número mínimo de fatores efetivos $(K)$ foram obtidas segundo fórmula de Castle - Wright (Castle, 1921 e Wright, 1921), sendo $K=$ $D^{2} / 8\left(\sigma_{F 2}^{2}-\sigma_{F 1}^{2}\right)$, na qual $D$ é a diferença entre as médias das linhagens 
genitoras, $\sigma_{F 1}$ é o desvio padrão da média da geração $F_{1}$ e $\sigma_{F 2}$ é 0 desvio padrão da média da geração $F_{2}$.

Tabela 3. Estimativas das somas de quadrado dos parâmetros para análise de média de gerações conjunta.

\begin{tabular}{|c|c|c|}
\hline Fonte de variação & G.L. & Estimativas das Somas de Quadrados \\
\hline Geraçōes & 12 & $\sum_{i} Y_{i}^{2}$ \\
\hline Parâmetros & 6 & SQparâmetros $=\operatorname{X} \gamma \beta(\hat{\mu}, \hat{a}, \hat{d}, \hat{l}, \hat{a l}, \hat{d l})$; modelo completo \\
\hline $\operatorname{Aditivo}(\hat{a})$ & 1 & $\mathrm{SQ} \hat{a}=\mathrm{SQ} \hat{\mu}, \hat{a}, \hat{d}, \hat{l}, \hat{a l}, \hat{d l}-\mathrm{SQ} \hat{\mu}, \hat{d}, \hat{l}, \hat{a l}, \hat{d l}$ \\
\hline Dominante $(\hat{d})$ & 1 & $\mathrm{SQ} \hat{d}=\mathrm{SQ} \hat{\mu}, \hat{a}, \hat{d}, \hat{l}, \hat{a l}, \hat{d l}-\mathrm{SQ} \hat{\mu}, \hat{a}, \hat{l}, \hat{a l}, \hat{d} l$ \\
\hline ambiente $(\hat{l})$ & 1 & $\mathrm{SQ} \hat{l}=\mathrm{SQ} \hat{\mu}, \hat{a}, \hat{d}, \hat{l}, \hat{a l}, \hat{d l}-\mathrm{SQ} \hat{\mu}, \hat{a}, \hat{d}, \hat{a l}, \hat{d l}$ \\
\hline$\hat{a l}$ & 1 & $\mathrm{SQ} \hat{a l}=\mathrm{SQ} \hat{\mu}, \hat{a}, \hat{d}, \hat{l}, \hat{a l}, \hat{d l}-\mathrm{SQ} \hat{\mu}, \hat{a}, \hat{d}, \hat{l}, \hat{d l}$ \\
\hline$\hat{d l}$ & 1 & $\mathrm{SQ} \hat{d l}=\mathrm{SQ} \hat{\mu}, \hat{a}, \hat{d}, \hat{l}, \hat{a l}, \hat{d l}-\mathrm{SQ} \hat{\mu}, \hat{a}, \hat{d}, \hat{l}, \hat{a l}$ \\
\hline Desvios & 6 & SQ total - Sqparâmetros \\
\hline Erro & 40 & SQ Erro \\
\hline
\end{tabular}


3.2 Mapeamento de locos de resistência quantitativa à mancha de Phaeosphaeria

\subsubsection{Material vegetal}

As linhagens DAS21 (suscetivel) e DAS95 (resistente) foram escolhidas para gerar população segregante utilizada no mapeamento de genes de resistência à mancha de Phaeosphaeria devido ao comportamento diferenciado destas frente ao caráter em estudo. A descrição destas linhagens encontra-se no item 3.1.1.

As gerações $F_{1}$, e $F_{2}$, antecessoras das 118 progênies $F_{3}$ utilizadas neste estudo, foram obtidas na estação experimental da Sementes DowAgroSciences Ltda, no ano agrícola de 1998/99, em Cravinhos-SP conforme descrito no item 3.1.1. As 118 famílias $F_{3}$ oriundas de DAS95 $x$ DAS21 foram obtidas no campo experimental da Fitopatologia da ESALQ-USP entre março e julho de 2000.

\subsubsection{Avaliação da resistência}

A resistência dos indivíduos das 118 progênies $F_{3}$ foi avaliada a campo em dois ensaios conduzidos sob condições naturais de infecção, com semeadura em 10/10/2000 e 02/12/2000, na Estação Experimental da Empresa Dow-Agroscience em Indianópolis (MG). Para assegurar a presença e a multiplicação do patógeno, foram plantadas bordaduras com o híbrido altamente suscetivel DAS8420. Os genitores (DAS95 e DAS21) e indivíduos $F_{1}$ foram utilizados como controle nos dois ensaios. $O$ delineamento experimental utilizado foi o látice $11 \times 11$ com 3 repetições, sendo que cada parcela foi constituída de uma linha de 5 metros com 5 plantas $/ \mathrm{m}$, totalizando 75 plantas por progênie avaliadas em cada ensaio.

As avaliações da severidade da mancha de Phaeosphaeria foram realizadas no florescimento e 15 e 30 dias após, considerando-se a planta inteira, através da escala diagramática da Agroceres (1996) (Quadro 2). Com 
base nos dados das três avaliações, foi calculado a AUDPC, a qual correspondente à integral da curva de progresso da doença, estimada através da fórmula:

$$
A U D P C=\sum_{i}^{n-1}\left(\frac{y_{i}+y_{i+1}}{2}\right) *\left(t_{i+1}-t_{i}\right)
$$

onde $n$ é o número de avaliações e $y$ é a severidade de doença no tempo $t$. A AUDPC obtida para cada genótipo foi padronizada dividindo-se a mesma pelo tempo total de duração da avaliação da epidemia. Neste trabalho, o período total de avaliação em cada ensaio foi de 30 dias a partir do início do florescimento. A estratégia de padronização da AUDPC pelo tempo total de duração das avaliações deve ser realizada para permitir uma comparação mais precisa das AUDPCs de diferentes trabalhos, uma vez que avaliações realizadas em outros trabalhos, em outras populações e em outros locais, podem ter duração diferente.

\subsubsection{Genotipagem com marcadores moleculares}

Plantas $F_{2}$ que deram origem, por autofecundação, às progênies $F_{3}$ avaliadas no item 3.2.2 foram genotipadas com marcadores moleculares conforme descrito a seguir.

\subsubsection{Extração e quantificação de DNA}

A extração de DNA do tecido vegetal das plantas $F_{2}$ foi realizada de acordo com a metodologia apresentada por Hoisington et al. (1994), modificada para tubos "eppendor" de 1,5 mL. A aproximadamente $200 \mathrm{mg}$ de material foliar macerado com nitrogênio líquido adicionou-se $600 \mu \mathrm{L}$ de tampão de extração 1\% CTAB $(70 \mu \mathrm{M}$ de $\mathrm{NaCl}, 50 \mu \mathrm{M}$ EDTA pH 8,0; $100 \mu \mathrm{M}$ Tris-HCl pH 7,5; 1\% $\mathrm{p} / \mathrm{v}$ de CTAB, $140 \mu \mathrm{M} \beta$ mercapto-etanol). As amostras foram incubadas em banho-maria a uma temperatura de $65^{\circ} \mathrm{C}$ por aproximadamente 1 hora, sendo agitadas cuidadosamente por quatro a cinco vezes durante esse período. Após esse tempo, o mesmo volume de clorofórmio/álcool-isoamílico (CIA) (24:1) foi 
adicionado às amostras, as quais foram centrifugadas à $12400 \mathrm{rpm}$ por 10 minutos. $O$ sobrenadante foi retirado e transferido para novos tubos. Esse procedimento foi repetido mais uma vez, com a finalidade de promover uma retirada de parte das proteínas, facilitando a precipitação do DNA. À fase aquosa remanescente foi adicionado igual volume de álcool etílico absoluto gelado, promovendo, então, a precipitação do DNA, o qual foi centrifugado e seco ao ar. Os "pelets" foram lavados com etanol $75 \%$ por 10 minutos e etanol absoluto por 20 minutos. Após esse procedimento, suspendeu-se o DNA em $100 \mu \mathrm{L}$ de TE $\mathrm{pH} 8,0$ (10mM de Tris-HCl e $1 \mathrm{mM}$ de EDTA) e procedeu-se 0 tratamento com $1 \mu \mathrm{L}$ de RNAse $(1 \mathrm{mg} / \mathrm{mL})$ por $2 \mathrm{~h}$ a $37^{\circ} \mathrm{C}$.

As amostras de DNA foram quantificadas em gel de agarose $0,8 \%$ (Gibco BRL), coradas com brometo de etídio $(10 \mathrm{mg} / \mathrm{mL})$, visualizadas sob luz ultra violeta e fotodocumentadas com aparelho ImageMaster®VDS (Pharmacia Biotech). Inicialmente, as amostras foram diluídas 30 vezes ( $3 \mu \mathrm{L}$ do DNA da solução estoque em $87 \mu \mathrm{L}$ de tampão TE) sendo aplicados no gel alícotas de 3 $\mu \mathrm{L}$ e $6 \mu \mathrm{L}$ da diluição cada indivíduo. A intensidade da banda referente às duas diluições foi comparada com padrões de DNA de fago $\lambda$, de concentrações conhecidas $(20,40,60$ e $80 \mathrm{ng} / \mu \mathrm{L})$. A quantidade de DNA ( $\mathrm{ng} / \mu \mathrm{L})$ presente na solução estoque foi então estimada para cada indivíduo. Com base nos valores estimados, procedeu-se a diluição das amostras para uma concentração de 10 $\mathrm{ng} / \mu \mathrm{L}$ de DNA. Para conferir se as concentrações foram estimadas corretamente, $4 \mu \mathrm{L}$ de DNA diluído foi submetido à eletroforese e comparado com padrões de 20, 40 e $60 \mathrm{ng}$. A partir dos resultados, foram realizadas novas diluições para a obtenção das amostras de trabalho (10 $\mathrm{ng} / \mu \mathrm{L})$.

\subsubsection{Genotipagem com marcadores microssatélites}

Foram selecionados 105 microssatélites (SSRs) através dos critérios, polimorfismo entre linhagens e qualidade da amplificação de loco marcador, a partir dos trabalhos de Brunelli (2002) e Ogliari (1999). Os SSR foram 
analisados em dois "Bulks" de DNA obtidos de um ensaio realizado, em março de 1999, em Taquarituba (SP), para resistência a mancha de Phaeosphaeria em uma população $F_{2}$, obtida a partir das linhagens DAS95 x DAS21 (dados não apresentados). Os informativos (polimórficos entre os "Bulks") foram analisados na população de mapeamento e ainda, foram escolhidos, em média, dois outros microssatélites por cromossomo, na tentativa de representar os 10 cromossomos do milho.

As reações de amplificação de locos microssatélites foram conduzidas conforme descrito por Senior et al. (1996), adicionando-se em um tubo 40ng de DNA; $2 \mu \mathrm{L}$ de tampão $10 \mathrm{X}(200 \mathrm{mM}$ de Tris- $\mathrm{HCl}, \mathrm{pH} 8,4 ; 500 \mathrm{mM} \mathrm{KCl}) ; 0,100 \mu \mathrm{M}$ dNTPs; 0,5 U Taq DNA polimerase; $2,0 \mathrm{mM}$ de $\mathrm{MgCl}_{2}$ e $0,2 \mu \mathrm{M}$ de "primers" "foward/reverse" em um volume de $20 \mu \mathrm{L}$ completado com água ultrapura autoclavada. Para evitar evaporação da reação durante a amplificação, cada amostra recebeu uma gota de óleo mineral. A amplificação foi conduzida em termociclador PTC-100 (MJ Research, USA) utilizando um programa de amplificação composto por 1 ciclo de 2 minutos a $94^{\circ} \mathrm{C}, 2$ ciclos de 1 minuto a $94^{\circ} \mathrm{C}, 20$ ciclos de 1 minuto a $94^{\circ} \mathrm{C}, 1$ minuto a $65^{\circ} \mathrm{C}$ e 2 minutos a $72^{\circ} \mathrm{C}$, sendo que a cada dois ciclos a temperatura de anelamento baixava $1^{\circ} \mathrm{C}$ até atingir, no ciclo $2055^{\circ} \mathrm{C}$, e por fim 5 minutos a $72^{\circ} \mathrm{C}$.

Após a amplificação, cada amostra recebeu $5 \mu \mathrm{L}$ de tampão de carregamento (500 $\mu \mathrm{L}$ de EDTA 0,5M pH 8,0, $500 \mu \mathrm{L}$ de glicerol $99 \%$ e 2,16 mg de bromofenol), sendo que os fragmentos amplificados foram resolvidos por eletroforese em gel de agarose (Gibco) 3\% em tampão TBE (0,09M Tris; 0,09M ácido bórico; $2 \mathrm{mM}$ EDTA) por aproximadamente $3 \mathrm{~V} / \mathrm{cm}$. A extremidade esquerda de cada gel recebeu um padrão molecular de 50pb (Promega) para informação do peso molecular dos fragmentos. Os géis foram corados com brometo de etídio e fotografados com aparelho de processamento de imagens ImageMaster®VDS (Pharmacia Biotech). 
$\mathrm{Na}$ interpretação dos géis, cada planta $\mathrm{F}_{2}$ foi caracterizada pelos seus respectivos alelos. Cada loco foi definido por um par de "primers" ("foward/reverse"), havendo a presença de dois alelos no indivíduo de genótipo heterozigótico e de apenas um nos homozigóticos.

\subsubsection{Genotipagem com marcadores AFLP}

Inicialmente foram analisados os padrões de amplificação e os polimorfismos dos fragmentos AFLPs nos genitores e entre dois "bulks" de DNA, constituídos pelos dez indivíduos mais resistentes e pelos mais suscetíveis da população de mapeamento. Posteriormente foram escolhidos "primers" que apresentaram bom padrão de amplificação, polimorfismos entre os "bulks" e o maior número de locos polimórficos ente os genitores para análise na população de mapeamento.

O protocolo de amplificação do marcador AFLP foi adaptado de http://www.msu.edu/user/hazensam/aflp/AFLPprotocolMSU.html.

Duas combinações de enzimas foram utilizadas na digestão do DNA genômico: EcoRI/Msel e Pstl/Msel. As reações de digestão com a combinação das enzimas de restrição EcoRI/Msel foram realizadas utilizando $400 \mathrm{ng}$ de DNA genômico, 5,0 $\mu \mathrm{L}$ do tampão "One Phor All" 10X (OPA; Amersham), albumina de soro bovino (BSA) $(10 \mu \mathrm{g} / \mu \mathrm{L}$ ), $0,5 \mu \mathrm{L}$ da enzima Msel (10 unidades $/ \mu \mathrm{L}$, New England Biolabs) e 0,5 $\mu \mathrm{L}$ da enzima EcoRI (10 unidades/ $\mu \mathrm{L}$, Gibco) em volume final completado para $50 \mu \mathrm{L}$ com água ultrapura autoclavada. Nas reações de digestão com a combinação Pstl/Msel foram utilizadas $400 \mathrm{ng}$ de DNA genômico, 5,0 $\mu \mathrm{L}$ do tampão React1 10X (Gibco), 0,5 $\mu \mathrm{L}$ de solução BSA (10 $\mu \mathrm{g} / \mu \mathrm{L}$ ), 0,5 $\mu \mathrm{L}$ da enzima Pstl (10 unidades/ $\mu \mathrm{L}$; Gibco) e 0,5 $\mu \mathrm{L}$ da enzima EcoRI (10 unidades/ $\mu \mathrm{L}$; Gibco) em volume final completado para $50 \mu \mathrm{L}$ com água ultrapura autoclavada. Para ambas combinações, as reações foram realizadas a $37^{\circ} \mathrm{C}$ durante 3 horas sendo cuidadosamente agitadas a intervalos de uma hora. Após a digestão, as enzimas foram inativadas a $70^{\circ} \mathrm{C}$ durante 15 
minutos. Para verificar o resultado da digestão, 10 uL da reação de digestão foram submetidos a eletroforese em gel de agarose $1 \%$ por 3 horas em tampão TEB 1X $(2,5 \mathrm{~V} / \mathrm{cm})$. Após a corrida, os géis foram corados com brometo de etídeo $(10 \mathrm{mg} / \mathrm{mL})$ durante 15 minutos e posteriormente fotografados sob luz UV.

\begin{tabular}{|c|c|c|}
\hline Enzima & $\mathrm{Sec}$ & üências \\
\hline \multirow{3}{*}{ EcoRI } & adaptador & $\begin{array}{l}\text { 5'- CTCGTAGACTGCGTACC-3' } \\
\text { 3'-CATCTGACGCATGGTTAA-5' }\end{array}$ \\
\hline & "primer" da pré-amplificação & 5'-GACTGCGTACCAATTCA-3' \\
\hline & $\begin{array}{l}\text { "primers" da amplificação seletiva } \\
\text { (Extensões ANN: AAC, ACA, ACT, } \\
\text { AGG, AAG, ACG, e AGC }\end{array}$ & 5'-GACTGCGTACCAATTCANN-3' \\
\hline \multirow{3}{*}{ Msel } & adaptador & $\begin{array}{r}\text { 5'-GACGATGAGTCCTGAG-3' }^{\prime} \\
\text { 3'-TACTCAGGACTCAT-5' }\end{array}$ \\
\hline & "primer" da pré-amplificação & 5'-GATGAGTCCTGAGTAAC-3' \\
\hline & $\begin{array}{l}\text { "primers" Msel da amplificação } \\
\text { seletiva } \\
\text { (Extensöes CNN: CAA, CAC, CAG, } \\
\text { CAT, CTA, CTC, CTG e CTT. }\end{array}$ & 5'-GATGAGTCCTGAGTAACNN-3' \\
\hline \multirow{3}{*}{ Pstl } & adaptador & $\begin{array}{c}\text { 5'-CATCTGACGCATGT-3" } \\
\text { 5'-CTCGTAGACTGCGTACATGCA-3' }\end{array}$ \\
\hline & "primer" da pré-amplificação & 5'-GACTGCGTACATGCAGA-3' \\
\hline & $\begin{array}{l}\text { "primer" da amplificação seletiva } \\
\text { (Extensões ANN: AAA, AAC, AAG, } \\
\text { ACA e ACC). }\end{array}$ & 5'-GACTGCGTACATGCAGANN-3' \\
\hline
\end{tabular}

Quadro 2 - Seqüências dos adaptadores e dos "primers" usados na avaliação das combinações de pré-amplificação e amplificação.seletiva.

Os adaptadores foram preparados em quantidade suficiente para ligações de 120 amostras. Para o preparo do adaptador EcoRI foram utilizados $3,4 \mu \mathrm{L}(1 \mu \mathrm{g} / \mu \mathrm{L})$ de adaptador "EcoRI oligo1" (5' CTCGTAGACTGCGTACC 3'), 3,0 $\mu \mathrm{L}(1 \mu \mathrm{g} / \mu \mathrm{L})$ de adaptador "EcoRI oligo2" (5' ATTTGGTACGCAGTCTAC 3'), 6,0 $\mu \mathrm{L}$ do tampão OPA 10X ("One Phor All", Amersham) e 107,6 $\mu \mathrm{L}$ de água ultrapura. No preparo do adaptador Msel foram utilizados $32,0 \mu \mathrm{L}(1,0 \mu \mathrm{g} / \mu \mathrm{L})$ de 
adaptador "Msel oligo1" (5' GACGATGAGTCCTGAG 3'), 28,0 $\mu \mathrm{L}(1,0 \mu \mathrm{g} / \mu \mathrm{L})$ de adaptador "Msel oligo2" (5' TACTCAGGACTCAT 3'), 7,0 $\mu \mathrm{L}$ do tampão OPA ("One Phor All", Amersham) e 53,0 $\mu \mathrm{L}$ de água ultrapura. As reações de hibridização das fitas foram realizadas em termociclador PTC-100 (MJ Research, USA) utilizando o seguinte programa: $65^{\circ} \mathrm{C} / 10 \mathrm{~min}$., $37^{\circ} \mathrm{C} / 10 \mathrm{~min}$. e $25{ }^{\circ} \mathrm{C} / 10 \mathrm{~min}$. Os adaptadores foram armazenados a $-20{ }^{\circ} \mathrm{C}$ após seu preparo.

Os adaptadores foram ligados aos fragmentos de DNA em uma reação contendo 2,0 $\mu \mathrm{L}$ do tampão das enzimas T4 DNA Ligase 5X (Invitrogen), 1,0 $\mu \mathrm{L}$ dos adaptadores das enzimas EcoRI ou Pstl, 1,0 $\mu \mathrm{L}$ do adaptador da enzima Msel, 1,0 $\mu \mathrm{L}$ de T4 DNA ligase (1 unidade/ $\mu \mathrm{L}$, Invitrogen), 5,0 $\mu \mathrm{L}$ de água ultrapura autoclavada e $40 \mu \mathrm{L}$ da reação de digestão descrita acima. As reações de ligação foram realizadas a $20^{\circ} \mathrm{C}$ durante 3 horas, sendo cuidadosamente agitadas a intervalos de uma hora. As amostras foram armazenadas a $-20^{\circ} \mathrm{C}$.

Os fragmentos de DNA foram amplificados em duas reações. $\mathrm{Na}$ primeira, denominada de pré-amplificação, foram utilizados "primers" com 1 nucleotídeo adicional (nucleotídeo seletivo) em seu terminal 3' (Quadro 2), ao passo que na segunda, denominada de amplificação seletiva, foram utilizados "primers" com 3 nucleotídeos adicionais em seu terminal 3', sendo o primeiro nucleotídeo correspondente ao utilizado na pré-amplificação. Ambas as reações foram efetuadas em termociclador PTC-100 (MJ Research).

Os "primers" EcoRI utilizados nas reações de pré-amplificação são representados por $\mathrm{E}+\mathrm{N}$, sendo $\mathrm{N}$ o nucleotídeo seletivo adicionado ao terminal 3' do "primer". Os "primers" das enzimas Msel e Pstl são representados por $M+N$ e $P+N$, respectivamente. Foram utilizadas 2 combinações de "primers", $E+A / M+C$ e $P+A / M+C$. As reações de pré-amplificação foram compostas por 3,0 $\mu \mathrm{L}$ da amostra de DNA digerido e ligado aos adaptadores conforme descrito acima, $0,5 \mu \mathrm{L}$ do "primer" da enzima de corte raro $(E+A, E+C$ ou $P+A)(50$ $n g / \mu L), 0,5 \mu L$ do "primer" da enzima de corte freqüente $(M+C$ ou $M+G)(50$ 
$\mathrm{ng} / \mu \mathrm{L}$ ), 4,0 $\mu \mathrm{L}$ de dNTP 2,5 mM (Gibco), 2,0 $\mu \mathrm{L}$ do tampão "Mg Free Buffer" 10X (Promega), 1,2 $\mu \mathrm{L} \mathrm{MgCl}_{2} 25 \mathrm{mM}, 0,6 \mu \mathrm{L}$ de Taq DNA polimerase (5,0 unidades $/ \mu \mathrm{L}$; Promega) e 8,2 $\mu \mathrm{L}$ de água ultrapura autoclavada. 0 programa de pré-amplificação foi composto de 26 ciclos de amplificação após desnaturação inicial a $94^{\circ} \mathrm{C}$ por $2 \mathrm{~min}$. Cada ciclo foi constituído de $1 \mathrm{~min}$ a $94^{\circ} \mathrm{C}$ (desnaturação), 1 min a $56^{\circ} \mathrm{C}$ (hibridização) e 1 min a $72^{\circ} \mathrm{C}$ (extensão). 0 ciclo final foi seguido de $5 \mathrm{~min}$ a $72^{\circ} \mathrm{C}$. Os produtos da pré-amplificação foram diluídos acrescentando $80 \mu \mathrm{L}$ de água ultrapura autoclavada e armazenados a $20^{\circ} \mathrm{C}$.

As seqüências dos "primers" utilizados na amplificação, seletiva são apresentadas no Quadro 3. Nas reações de amplificação foram utilizados 1,5 $\mu \mathrm{L}$ do produto da pré-amplificação diluído, $0,5 \mu \mathrm{L}$ do "primer" das enzimas de corte raro $(E+N N N$ ou $P+N N N)(50 \mathrm{ng} / \mu \mathrm{L}), 0,6 \mu \mathrm{L}$ do "primer" $\mathrm{M}+\mathrm{NNN}(50 \mathrm{ng} / \mu \mathrm{L}), 1,6$ $\mu \mathrm{L}$ de dNTP 2,5 mM (Gibco), 2,0 $\mu \mathrm{L}$ do tampão da Taq polimerase 10X (Promega), 1,2 $\mu \mathrm{L}$ de $\mathrm{MgCl}_{2} 25 \mathrm{mM}, 0,32 \mu \mathrm{L}$ de Taq DNA polimerase (5 unidades/ $\mu \mathrm{L}$, Promega) e 12,28 $\mu \mathrm{L}$ de água ultrapura autoclavada. 0 programa de amplificação seletiva consistiu de desnaturação inicial a $94^{\circ} \mathrm{C}$ durante 2 minutos, 12 ciclos compostos de 30 segundos a $94^{\circ} \mathrm{C}, 30$ segundos a $65^{\circ} \mathrm{C}$ ($7^{\circ} \mathrm{C} /$ ciclo) e 1 min a $72{ }^{\circ} \mathrm{C}$ seguidos de 23 ciclos compostos de 30 segundos a $94^{\circ} \mathrm{C}, 30$ segundos a $56^{\circ} \mathrm{C}$ e 1 minuto a $72^{\circ} \mathrm{C}$. O ciclo final de extensão foi seguido de $2 \min$ a $72^{\circ} \mathrm{C}$.

Após a amplificação seletiva, as amostras foram submetidas à eletroforese em gel de poliacrilamida [acrilamida/bisacrilamida (19:1) 6\%, uréia $7.5 \mathrm{M}$, tampão $1 \mathrm{X}$ TEB] de $0,5 \mathrm{~mm}$ de espessura. Foi utilizado o sistema eletroforético "Sequi-Gen GT" (Biorad) de $38 \times 50 \mathrm{~cm}$ e pente para 65 amostras.

No preparo de um 1 litro da solução matriz dos géis, foram utilizados $420,4 \mathrm{~g}$ de uréia, $200 \mathrm{~mL}$ de TEB $5 \mathrm{X}, 150 \mathrm{~mL}$ de acrilamida/bisacrilamida $40 \%$ (19:1), sendo o volume final ajustado para $1 \mathrm{~L}$ com água ultrapura. A solução 
matriz foi filtrada em filtro $0,2 \mu \mathrm{m}$ e armazenada em frascos âmbar envoltos em papel aluminio e mantida em refrigerador.

As placas utilizadas na montagem do gel foram cuidadosamente limpas utilizando-se etanol $95 \%$. Na placa maior foram aplicados $2 \mathrm{~mL}$ de REPEL (Amersham). $O$ produto foi cuidadosamente espalhado utilizando-se lenços de papel com movimentos circulares. $O$ excesso foi removido com lenço de papel umedecido em água 5 minutos após a secagem do produto. Para 0 tratamento da placa menor, foram misturados, em um tubo "eppendorf" de 1,5 $\mathrm{mL}, 995 \mu \mathrm{L}$ de etanol $95 \%, 5 \mu \mathrm{L}$ de ácido acético glacial e $5 \mu \mathrm{L}$ de BIND (Amersham). Em seguida, o produto foi aplicado sobre a placa $e$ cuidadosamente espalhado utilizando lenços de papel com movimentos circulares. $O$ excesso foi retirado com lenço de papel umedecido após 5 minutos.

Para o preparo de um gel utilizou-se $120 \mathrm{~mL}$ da solução matriz, $120 \mu \mathrm{L}$ de TEMED e $800 \mu \mathrm{L}$ de persulfato $10 \%$. Antes de carregar os produtos da amplificação seletiva $(20 \mu \mathrm{L})$ no gel, estas foram adicionadas de $10 \mu \mathrm{L}$ de tampão formamida (formamida 98\%, EDTA $10 \mathrm{mM} \mathrm{pH} \mathrm{8,0,} \mathrm{azul} \mathrm{de} \mathrm{bromofenol}$ $0,002 \%(p / v)$ e xileno cianol $0,002 \% p / v)$ e desnaturadas a $95^{\circ} \mathrm{C}$ por 5 minutos. Em seguida, $14 \mu \mathrm{L}$ de cada amostra foram aplicados no gel. Antes da aplicação, porém, o gel foi submetido a uma eletroforese inicial ("pré-corrida") sob potência constante de $80 \mathrm{~W}$ por uma hora. Na parte superior da cuba foi utilizado TEB $1 \mathrm{X}$ e, na parte inferior, TEB $1 \mathrm{X} /$ acetato de sódio $0,375 \mathrm{M}$. Após a pré-corrida, os poços foram cuidadosamente limpos utilizando uma agulha acoplada a uma seringa e então iniciada a aplicação das amostras. Uma vez aplicadas, as amostras foram submetidas à eletroforese sob potência constante de $80 \mathrm{~W}$ durante 4:30 h.

Para revelação dos géis foi utilizado o método de coloração com nitrato de prata seguindo o protocolo proposto por Creste et. al. (2001). Após a eletroforese, as placas foram cuidadosamente separadas e o gel aderido a 
placa menor foi corado com nitrato de prata. Para tanto, o gel foi imerso em $2 \mathrm{~L}$ de solução para fixação (etanol $10 \%$ e ácido acético 1\%) e mantido sob lenta agitação durante 10 minutos. Após a fixação, o gel foi lavado sob lenta agitação em $2 \mathrm{~L}$ de água ultrapura durante 1 minuto e, em seguida, submetido a um prétratamento pela imersão em solução de oxidação (ácido nítrico 1,5\%) durante 3 minutos. $\mathrm{O}$ gel foi então lavado sob lenta agitação em $2 \mathrm{~L}$ de água ultrapura durante 1 minuto e imerso em $2 \mathrm{~L}$ de solução $0,2 \%$ de $\mathrm{AgNO}_{3}$ durante 20 minutos sob agitação. Em seguida, foram realizadas duas lavagens de $\mathbf{3 0}$ segundos com água ultrapura sob lenta agitação e uma incubação em $1 \mathrm{~L}$ de solução de revelação $\left(\mathrm{Na}_{2} \mathrm{CO}_{3} 3 \%\right.$ e formaldeído $\left.0,02 \%\right)$ sob agitação lenta e constante. Quando começaram a surgir as primeiras bandas no gel, o mesmo foi transferido para nova solução de revelação de igual volume e agitado constantemente. Após obter o padrão de revelação desejado, o gel foi imerso em $2 \mathrm{~L}$ de solução bloqueadora (ácido acético glacial $5 \%$ ) e mantido 5 minutos sob lenta agitação. Em seguida, o gel foi submetido a uma lavagem final pela imersão em $2 \mathrm{~L}$ de água ultrapura sob agitação durante $1 \mathrm{~min}$. Os géis foram mantidos a temperatura ambiente para secar e após totalmente secos, as imagem dos mesmos foram capturadas utilizando um "scanner". O registro da imagem foi realizado para consultas futuras quanto a presença e ausência dos fragmentos das amostras analisadas. A leitura dos géis foi realizada antes do descarte dos mesmos, colocando-os diretamente sobre transiluminador de luz branca. Foi avaliada a presença e a ausência de determinado fragmento em todos os individuos analisados, sendo representada pelos valores 0 (zero) e 1 (um), respectivamente. Para se referir a um produto polimórfico amplificado, foi utilizada a denominação descrita por Castiglione et al. (1999). Por exemplo: o loco E4048293 corresponde ao fragmento de AFLP amplificado pela combinação de primes Eco40/Mse48, cujo tamanho do fragmento é de 293 pb. $O$ peso molecular do fragmento foi determinado a partir de uma equação de regressão, obtida com base nas distâncias de migração dos fragmentos de DNA de um padrão de peso molecular de 50pb (Promega). 


\subsubsection{Análises estatísticas}

\subsubsection{Análises de variância}

Inicialmente foram realizadas análises de variância da reação dos genótipos à mancha de Phaeosphaeria para cada experimento individualmente, considerando o modelo aleatório. A análise foi realizada de acordo com 0 seguinte modelo estatístico (Cochran e Cox,1963):

$Y_{i j k}=m+t_{i}+r_{j}+b_{k(j)}+e_{i j k}$

em que:

$Y_{\mathrm{ijk}}$ : é o valor observado do tratamento i no bloco incompleto $\mathrm{K}$ da repetição j;

$\mathrm{m}$ : é média geral do experimento;

$t_{i}$ : efeito do tratamento $i(i=1,2, \ldots ., 121)$;

$r_{j}$ : efeito da repetição $j(j=1,2,3)$;

$b_{k(j)}$ : efeito do bloco incompleto $K$ dentro da repetição j $(k=1,2, \ldots ., 11)$;

$\mathrm{e}_{\mathrm{ijk}}$ : erro aleatório associado à observação $\mathrm{Y}_{\mathrm{ijk}}$.

Posteriormente, para proceder com as análises conjuntas verificou-se o atendimento do critério da homogeneidade de variâncias $(>Q M R /<Q M R$ inferior a 7) sugerido por Gomes (1990). A análise conjunta de variância envolvendo as duas épocas, considerando os efeitos aleatórios, foi realizada utilizando-se o seguinte modelo estatístico:

$Y_{i j k g}=m+r_{j(g)}+b_{k(j g)}+t_{i}+d_{g}+(t d)_{j g}+e_{i j k g}$

$Y_{j \mathrm{jkg}}$ : valor do tratamento $\mathrm{i}$, na repetição j, no bloco k, na época g;

m: média geral;

$\mathrm{r}_{\mathrm{j}(\mathrm{g})}$ : 0 efeito da repetição j dentro da época $\mathrm{g}$;

$b_{k(j g)}$ o efeito do bloco $k$, dentro da repetição j dentro da época $g$;

$t_{i}$ : efeito do tratamento $\mathrm{i}$; 
$d_{g}$ : efeito da época $g$;

(td) $)_{\mathrm{jg}}$ : efeito do tratamento i com a época $\mathrm{g}$;

$e_{\mathrm{ijkg}}$ : erro aleatório associado à observação $Y_{\mathrm{ijkg}}$.

Foi realizado o agrupamento das médias ajustadas, obtidas a partir das análises de variância de cada ensaio, pelo teste Scott-Knott. Em todas as análises de variâncias foram estimados os valores da relação b entre 0 coeficiente de variação genético e o coeficiente de variação experimental e a herdabilidade de progênies no sentido amplo. Também foram calculados os coeficientes de correlação entre cada uma das avaliações e a AUDPC.

\subsubsection{Testes de segregação mendeliana}

Testes de qui-quadrado foram realizados individualmente para cada loco marcador a fim de determinar se as freqüências alélicas do mesmo apresentaram proporções esperadas no caso de segregação mendeliana. Quando o teste de qui-quadrado apresentava-se significativo indicava que 0 marcador não seguia o padrão de segregação mendeliana. Desta forma, o marcador não foi utilizado para a detecção de QRLs.

Quando são realizados vários $\mathbf{n}$ testes independentes, a probabilidade de erro tipo I do experimento é dado por:

$$
\alpha=1-\left(1-\alpha_{T}\right)^{n} .
$$

Assim, em cada teste deve-se tomar, para um dado $\alpha$ : .

$$
\alpha_{T}=1-(1-\alpha)^{1 / n} \cong \alpha / n \text { (correção de Bonferroni). }
$$

Neste trabalho, utilizou-se um $\alpha=5 \%$ com $n=216$ marcadores, portanto, realizou-se o teste de qui-quadrado com $\alpha_{T}=0,023 \%$.

No caso de marcadores microssatélites, testou-se a hipótese de que os alelos marcadores apresentavam uma segregação $1: 2: 1$, que é a proporção esperada de genótipos de um loco co-dominante em uma população $F_{2}$, obtida da autofecundação da geração $F_{1}$ resultante do cruzamento de duas 
linhagens homozigotas. Utilizou-se a seguinte expressão para o teste de quiquadrado:

$\left.\chi^{2}=\left\{\left(\left(n_{11}-n e_{11}\right)^{2} / n e_{11}\right]+\left[\left(n_{12}-n e_{12}\right)^{2} / n e_{12}\right]+\left[\left(n_{22}-n e_{22}\right)^{2} / n e_{22}\right]\right]\right\}$

onde $n_{11}$ e ne $e_{11}$ são os números observados e esperados de plantas com a presença do marcador que representa o indivíduo homozigoto com o alelo do pai resistente, $n_{12}$ e ne ${ }_{12}$ são os números observados e esperados de plantas heterozigotas e $n_{22}$ e ne ${ }_{22}$ são os números observados e esperados de plantas homozigotas para alelo marcado do pai suscetível, respectivamente.

No caso de marcadores AFLPs, testou-se a hipótese de segregação de alelos na proporção 3:1, que é a segregação esperada de alelos de um loco dominante em uma geração $F_{2}$ (obtida da autofecundação da geração $F_{1}$ de duas linhagens homozigotas). Neste caso, utilizou-se a seguinte expressão para o teste de qui-quadrado:

$\chi^{2}=\left\{\left[\left(n_{1}-n e_{1}\right)^{2} / n e_{1}\right]+\left[\left(n_{0}-n e_{0}\right)^{2} / n e_{0}\right]\right\}$

onde $n_{1}$ e ne ${ }_{1}$ são os números observados e esperados de plantas com a presença do marcador e $n_{0}$ e ne $e_{0}$ são os números observados e esperados de plantas com a ausência do marcador.

3.2.5 Identificação de marcadores ligados a QRLs com análise de regressão linear múltipla

Uma análise de regressão múltipla foi realizada envolvendo todos os marcadores microssatélites e AFLPs que apresentaram segregação mendeliana com as médias ajustadas dos experimentos analisados individualmente e também com as médias ajustadas da análise conjunta, considerando as duas épocas. A análise de regressão linear múltipla dos marcadores foi realizada conforme Edwards et al. (1987), que consideram genótipos em locos 
marcadores como variáveis independentes e as características fenotípicas como variáveis dependentes. Os locos marcadores de maior significância foram identificados através de valores do teste $F$ parcial $(P<0,05)$ e a porcentagem da variação explicada por eles foi explicada pelo coeficiente de determinação parcial (Draper \& Smith, 1981).

O processo "Stepwise" de seleção de variáveis regressoras (Draper \& Smith, 1981) foi aplicado para obter uma estimativa ótima dos valores genótípicos dos QRLs, dos erros padrão e da porcentagem genética explicada em cada situação. Nesse processo, coloca-se inicialmente no modelo de regressão somente o marcador com maior valor de $\mathrm{F}$ parcial que tenha sido significativo. Em seguida, testa-se o loco marcador, dentre os candidatos a entrar no modelo, que tem o maior de $F$ parcial, na presença do primeiro marcador. Dentre os marcadores do modelo recém formado, aqueles que apresentarem teste $F$ não significativos são retirados do modelo e os que apresentarem teste $F$ significativo são mantidos. Esses testes são efetuados um por um a cada passo. O processo continuará até que todos marcadores candidatos a entrar no modelo sejam testados, resultando num modelo onde todos os marcadores tenham $\mathrm{F}$ parcial significativo.

\subsubsection{Mapeamento de QRLs utilizando a metodologia de intervalo composto (MIC)}

Antes da realização das análises estatísticas para o mapeamento de QRLs, foi realizada a construção de um mapa genético de ligação com os marcadores AFLPs e SSRs que apresentaram segregação mendeliana, utilizando o programa MAPMAKER (Lander et al., 1987), versão 3.0. Os grupos de ligação foram estabelecidos utilizando o comando "group" com um "lod score" (LOD) de 4,0 e freqüência máxima de recombinação $\theta=0,30$. As freqüências de recombinação foram convertidas em distâncias de mapa utilizando a função de mapeamento de Haldane (1919). Após o agrupamento dos locos marcadores em grupos de ligação, a ordem destes foi então 
determinada. No caso de grupos com número de marcadores menor ou igual a 8 , a ordem mais provável foi obtida usando o comando "compare" e, para os demais grupos, foi usado o comando "order", adotando-se como critério de ordenação um LOD > 3,0. Para confirmação da ordem obtida, utilizou-se o comando "ripple", adotando-se um LOD > 2. Uma vez obtido o grupo de ligação e confirmada a ordem dos marcadores, foi feita uma tentativa de adicionar marcadores que não entraram nos grupos através do comando "try". Após a adição destes, a nova ordem foi submetida à confirmação usando o comando "ripple". No caso de confirmação (LOD > 2,0) estes passaram então a compor o grupo, do contrário foram retirados.

Após a construção do mapa de ligação, realizou-se o mapeamento de QRLs, para todas as avaliações fenotípicas e para a AUDPC, utilizando o programa QTL Cartographer para Windows (versão 1.21) (Basten et al., 2000). O mapeamento foi realizado para cada ensaio e também para a média dos dois ensaios.

Utilizou-se a metodologia de mapeamento por intervalo composto (Zeng, 1994) que é uma combinação do mapeamento por intervalo e regressão linear múltipla, utilizando os marcadores como variáveis regressoras. 0 processo "Stepwise" foi utilizado para seleção dos locos marcadores na regressão múltipla. Para declarar a presença de um QTL foi usado como critério um valor de $L O D>2,5$.

O modelo genético estatístico para o mapeamento por intervalo composto em um segmento entre os marcadores i e i+1 é o seguinte: em que:

$$
\mathrm{y}_{\mathrm{j}}=\mathrm{b}_{0}+\mathrm{b}_{\mathrm{i}} \mathrm{X}_{\mathrm{ij}}+\sum_{k \neq i, i+1} \mathrm{~b}_{\mathrm{k}} \mathrm{X}_{\mathrm{kj}}+\mathrm{e}_{\mathrm{j}}
$$

$\mathrm{y}_{\mathrm{j}}$ : valor da característica analisada para a família j;

$b_{0}$ : intercepto do modelo; 
$b_{i}$ : efeito genético de um QTL localizado entre os dois marcadores i e $i+1$;

$\mathrm{X}_{\mathrm{ij}}$ : variável "dummy" que pode assumir valores de 0 e 1 conforme a combinação dos genótipos dos marcadores i e i+1; cada classe dos genótipos marcadores tem uma determinada probabilidade de ocorrência, que é função da distância entre marcador i com o QTL e entre os marcadores i e i+1.

$b_{k}$ : coeficiente de regressão parcial do valor da característica do marcador $K$;

$\mathrm{X}_{\mathrm{kj}}$ : variável dummy para o marcador $\mathrm{K}$ na família j;

$\mathrm{e}_{\mathrm{ij}}$ :erro do modelo; 


\section{RESULTADOS E DISCUSSÃO}

\subsection{Análise de médias de gerações}

Para as análises de variância e de médias de gerações foi considerada a média entre as notas dos dois avaliadores, visando assim diminuir o erro experimental inerente à avaliação visual. A distribuição das freqüências da severidade da doença é representada de maneira gráfica na figura 1. Tal distribuição é uma simplificação do agrupamento das médias usando-se os limites de classificação da escala diagramática nas gerações $F_{2}$, $R C P_{1}$ e RCP 2 . A distribuição comportou-se de maneira não normal.

Os resultados da avaliação fenotípica foram submetidos à análise de variância individual e conjunta (Tabelas 4 e 5). A homogeneidade das variâncias dos experimentos foi verificada a partir da razão entre o maior e o menor quadrado médio do resíduo. Sendo esta relação inferior a 7 , as variâncias residuais dos experimentos foram consideradas homogêneas (Gomes, 1990).

Os experimentos de campo foram conduzidos sob condições favoráveis ao desenvolvimento da doença, caracterizadas por alta umidade relativa e alta temperatura na época do florescimento. Os valores do coeficiente de variação experimental $\left(\mathrm{CV}_{\mathrm{e}}\right)$ foram de $11,54 \%$ e $8,05 \%$ nas análises individuais e 9,59\% na análise conjunta. Considerando que a avaliação de doenças por meio de notas normalmente é bastante trabalhosa e sujeita a alta margem de erro, pode-se considerar bom o nível de precisão dos experimentos. 
DAS95 x DAS21 - Experimento 1
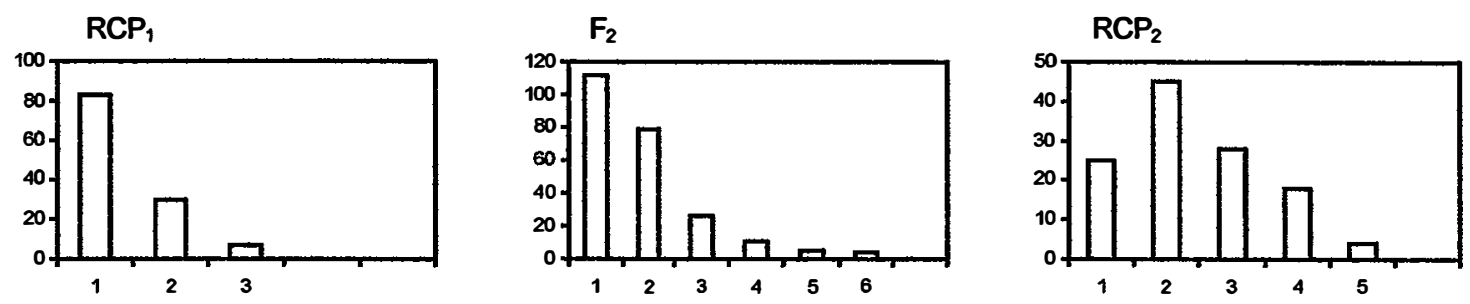

DAS72 x DAS21-Experimento 1
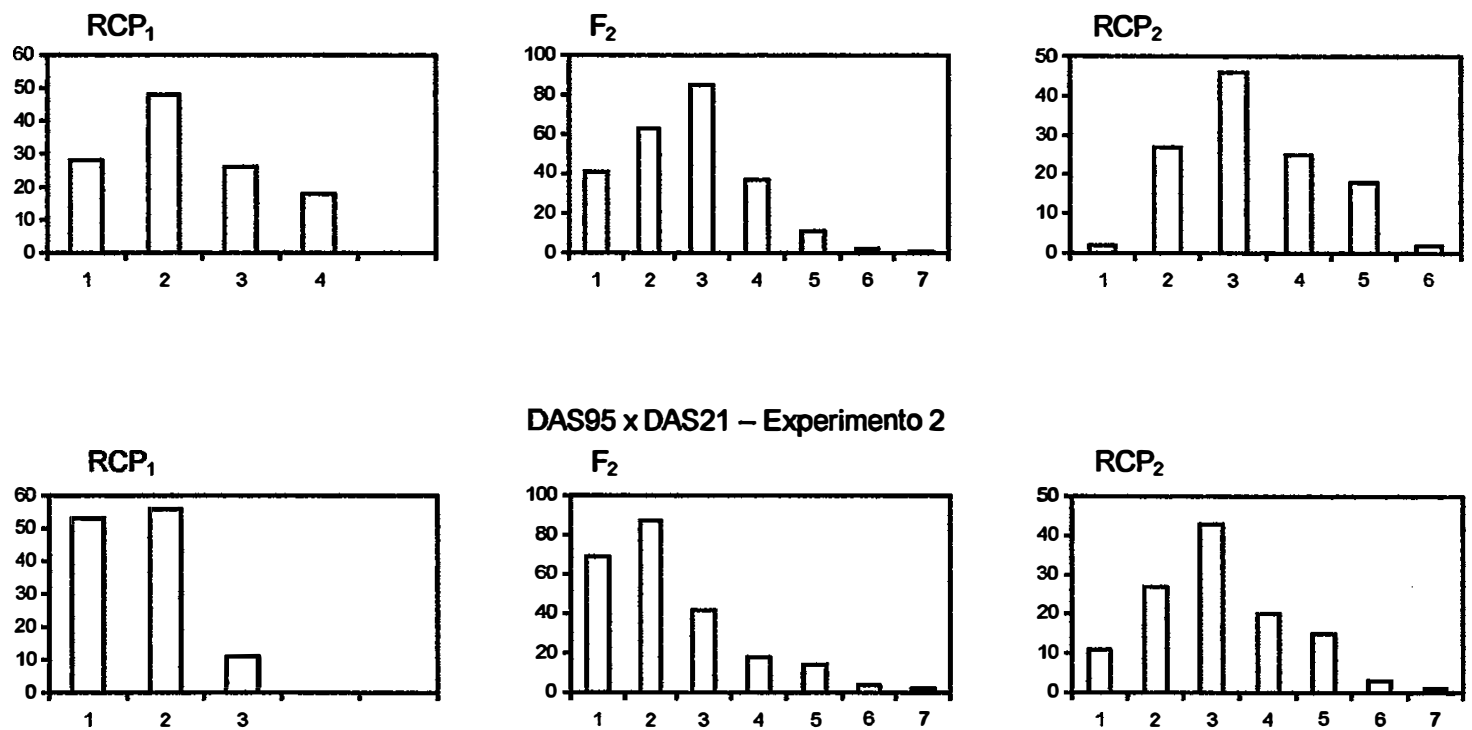

DAS95 xDAS21 - Experimento 2
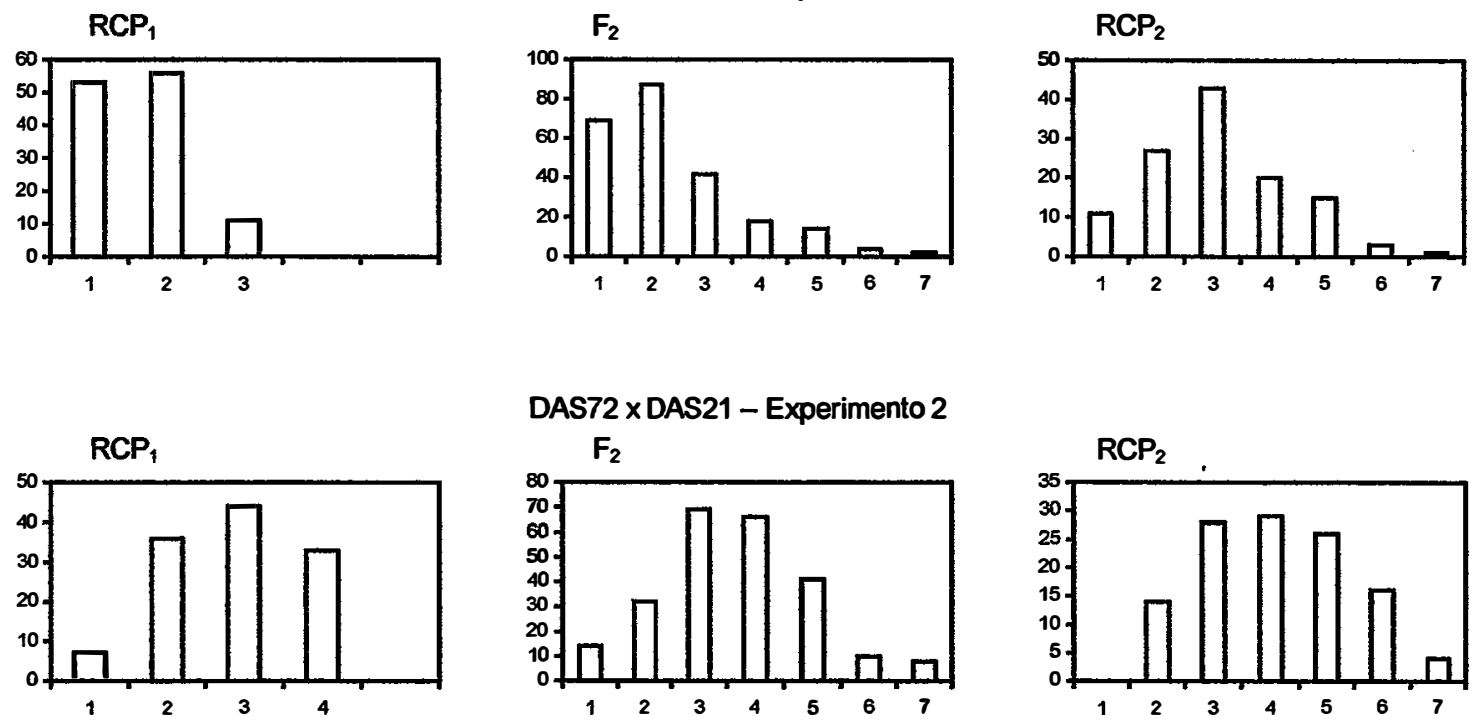

DAS72 x DAS21 - Experimento 2
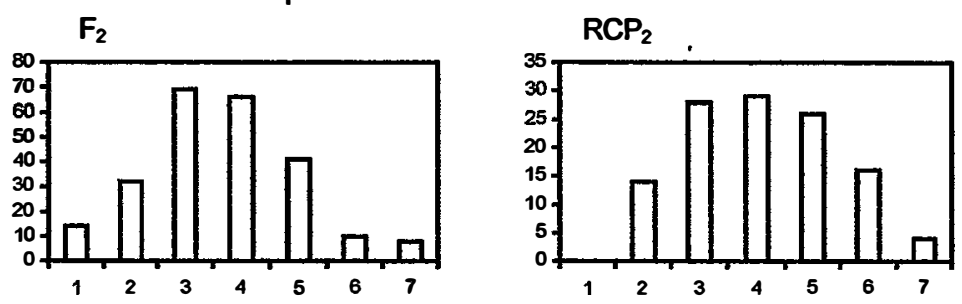

Figura 1 - Distribuição das médias da severidade da mancha de Phaeosphaeria nos cruzamentos entre as linhagens DAS95 x DAS21 e DAS72 x DAS21, para três gerações. Indianópolis, 2000. 
Tabela 4. Resumo da análise de variância individual e médias das gerações da avaliação da severidade da mancha de Phaeosphaeria, dos experimentos 1 e 2. Indianópolis, MG, 2000/2001.

\begin{tabular}{|c|c|c|c|c|c|}
\hline \multirow[t]{2}{*}{$\begin{array}{l}\text { Fonte de } \\
\text { variação }\end{array}$} & \multirow[t]{2}{*}{ GL } & \multicolumn{4}{|c|}{ QM } \\
\hline & & \multicolumn{2}{|c|}{ Época 1} & \multicolumn{2}{|c|}{ Época 2} \\
\hline \multirow[t]{2}{*}{$\begin{array}{l}\text { Bloco } \\
\text { Tratamento } \\
\text { Resíduo }\end{array}$} & $\begin{array}{c}2 \\
10 \\
20\end{array}$ & \multicolumn{2}{|c|}{$\begin{array}{c}0,1239 \\
2,8444^{*} \\
0,0705\end{array}$} & \multicolumn{2}{|c|}{$\begin{array}{c}0,0075 \\
5,8801^{*} \\
0,5771\end{array}$} \\
\hline & & DAS95 x DAS21 & DAS72 x DAS21 & DAS95 x DAS21 & DAS72 $\times$ DAS21 \\
\hline $\begin{array}{l}\text { Média P1 } \\
\text { Média P2 } \\
\text { Média F1 } \\
\text { Média F2 } \\
\text { Média RCP1 } \\
\text { Média RCP2 } \\
\text { CV(\%) } \\
\end{array}$ & & $\begin{array}{ll}1,108 & \\
4,513 & \\
1,299 & \\
1,833 & \\
1,395 & \\
2,211 & \\
& 11 \\
\end{array}$ & $\begin{array}{r}2,109^{\circ} \\
4,513 \\
2,387 \\
2,683 \\
2,531 \\
\\
\quad 3,233 \\
, 54 \\
\end{array}$ & $\begin{array}{l}1,123 \\
5,970 \\
1,426 \\
2,298 \\
1,650 \\
3,168 \\
\end{array}$ & $\begin{array}{l}2,762 \\
5,970 \\
3,277 \\
3,736 \\
3,070 \\
4,327\end{array}$ \\
\hline
\end{tabular}

Tabela 5. Resumo da análise de variância conjunta e médias das gerações da avaliação da severidade da mancha de Phaeosphaeria. Indianópolis, 2000/2001.

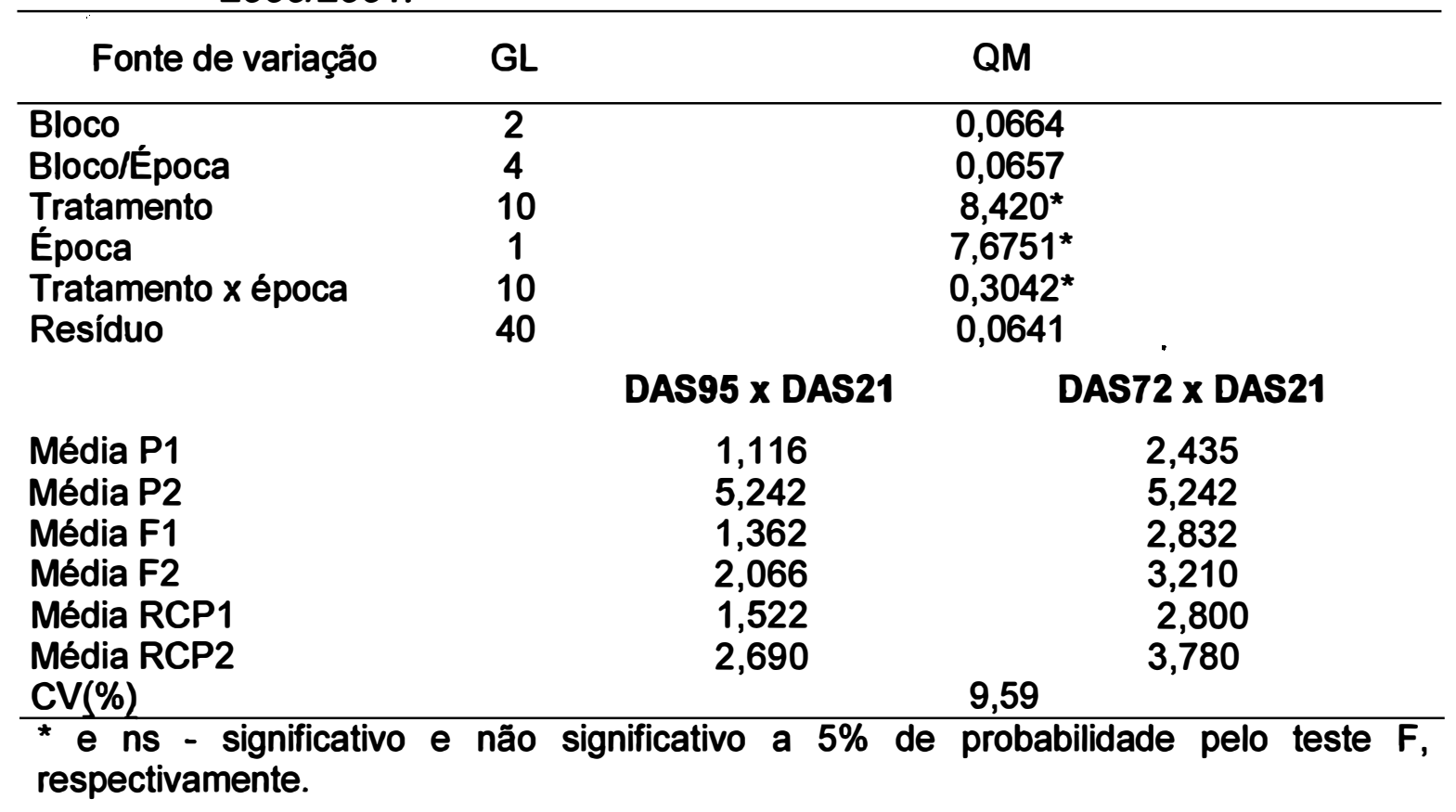


Nas análises de variância individual e conjunta dos experimentos, observou-se efeito significativo de tratamentos $(P<0,05)$, indicando que as linhagens genitoras das gerações segregantes são contrastantes para resistência à doença (Tabelas 4 e 5). Na análise conjunta verificou-se efeito significativo de época decorrente de alterações nas médias das gerações do primeiro e do segundo experimento. Também foi verificado efeito significativo para a interação genótipo x época, indicando resposta diferencial das gerações em função da época. Essa interação pode ser devida a diferenças na quantidade de inóculo e/ou na composição genética das populações patogênicas presentes em cada um dos experimentos, uma vez que esta avaliação foi realizada com incidência natural do patógeno.

A linhagem DAS95 apresentou maior resistência à doença (médias 1,10 e 1,12, experimentos 1 e 2 , respectivamente), seguida pela linhagem DAS72 (médias 2,10 e 2,76, experimentos 1 e 2, respectivamente), sendo a linhagem DAS21 a mais suscetivel (médias 4,51 e 5,97, experimentos 1 e 2, respectivamente). Os comportamentos dessas linhagens quanto a resistência à Phaeosphaeria foram semelhantes aos relatados por Silva (2002). Os hibridos $\left(F_{1}\right)$ resultantes dos dois cruzamentos apresentaram médias próximas à linhagem resistente em cada cruzamento. As gerações $F_{2}$ apresentaram médias intermediárias aos genitores e as médias dos retrocruzamentos tenderam a aproximar-se das médias das linhagens utilizadas como genitor recorrente.

As estimativas dos parâmetros genéticos com base nas médias das gerações foram obtidas usando o modelo reduzido composto pelos parâmetros $m$, a e $d$ e realizada análise de variância. Tanto nas análises de variância individual (Tabela 6) como na análise conjunta (Tabela 7) os efeitos genéticos aditivos foram mais importantes na determinação do caráter, com participação bem inferior dos efeitos dominantes para as duas populações estudadas. Nas análises individuais os efeitos genéticos aditivos representaram $74,99 \%$ e $84,74 \%$ da variação genética total. Essas proporções foram bem superiores às dos efeitos genéticos dominantes, que variaram de $12,86 \%$ a $23,30 \%$ e também 
variação total no cruzamento DAS95 x DAS21 e 73,95 \% no cruzamento DAS72 x DAS21. E a variação devido a dominância foi de $20,52 \%$ e $12,83 \%$ nos respectivos cruzamentos. A variância aditiva é um dos fatores determinantes da covariância entre parentes e, por esta razão, sua existência é um indicativo de um grande relacionamento entre o comportamento da unidade de seleção e a unidade melhorada (Cruz e Regazzi, 1997). A prevalência de efeitos aditivos no controle genético da resistência a mancha de Phaeosphaeria indicam uma condição favorável ao melhoramento, não devendo haver dificuldades na identificação de genótipos superiores, com maior concentração de alelos favoráveis.

Tabela 6. Quadrados médios (QM) da análise de variância da avaliação da severidade da mancha de Phaeosphaeria de seis gerações dos cruzamentos (DAS95 x DAS21 e DAS72 x DAS21) e porcentagens (\%) da variação explicada pelas somas de quadrados dos efeitos genéticos aditivos, dominantes e desvio do modelo aditivo dominante, de dois experimentos no ano agricola de 2000/2001.

\begin{tabular}{|c|c|c|c|c|c|c|c|c|c|}
\hline \multirow{3}{*}{$\begin{array}{l}\text { Fonte de } \\
\text { variação }\end{array}$} & \multirow{3}{*}{ GL } & \multicolumn{4}{|c|}{ DAS95 x DAS21 } & \multicolumn{4}{|c|}{ DAS72 x DAS21 } \\
\hline & & \multicolumn{2}{|c|}{ Experimento 1} & \multicolumn{2}{|c|}{ Experimento 2} & \multicolumn{2}{|c|}{ Experimento 1} & \multicolumn{2}{|c|}{ Experimento 2} \\
\hline & & QM & $\%$ & QM & $\%$ & QM & $\%$ & QM & $\%$ \\
\hline Total & 6 & & & & & & & & \\
\hline Parâmetros & 3 & & & & & & & & \\
\hline Aditivo & 1 & 5,8166 * & 74,99 & 12,570 * & 78,58 & 3,0373 * & 82,07 & 5,8880 * & 84,00 \\
\hline Dominante & 1 & $1,8074^{*}$ & 23,30 & 3,3100 * & 20,68 & 0,6208 * & 16,77 & $0,9010 \mathrm{~ns}$ & 12,86 \\
\hline Desvios & 3 & 0,0440 ns & 1,70 & 0,0333 ns & 0,74 & $0,0153 \mathrm{~ns}$ & 1,15 & $0,0733 \mathrm{~ns}$ & 3,12 \\
\hline Erro & 20 & 0,0705 & & 0,5771 & & 0,0705 & & 0,5771 & \\
\hline
\end{tabular}


Tabela 7. Quadrados médios (QM) da análise de variância conjunta da avaliação da severidade da mancha de Phaeosphaeria de seis gerações dos cruzamentos (DAS95 x DAS21 e DAS72 x DAS21) e porcentagens (\%) da variação explicada pela soma de quadrados dos efeitos genéticos aditivos, dominantes, ambiente, interação aditivo e ambiente, interação dominância e ambiente e desvio do modelo aditivo dominante, dos experimentos 1 e 2. Indianópolis, MG, 2000/2001.

\begin{tabular}{|c|c|c|c|c|c|}
\hline \multirow{2}{*}{ Fonte de variaçăo } & \multirow{2}{*}{ GL } & \multicolumn{2}{|c|}{ DAS95 x DAS21 } & \multicolumn{2}{|c|}{ DAS72 x DAS21 } \\
\hline & & QM & $\%$ & QM & $\%$ \\
\hline Total & 12 & & & & \\
\hline Parâmetros & 6 & & & & \\
\hline Parâmetros & 1 & 17,7435 * & 72,83 & 8,6896 * & 73,95 \\
\hline $\operatorname{Aditivo}(\hat{a})$ & 1 & $5,0016^{*}$ & 20,52 & 1,5070 * & 12,83 \\
\hline Dominante $(\hat{d})$ & 1 & $0,7407^{*}$ & 3,04 & 1,2826 * & 10,92 \\
\hline Ambiente $(\hat{l})$ & 1 & 0,6430 * & 2,63 & 0,2339 ns & 1,99 \\
\hline$\hat{a l}$ & 1 & 0,1127 ns & 0,46 & 0,0133 ns & 0,11 \\
\hline$\hat{d l}$ & 6 & 0,1223 ns & 0,50 & 0,0324 ns & 0,28 \\
\hline Erro & 40 & 0,0641 & & 0,0641 & \\
\hline
\end{tabular}

* e ns - significativo e não significativo a $5 \%$ de probabilidade pelo teste $F$, respectivamente.

Em geral, a predominância dos efeitos genéticos aditivos, observada neste trabalho, concorda com os resultados obtidos por Carson (2001), Lima et al. (1998), Paterniani (1988), Pegoraro et al. (2000) e Silva (2002), porém divergem dos dados obtidos por Das et al. (1989a, 1989b) que evidenciaram os efeitos genéticos dominantes como o principal componente genético da resistência a mancha de Phaeosphaeria em milho.

As estimativas da herdabilidade no sentido amplo para resistência a mancha de Phaeosphaeria foram altas, de aproximadamente $84 \%$ e $75 \%$ nas 
análises individuais e de 71 \% na análise conjunta para o cruzamento DAS95 x DAS21, e de $71 \%$ e $61 \%$ nas individuais e $63 \%$ na conjunta para o cruzamento DAS21 x DAS972. Essa magnitude de herdabilidade também foi obtida por Carson (2001), com variação de 70 a 85 \%, e Silva (2002), com variação de 63 a $88 \%$.

Os altos valores de herdabilidade e a grande importância do efeito genético aditivo no controle do caráter são favoráveis ao melhoramento para características controladas por vários genes. As estimativas do número mínimo de genes envolvidos no controle genético da resistência a Phaeosphaeria, considerando os cruzamentos estudados, indicam a provável existência de dois e três genes para DAS95 x DAS21 e DAS72 x DAS21, respectivamente. Carson (2001) estimou em três ou quatro o número de genes ao passo que Silva (2002), de um a três. Verifica-se, portanto, uma consonância entre os resultados obtidos. Vale ressaltar que as expressões utilizadas para a estimativa do número de genes ou blocos gênicos são baseadas em uma série de pressuposições e, por esta razão, podem não apresentar uma estimativa correta (Cruz e Regazzi, 1997). De qualquer modo, estas estimativas corroboram com uma hipótese de controle oligogênico (Carson, 2001; Silva, 2002). Trabalhos visando o mapeamento de genes de resistência a Phaeosphaeria usando marcadores moleculares vêm sendo desenvolvidos a fim de complementar os resultados aqui apresentados.

\subsection{Mapeamento de genes de resistência a mancha de Phaeosphaeria em milho}

\subsubsection{Avaliação de progênies F3 de milho para resistência a mancha de Phaeosphaeria}

Os ensaios de campo apresentaram alta incidência da doença, o que facilitou a discriminação das progênies quanto ao seu grau de 
resistência/suscetibilidade. As epidemias tiveram início por volta do estádio de florescimento e progrediram até o desenvolvimento de grãos. A distribuição das freqüências de classes de severidades médias das progênies verificadas na terceira avaliação e das AUDPCs pode ser visualizada, para ambos experimentos, nas figuras 2 e 3 . A análise deste gráficos permite observar comportamentos bem distintos das linhagens genitoras frente a doença e uma distribuição não normal, com maior número de progênies dentro de classes consideradas na prática como resistentes ou medianamente resistentes, um indicativo de herança oligogênica.

A análise de variância das avaliações pontuais e AUDPC de cada experimento (Tabela 8 ) atendeu ao critério da homogeneidade de variâncias, o que possibilitou uma análise conjunta dos mesmos (Tabela 9). Não obstante a subjetividade comumente associada a avaliações realizadas por meio de escalas de notas, verificou-se um bom nivel de precisão dos experimentos, a julgar pelos valores dos coeficientes de variação (CV) experimental (Tabelas 8 e 9), fato que pode ser devido, ao menos em parte, pela utilização de dois avaliadores. Coeficientes de variação de mesma magnitude foram encontrados nas avaliações dos ensaios de médias de gerações apresentados anteriormente. 

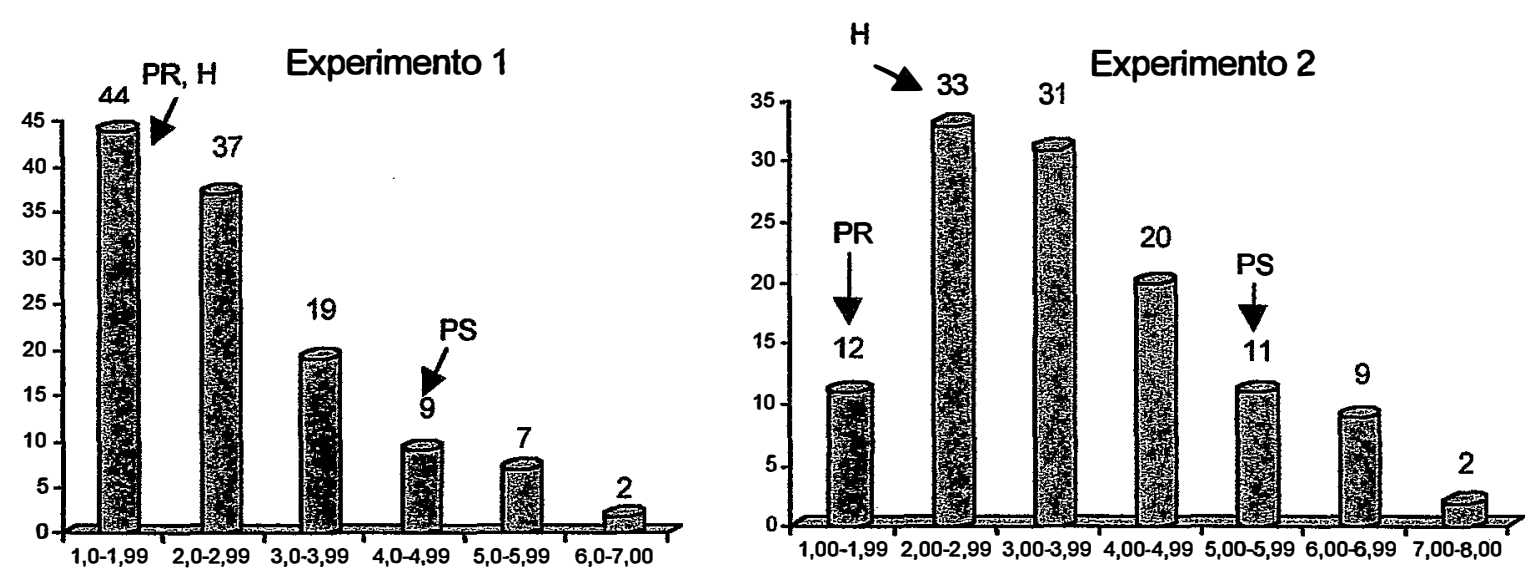

Figura 2 - Distribuição das médias da severidade da mancha de Phaeosphaeria em progênies $F_{3}$ de milho obtidas a partir das linhagens DAS95 $x$ DAS21, na terceira avaliação dos experimentos 1 e 2 . Indianópolis, MG.
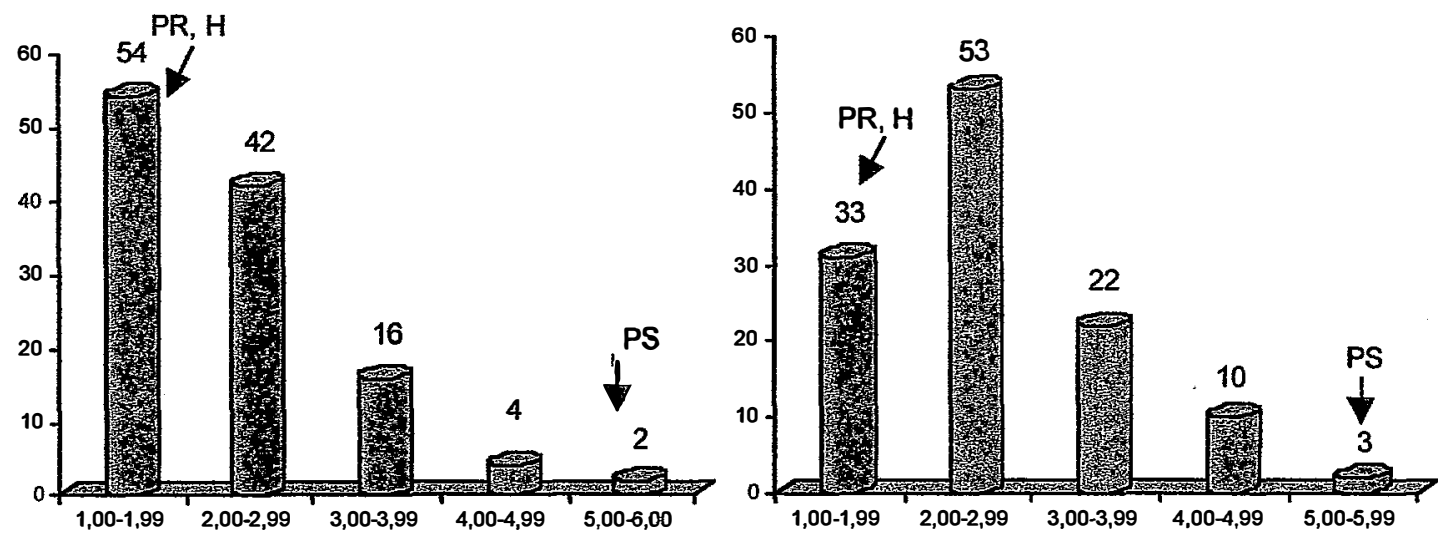

Figura 3 - Distribuição das médias da severidade da mancha de Phaeosphaeria em progênies $F_{3}$ de milho obtidas a partir das linhagens DAS95 $x$ DAS21, para a AUDPC dos experimentos 1 e 2. Indianópolis, MG. 
Nas Tabelas 10 e 11 (Anexo) são apresentados os agrupamentos das médias ajustadas, por experimento, segundo o teste Scott Knott para as três avaliações e também AUDPC. Os tratamentos apresentaram niveis mais elevados de severidade no segundo ensaio, o que pode ser devido à ocorrência precoce da doença e maior pressão de inóculo neste experimento em função de um acúmulo do mesmo produzido no primeiro ensaio. Verificou-se variação significativa entre progênies em todas as avaliações, sugerindo a presença de segregantes transgressivos, indivíduos mais suscetiveis que o genitor suscetivel. 0 agrupamento de médias pelo teste Scott-Knott mostra um comportamento intermediário do genitor suscetivel quando comparado às progênies resistente e suscetíveis, variando em magnitude dependendo das progênies consideradas, e corrobora a hipótese levantada no trabalho de Silva (2002), de que a linhagem DAS21 possui alelos de resistência à mancha de Phaeosphaeria.

A análise de variância conjunta detectou diferenças significativas entre progênies para as 3 avaliações e para a AUDPC (Tabela 9). Os resultados indicaram efeitos de ambiente e também efeitos de interação tratamentos $x$ ambiente. As interaçōes podem ser devidas a diferenças na quantidade e na composição genética das populações patogênicas que atuaram em cada um dos dois ensaios bem como a diferenças nas condições climáticas. Vale lembrar que o segundo ensaio foi conduzido tardiamente, aproximando-se da época já considerada de milho "safrinha", quando geralmente as. condições são mais propícias ao patógeno. Relatos de interação genótipo $\mathrm{x}$ ambiente em avaliações de resistência de genótipos de milho a $P$. maydis também foram encontrados por Brunelli et al. (2002). Os autores verificaram que a linhagem DAS72 apresentou resistência a doença quando avaliada no municipio Cravinhos/SP, porém, em Taquarituba/SP, apresentou-se suscetivel. Foi verificado ainda que outros genótipos avaliados mantiveram o mesmo nivel de resistência em ambos os locais. Atribuiu-se a quebra da resistência de DAS72 em Taquarituba à ocorrência de raças diferentes do patógeno entre os locais, 
ou ainda a diferenças de intensidade de inóculo. As interações aqui discutidas podem ser melhor avaliadas e caracterizadas a partir do mapeamento dos genes envolvidos no controle genético da resistência (Camargo, 2000). 0 mapeamento de genes de resistência a mancha de Phaeosphaeria possibilitará compreender melhor as relações Phaeosphaeria x Zea maydis e estabelecer estratégias mais eficientes para o desenvolvimento de variedades resistentes, como a seleção assistida por marcadores.

Foram verificados valores altos de herdabilidades em ambos os ensaios, principalmente para a terceira avaliação e para a variável AUDPC (Tabelas 8 e 9). $O$ coeficiente $b$, indicador de sucesso em um programa de melhoramento, que expressa a razão entre $\mathrm{CV}_{\mathrm{g}}$ e $\mathrm{CV}_{\mathrm{e}}$ (Vencovsky \& Barriga, 1992) também foi maior para a variável AUDPC (Tabelas 8 e 9), indicando ser esta variável a mais apropriada para avaliações fenotípicas em programas de melhoramento. Não obstante, valores próximos também podem ser obtidos através de uma única avaliação realizada 30 dias após o florescimento.

Embora a AUDPC seja mais adequada para representar uma epidemia, para obtê-la é necessário dispor da informação de pelo menos três avaliações durante a condução do experimento. Em termos práticos, a execução dessas avaliações nem sempre é possível. Por isso, é importante comparar os resultados das avaliações pontuais com a AUDPC e verificar quão eficientes estas são como critério de seleção para resistência tendo como referência a seleção baseada na AUDPC. Para tanto, procedeu-se uma análise de correlação entre severidades médias de progênies em cada avaliação e suas respectivas AUDPCs (Tabela 12). Em geral, estas variáveis apresentaram altos níveis de correlação, variando de 0,7586 a 0,9917. Este resultado, de certa forma, era esperado, pois a AUDPC é calculada em função das avaliações pontuais. No entanto, é interessante notar que, a partir dos resultados das correlações é possível estabelecer um período em que a realização de uma avaliação pontual seria tão informativa quanto a AUDPC. Considerando que os valores das correlações entre as médias da segunda e 
terceira avaliação com a AUDPC foram os mais altos, pode-se inferir que o período entre 15 e 30 dias após o florescimento seja o mais adequado para realização de uma avaliação da resistência à Phaeosphaeria em milho. 


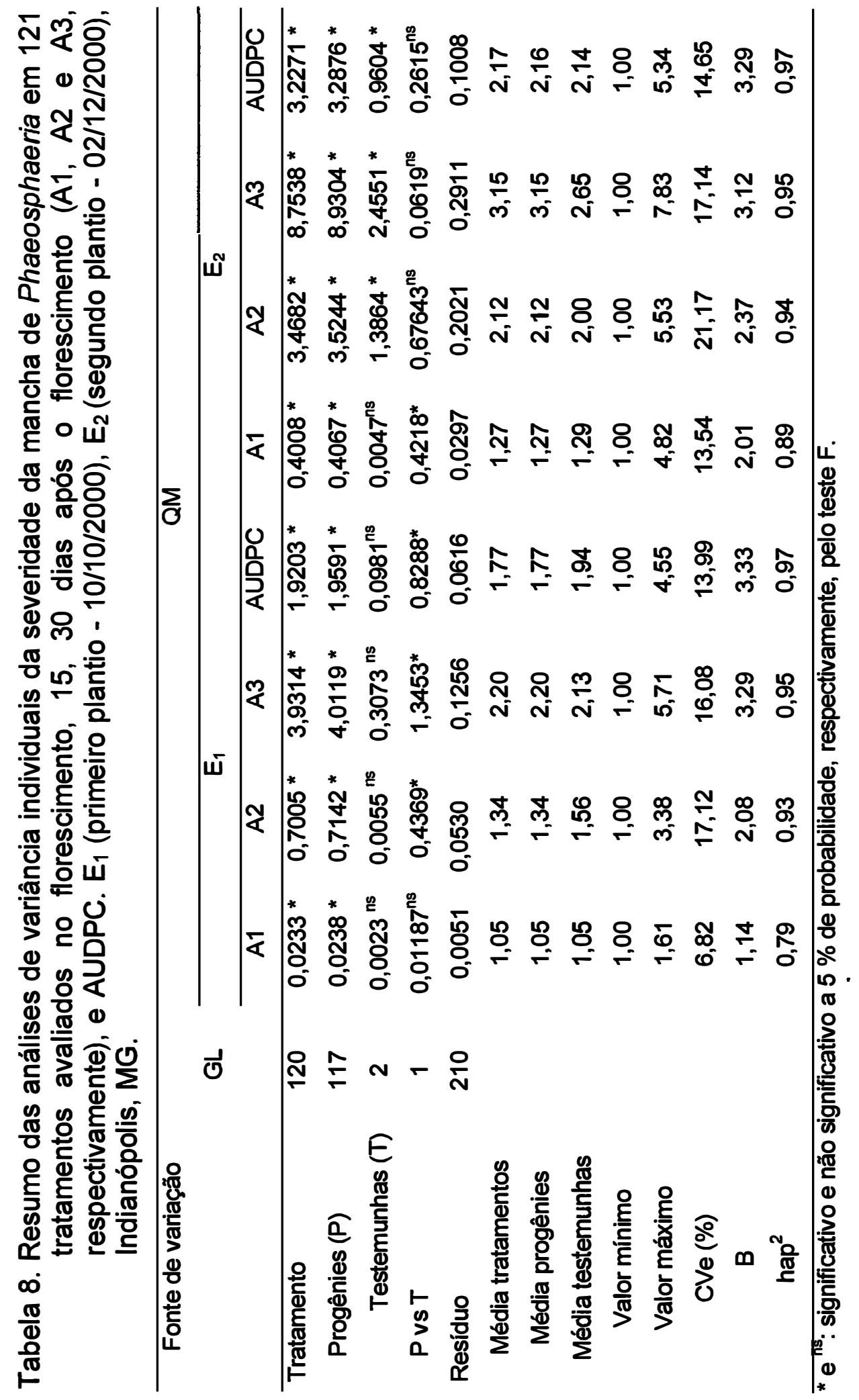


Tabela 9. Resumo da análise de variância conjunta de dois experimentos da severidade de Phaeosphaeria maydis em 121 tratamentos avaliados no florescimento e 15 e 30 dias após o florescimento (A1, A2 e A3, respectivamente), e AUDPC. Indianópolis, MG.

\begin{tabular}{lccccc}
\hline Fonte de variação & $\mathrm{GL}$ & \multicolumn{4}{c}{$\mathrm{QM}$} \\
\hline & & $\mathrm{A} 1$ & $\mathrm{~A} 2$ & $\mathrm{~A} 3$ & $\mathrm{AUDPC}$ \\
\hline Epocas (E) & 1 & $9,3809^{*}$ & $110,1198^{*}$ & $162,0812^{*}$ & $28,0639^{*}$ \\
Tratamento (T) & 120 & $0,2828^{*}$ & $3,4456^{*}$ & $11,8503^{*}$ & $4,9310^{*}$ \\
Progênies (P) & 117 & $0,2872^{*}$ & $3,5081^{*}$ & $12,1047^{*}$ & $5,0298^{*}$ \\
Testemunhas (T) & 2 & $0,0024^{\text {ns }}$ & $0,7670^{*}$ & $2,0852^{*}$ & $0,8010^{*}$ \\
P vs T & 1 & $0,2876^{*}$ & $1,1002^{*}$ & $0,4150^{\text {ns }}$ & $1,0107^{*}$ \\
Trat X E & 120 & $0,1414^{*}$ & $0,7213^{*}$ & $0,8161^{*}$ & $0,2103^{*}$ \\
Resíduo & 420 & 0,0174 & 0,1276 & 0,2084 & 0,0812 \\
Média tratamentos & & 1,16 & 1,73 & 2,68 & 1,97 \\
Média progênies & & 1,17 & 1,73 & 2,68 & 1,97 \\
Média testemunhas & & 1,29 & 2,00 & 2,65 & 2,14 \\
Valor mínimo & & 1,00 & 1,00 & 1,00 & 1,00 \\
Valor máximo & & 3,17 & 4,36 & 6,74 & 4,89 \\
CVe (\%) & & 11,37 & 20,60 & 17,06 & 14,46 \\
b & & 1,18 & 1,93 & 3,06 & 3,2 \\
ha & & 0,53 & 0,79 & 0,93 & 0,86 \\
\hline${ }^{2}$ & & & & & \\
\hline
\end{tabular}

Tabela 12. Coeficientes de correlação entre avaliações e AUDPC dos ensaios de primeira época, segunda época e para a média das épocas de avaliação da severidade da mancha de Phaeosphaeria em DAS21, DAS95, DAS95 x DAS21 e 118 progênies F3.

\begin{tabular}{cc} 
Avaliação & Correlação \\
\hline Avaliação 1 e AUDPC, média do Ensaio 1 & $0,7586^{*}$ \\
Avaliação 2 e AUDPC, média do Ensaio 1 & $0,9609^{*}$ \\
Avaliação 3 e AUDPC, média do Ensaio 1 & $0,9931^{*}$ \\
Avaliação 1 e AUDPC, média do Ensaio 2 & $0,9088^{*}$ \\
Avaliação 2 e AUDPC, média do Ensaio 2 & $0,9935^{*}$ \\
Avaliação 3 e AUDPC, média do Ensaio 2 & $0,9840^{*}$ \\
Avaliação 1 e AUDPC, média dos Ensaios 1 e 2 & $0,9222^{*}$ \\
Avaliação 2 e AUDPC, média dos Ensaios 1 e 2 & $0,9917^{*}$ \\
Avaliação 3 e AUDPC, média dos Ensaios 1 e 2 & $0,9807^{\star}$ \\
\hline
\end{tabular}

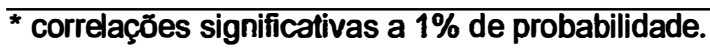




\subsubsection{Análise de marcadores microssatélites}

Um total de 105 marcadores microssatélites (SSR) foram analisados nas linhagens genitoras, no híbrido e nos "Bulks" constituídos do DNA dos 10 indivíduos extremo resistentes e dos 10 extremos suscetiveis. Dos marcadores analisados, 58 mostraram-se não informativos, ou seja, não revelaram polimorfismos entre as linhagens genitoras, 47 revelaram polimorfismo entre as linhagens e destes, 4 apresentaram também polimorfimos entre os "Bulks" de DNA (bnlg439, umc1026, mttgb02 e bngl1306) (Tabela 13). 0 alto polimorfismo encontrado entre as linhagens genitoras deve-se principalmente à seleção prévia realizada nos trabalhos de Brunelli (2002) e Ogliari (1999). Dos marcadores polimórficos, 21 foram analisados em todos os indivíduos da população e usados na construção do mapa genético junto com os marcadores AFLP também analisados nessa população. Na escolha dos "primers" dos marcadores SSR procurou-se contemplar locos de todos os cromossomos para que os grupos de ligação pudessem ser associados ao conjunto cromossômico do milho, no entanto, não foi usado nenhum "primer" de locos dos cromossomos 3 e 10. Na figura 4 pode ser observada-a segregação de indivíduos $F_{2}$ a partir de um gel do marcador mttgb02.

Tabela 13. Polimorfismo de 105 marcadores SSR entre as linhagens DAS21 e DAS95.

\begin{tabular}{ccccccccc}
\hline Loco SSR & "Bin" & "Status" & Loco SSR & "Bin" & "Status" & Loco SSR & "Bin" & "Status" \\
\hline bnlg 182 & 1.00 & NI & bnlg 197 & 3.07 & NI & phi 057 & 7.01 & NI \\
bnlg 149 & 1.00 & I & bnlg 372 & 4.00 & NI & phi 034 & 7.01 & NI \\
phi 056 & 1.01 & NI & phi 072 & 4.00 & I & phi 114 & 7.02 & NI \\
bnlg 109 & 1.02 & NI & nc004 & 4.03 & I & bnlg 398 & 7.02 & NI \\
bnlg 176 & 1.02 & NI & phi 021 & 4.03 & I & bnlg 434 & 7.03 & I \\
phi 001 & 1.03 & I & phi 074 & 4.04 & NI & bnlg 339 & $7.03 / 7.06$ & NI \\
bnlg 439 & 1.03 & I & phi 079 & 4.05 & I & phi 116 & 7.06 & I \\
bnlg 652 & 1.04 & NI & phi 026 & 4.05 & I & bnlg 572 & $7.06 / 7.04$ & I \\
bnlg 615 & 1.07 & NI & phi 096 & 4.05 & I & phi 082 & 7.06 & NI \\
bnlg 652 & 1.04 & NI & bnlg 252 & 4.05 & NI & mace01c08 & 8.02 & NI \\
bnlg 615 & 1.07 & NI & mitgbo2 & $4.06 / 4.07$ & I & bnlg 669 & 8.03 & I
\end{tabular}


Tabela 13. Polimorfismo de 105 marcadores SSR entre as linhagens DAS21 e DAS95.

\begin{tabular}{|c|c|c|c|c|c|c|c|c|}
\hline Loco SSR & "Bin" & "Status" & LOCO SSR & "Bin" & "Status" & Loco SSR & "Bin" & "Status" \\
\hline phi 055 & 1.09 & NI & phi 093 & 4.08 & NI & bnlg 119 & 8.04 & I \\
\hline bnlg 100 & 1.09 & NI & bnlg 292A & 4.09/9.06 & NI & phi 060 & 8.04 & NI \\
\hline phi 011 & 1.09 & NI & bnlg 589 & 4.10 & NI & phi 115 & 8.04 & I \\
\hline bnlg 504 & 1.11 & 1 & phi 019 & 4.11 & NI & phi 014 & 8.04 & NI \\
\hline phi 064 & 1.11 & NI & phi 024 & 5.00 & NI & bnlg 666 & 8.05 & NI \\
\hline bnlg 257 & 1.12 & $\mathrm{NI}$ & mace0b03 & 5.01 & NI & bnlg 162 & 8.05 & NI \\
\hline bnlg 469 & $2.02 / 9.03$ & I & bnlg 105 & 5.03 & I & bnlg 240 & 8.06 & I \\
\hline bnlg 125 & 2.03 & I & bnlg 557 & 5.03 & I & phi 080 & 8.08 & NI \\
\hline bnlg 381 & 2.03 & I & bnlg 150 & $5.03 / 5.04$ & NI & phi 015 & 8.08 & NI \\
\hline bnlg 108 & 2.04 & I & bnlg 653 & 5.04 & NI & mact02b08 & $9.01 / 9.02$ & NI \\
\hline bnlg 121 & 2.04 & NI & macee1a03 & 5.04 & 1 & bnlg 2122 & 9.01 & 1 \\
\hline umc 1026 & 2.04 & I & bnlg 1306 & 5.07 & I & phi 065 & 9.02 & I \\
\hline bnlg 166 & 2.04 & NI & phi 085 & 5.07 & I & phi 061 & 9.03 & I \\
\hline mage05 & $2.05 / 2.06$ & I & bnlg 118 & 5.08 & I & phi 016 & 9.04 & 1 \\
\hline bnlg 180 & 2.06 & NI & bnlg 389 & 509 & NI & bnlg 430 & 9.04 & I \\
\hline bnlg 371 & $2.06 / 2.10$ & NI & bnlg 238 & 6.01 & I & bnlg 128 & 9.07 & I \\
\hline mag01f03 & 2.08 & I & phi 077 & 6.01 & I & phi 059 & 10.02 & I \\
\hline mag01a01 & 2.08 & NI & bnlg 107 & 6.01 & I & phi 063 & 10.02 & NI \\
\hline bnlg 198 & 2.08 & 1 & bnlg 249 & 6.01 & I & bnlg 210 & 10.03 & NI \\
\hline bnlg 602 & 3.04 & I & Nc 009 & 6.04 & 1 & phi 062 & 10.04 & NI \\
\hline phi 029 & 3.04 & NI & bnlg 480 & 6.04 & NI & phi 062 & 10.04 & NI \\
\hline phi 073 & 3.05 & NI & phi 078 & 6.05 & NI & phi 071 & 10.04 & NI \\
\hline bnlg 420 & 3.05 & 1 & phi 070 & 6.07 & NI & phi 84 & 10.04 & NI \\
\hline mag01a03 & 3.07 & I & phi 112 & 7.01 & NI & bnlg 153 & 10.06 & NI \\
\hline
\end{tabular}

Obs: I (infonnativo) e NI (não informativo). 


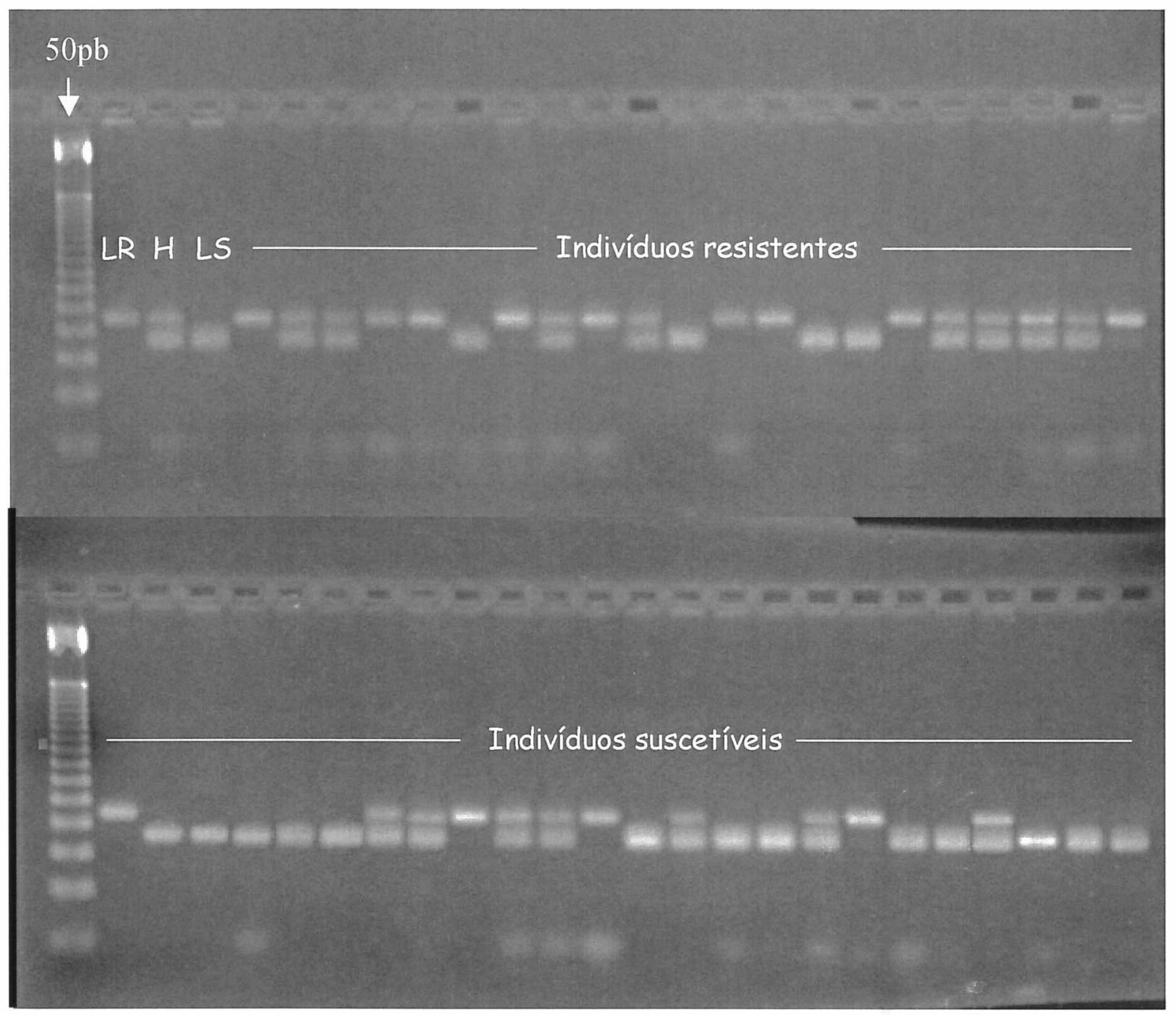

Figura 4 - Genotipagem de indivíduos da população segregante com o marcador microssatélite mttgb02. LR, LS e H, linhagem resistente, suscetível e híbrido, respectivamente. 


\subsubsection{Análise de marcadores AFLPs}

$\mathrm{Na}$ avaliação das combinações de "primers" AFLP, foram usados os genitores, o híbrido e os "Bulks" de DNA dos 10 indivíduos extremos resistentes e dos 10 mais suscetíveis da população $F_{2}$ avaliada em duas épocas de plantio em Indianópolis MG. Os marcadores AFLP são dominantes, portanto foram considerados polimórficos os locos onde a banda foi amplificada em um genitor e no outro não. Foram testadas 56 combinações de "primers" usando as enzimas EcoRI e Pstl com 1 nucleotídeo seletivo na pré-amplificação e 3 na amplificação seletiva (E+ANN/M+CNN e 10 P+ANÑ/M+CNN). Das 66 combinações analisadas, 5 combinações $E+M$ não apresentaram qualidade de amplificação satisfatórias. $O$ número de locos polimórficos das 56 combinações usando os "primers" E+ANN/M+CNN variou de 10 a 36, com média aproximada de 16/combinação. Entre as 10 combinações utilizando os "primers" $\mathrm{P}+\mathrm{ANN} / \mathrm{M}+\mathrm{CNN}$, o número de locos polimórficos variou de 3 a 11, com média de 8,7/combinação. Considerando todas as 59 combinações em que foi possível contar o número de bandas, foram encontrados 897 locos polimórficos, com média de 14,7/combinação (Tabela 14).

As combinações de primers analisadas na população segregante foram selecionadas considerando o polimorfismo entre os "Bulks" suscetível e resistente, o número de locos polimórficos e a qualidade da revelação dos locos. Foram analisadas 14 combinações de "primers" nos 118 indivíduos da população $F_{2}$ e realizada a leitura de 191 locos polimórficos. A figura 5 ilustra a segregação de indivíduos $F_{2}$ da população de mapeamento em uma faixa de um gel de AFLP. 
Tabela 14. Resultado do teste de combinações de "primers" AFLP.

\begin{tabular}{|c|c|c|c|c|}
\hline $\begin{array}{c}\text { Combinações de } \\
\text { "primers" }\end{array}$ & $\begin{array}{c}\text { Código de } \\
\text { identificação }\end{array}$ & $\begin{array}{l}\text { Número total } \\
\text { de locos }\end{array}$ & $\begin{array}{c}\text { Número de locos } \\
\text { polimórficos entre os } \\
\text { genitores }\end{array}$ & $\begin{array}{l}\text { Polimórficos } \\
\text { entre os } \\
\text { "Bulks" }\end{array}$ \\
\hline $\begin{array}{l}\text { EAAC/MCAA } \\
\text { EAAC/MCAC } \\
\text { EAAC/MCAG } \\
\text { EAAC/MCAT } \\
\text { EAAC/MCTA } \\
\text { EAAC/MCTC } \\
\text { EAAC/MCTG } \\
\text { EAAC/MCTT } \\
\text { EACAMCAA } \\
\text { EACAMCAC } \\
\text { EACAMCAG } \\
\text { EACAMCAT } \\
\text { EACAMCTA } \\
\text { EACAMCTC } \\
\text { EACAMCTG } \\
\text { EACAMCTT } \\
\text { EACTMCAA } \\
\text { EACTMCAC } \\
\text { EACT/MCAG } \\
\text { EACT/MCAT } \\
\text { EACT/MCTA } \\
\text { EACT/MCTC } \\
\text { EACT/MCTG } \\
\text { EACT/MCTT } \\
\text { EAGG/MCAA } \\
\text { EAGG/MCAC } \\
\text { EAGG/MCAG } \\
\text { EAGG/MCAT } \\
\text { EAGG/MCTA } \\
\text { EAGG/MCTC } \\
\text { EAGG/MCTG } \\
\text { EAGG/MCTT } \\
\text { EAAG/MCAA } \\
\text { EAAG/MCAC } \\
\text { EAAG/MCAG } \\
\text { EAAG/MCAT } \\
\text { EAAG/MCTA } \\
\text { EAAG/MCTC } \\
\text { EAAG/MCTG } \\
\text { EAAG/MCTT } \\
\text { EACG/MCAA } \\
\text { EACG/MCAC } \\
\text { EACG/MCAG } \\
\text { EACG/MCAT } \\
\text { EACG/MCTA } \\
\text { EACG/MCTC } \\
\text { EACG/MCTG } \\
\text { EACG/MCTT }\end{array}$ & $\begin{array}{l}\text { E32/M47 } \\
\text { E32/M48 } \\
\text { E32/M49 } \\
\text { E32/M50 } \\
\text { E32/M59 } \\
\text { E32/M60 } \\
\text { E32/ M61 } \\
\text { E32/M62 } \\
\text { E44/M47 } \\
\text { E44/M48 } \\
\text { E44/M49 } \\
\text { E44/M50 } \\
\text { E44/M59 } \\
\text { E44/M60 } \\
\text { E44/M61 } \\
\text { E44/M62 } \\
\text { E38/M47 } \\
\text { E38/M48 } \\
\text { E38/M49 } \\
\text { E38/M50 } \\
\text { E38/M59 } \\
\text { E38/M60 } \\
\text { E38/M61 } \\
\text { E38/M62 } \\
\text { E41/M47 } \\
\text { E41/M48 } \\
\text { E41/M49 } \\
\text { E41/M50 } \\
\text { E41/M59 } \\
\text { E41/M60 } \\
\text { E41/M61 } \\
\text { E41/M62 } \\
\text { E33/M47 } \\
\text { E33/M48 } \\
\text { E33/M49 } \\
\text { E33/M50 } \\
\text { E33/M59 } \\
\text { E33/M60 } \\
\text { E33/M61 } \\
\text { E33/M62 } \\
\text { E41/M47 } \\
\text { E41/M48 } \\
\text { E41/M49 } \\
\text { E41/ M50 } \\
\text { E41/ M59 } \\
\text { E41/M60 } \\
\text { E41/M61 } \\
\text { E41/M62 }\end{array}$ & $\begin{array}{c}\text { Fraco } \\
72 \\
75 \\
\text { Fraco } \\
59 \\
71 \\
54 \\
\text { Fraco } \\
45 \\
45 \\
43 \\
69 \\
59 \\
48 \\
67 \\
\text { Fraco } \\
50 \\
43 \\
42 \\
46 \\
44 \\
56 \\
55 \\
\text { Fraco } \\
73 \\
77 \\
65 \\
52 \\
40 \\
53 \\
48 \\
48 \\
47 \\
54 \\
58 \\
64 \\
68 \\
46 \\
47 \\
62 \\
79 \\
56 \\
68 \\
38 \\
41 \\
30 \\
36 \\
37\end{array}$ & 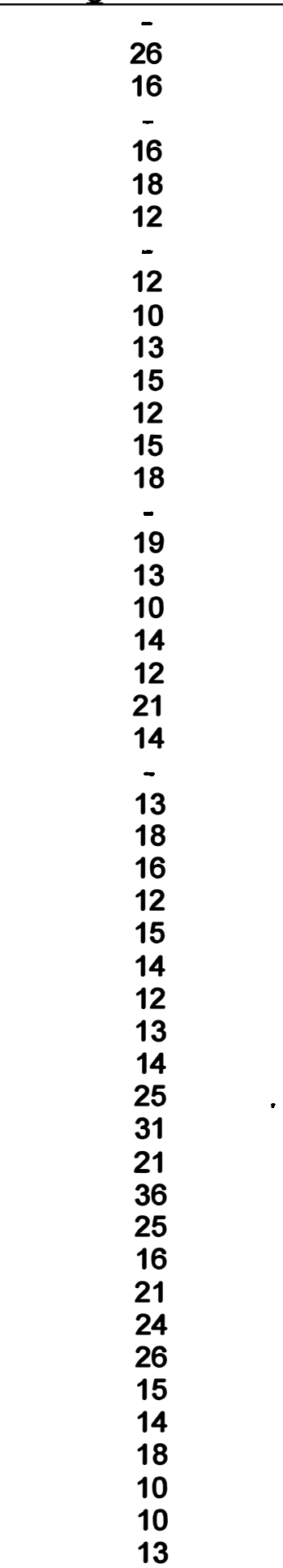 & $\begin{array}{l}- \\
1 \\
- \\
- \\
2 \\
- \\
- \\
- \\
1 \\
2 \\
1 \\
- \\
- \\
- \\
- \\
- \\
- \\
- \\
- \\
- \\
1 \\
- \\
2 \\
1 \\
- \\
- \\
- \\
- \\
- \\
- \\
- \\
- \\
- \\
- \\
- \\
- \\
- \\
-\end{array}$ \\
\hline
\end{tabular}


Tabela 14. Resultado do teste de combinações de "primers" AFLP.

\begin{tabular}{ccccc}
\hline $\begin{array}{c}\text { Combinações de } \\
\text { "primers" }\end{array}$ & $\begin{array}{c}\text { Código de } \\
\text { identificaçäo }\end{array}$ & $\begin{array}{c}\text { Número total } \\
\text { de locos }\end{array}$ & $\begin{array}{c}\text { Número de locos } \\
\text { polimórficos entre os } \\
\text { genitores }\end{array}$ & $\begin{array}{c}\text { Polimóifficos } \\
\text { entre os } \\
\text { "Bulks" }\end{array}$ \\
\hline EAGC/MCAA & E40/M47 & 52 & 18 & - \\
EAGC/MCAC & E40/ M48 & 46 & 27 & - \\
EAGC/MCAG & E40/M49 & 35 & 18 & - \\
EAGC/MCAT & E40/ M50 & 56 & 10 & - \\
EAGC/MCTA & E40/M59 & 62 & 14 & - \\
EAGCMCTC & E40/ M60 & 54 & 21 & - \\
EAGC/MCTG & E40/M61 & 48 & 14 & - \\
EAGC/MCTT & E40/ M62 & 37 & 12 & - \\
PAAAMCAG & P31/M49 & 38 & 10 & - \\
PAAAMCAC & P31/M48 & 43 & 11 & - \\
PAAC/MCAG & P32/M49 & 42 & 3 & - \\
PAAC/MCAC & P32M48 & 38 & 10 & - \\
PAAC/MCAG & P33/M49 & 44 & 11 & - \\
PAAG/MCAC & P33/M48 & 58 & 8 & - \\
PACAMMAG & P35/M49 & 45 & 8 & - \\
PACA/MCAC & P35/M48 & 52 & 7 & - \\
PACC/MCAG & P36/M49 & 44 & 11 & - \\
PACC/MCAC & P36/M48 & 36 & 8 & - \\
\hline
\end{tabular}




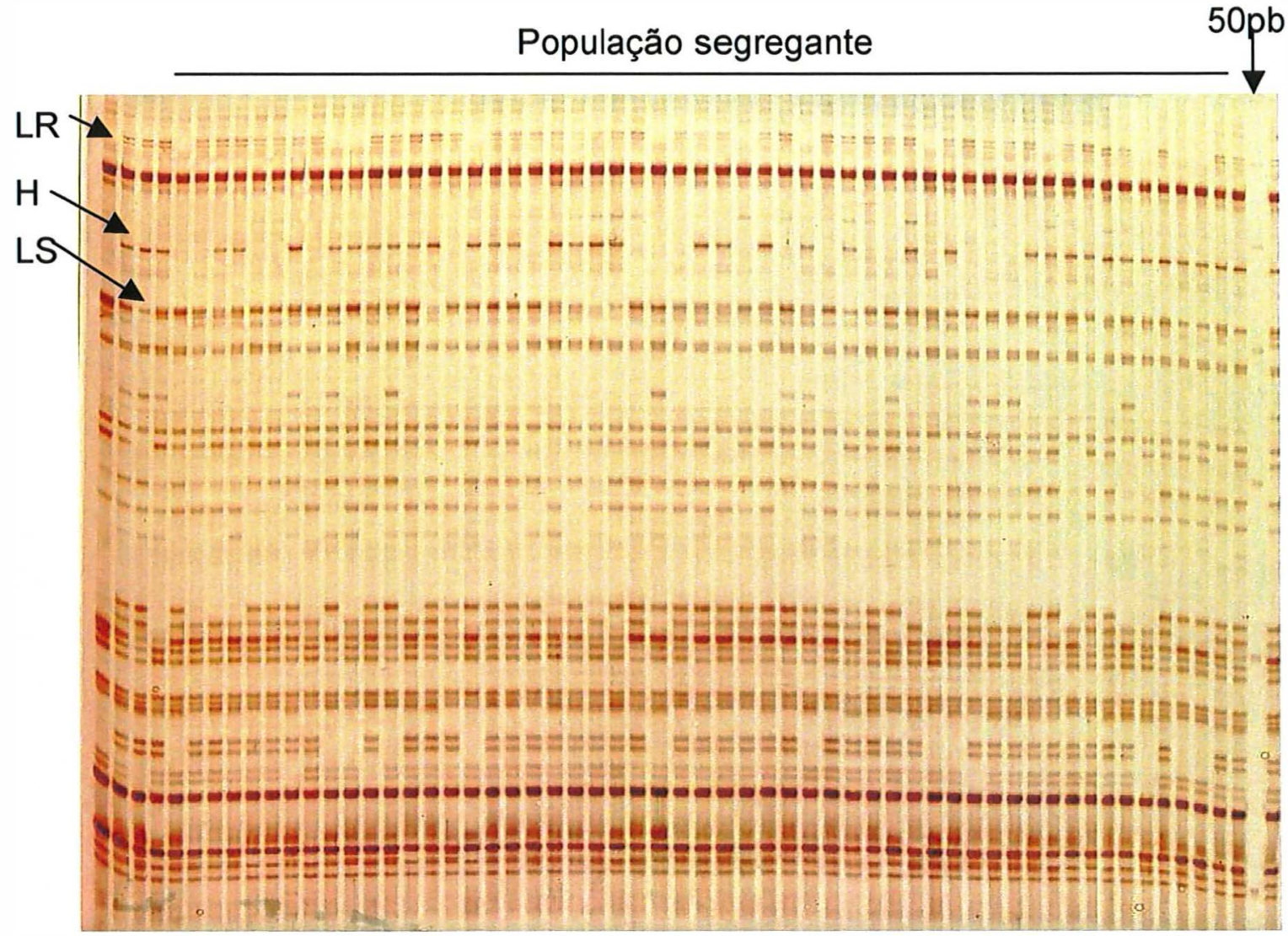

Figura 5 - Faixa de gel de AFLP mostrando a presença e a ausência de bandas na LR (linhagem resistente), LS (linhagem suscetivel) e $\mathrm{H}$ (híbrido) e segregação de indivíduos $F_{2}$. 
O Nivel de polimorfismo encontrado neste trabalho $(28,3 \%)$ foi superior ao encontrado por de Castiglioni et al. (1999) (21,7\%). A porcentagem de locos informativos aqui apresentadas diferiu entre combinações de EcoRI/Msel (31,3\%) e Pstl/Msel (19,7\%). Castiglioni et al. (1999) relata o maior polimorfismo Pstl/Msel (19,6 \%) comparado a EcoRI/Msel $(14,9)$, mas, convém ressaltar que o autor usou "primers" da enzima Pstl com dois nucleotídeos seletivos na amplificação seletiva e três nos "primers" EcoRI.

\subsubsection{Construção do mapa genético}

Os testes de aderência das proporções genotípicas ao modelo de segregação mendeliana dos 212 locos polimórficos (21 microssatélites e 191 AFLPs), adotando o critério de Bonferroni para controlar o nivel de significância individual, detectaram 16 marcadores distorcidos (2 microssatélites e 14 AFLPs), os quais não foram utilizados para construção do mapa de ligação. Das 196 marcas não distorcidas, 174 foram agrupadas em 10 grupos de ligação e, entre essas, 81 marcas (47\%) puderam ser ordenadas de acordo com o critério estabelecido (LOD > 2,0) (Tabela 15). Dos 10 grupos de ligação, 8 cromossomos foram relacionados aos cromossomos baseando-se na presença dos marcadores microssatélites. Apenas os cromossomos 3 e 10 não foram identificados devido a ausência de SSRs informativo (Figura 6).

0 número médio de marcadores por grupo de ligação foi de 8 , com no mínimo de 4 e o máximo 17. O comprimento médio dos grupos de ligação (cM) foi de 115,67 , sendo o menor de $23,14 \mathrm{cM}$ e o maior de $301,72 \mathrm{cM}$. O intervalo médio entre marcadores adjacentes foi de 14,28 cM. Mapas genéticos de alta densidade, foram construídos por Vulysteke et al. (1999), a partir de população $F_{2}$ e de linhas puras recombinantes (RILs), utilizando marcadores RFLP, isoenzimas, SSR e AFLP. O mapa construído pelos autores, em comprimento (1.375,6 cM e 1.178,1 cM para $F_{2}$ e RILs, respectivamente) não difere significativamente do mapa deste trabalho, embora este apresente um número de saturação inferior. 
Tabela 15. Número de marcas agrupadas e ordenadas e comprimento em (cM) de cada grupo de ligação.

\begin{tabular}{cccc}
\hline $\begin{array}{c}\text { Cromossomo } \\
\text { (Grupo) }\end{array}$ & $\begin{array}{c}\text { Número de marcas } \\
\text { agrupadas }\end{array}$ & $\begin{array}{c}\text { Número de marcas } \\
\text { ordenadas }\end{array}$ & Comprimento em cM \\
\hline Cromossomo 1 & 20 & 7 & 112,04 \\
Cromossomo 2 & 21 & 8 & 99,73 \\
Cromossomo 4 & 25 & 14 & 197,84 \\
Cromossomo 5 & 31 & 17 & 301,72 \\
Cromossomo 6 & 7 & 4 & 23,14 \\
Cromossomo 7 & 13 & 5 & 53,57 \\
Cromossomo 8 & 17 & 7 & 41,99 \\
Cromossomo 9 & 20 & 10 & 126,67 \\
Grupo 1 & 12 & 4 & 75,59 \\
Grupo 2 & 8 & 5 & 124,43 \\
Total & 174 & 81 & $1.156,72$ \\
\hline
\end{tabular}




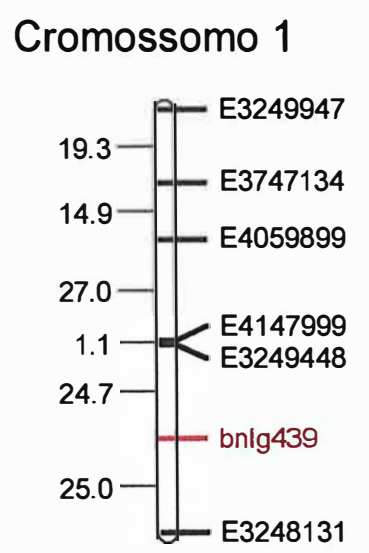

\section{Cromossomo6}

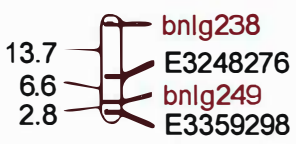

\section{Cromossomo 8}

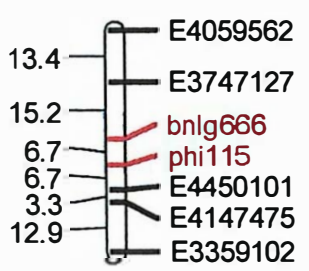

\section{Cromossomo 2}

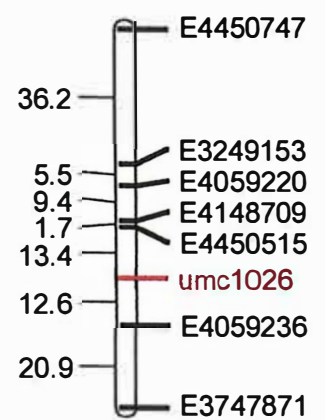

\section{Cromossomo 7}

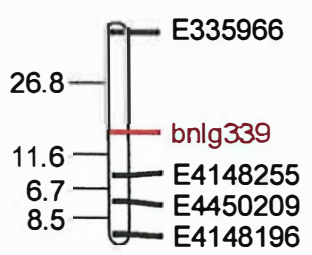

\section{Cromossomo 9}

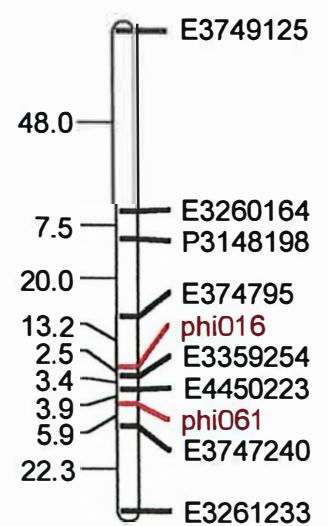

Cromossomo 4

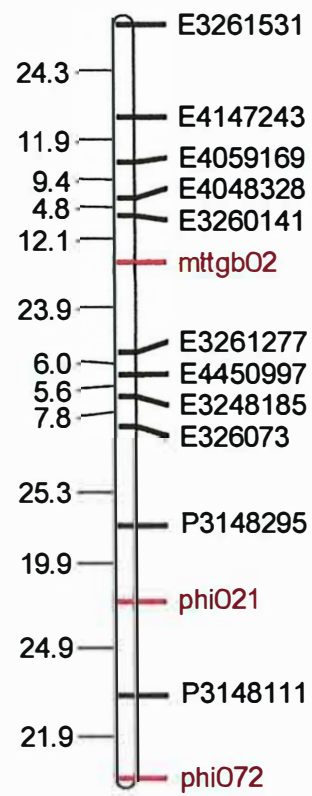

\section{Grupo 2}

(sem referência cromossômica)

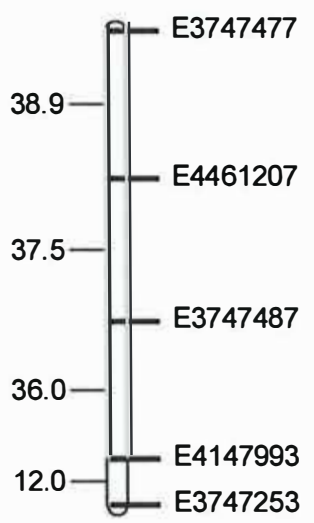

\section{Cromossomo5}

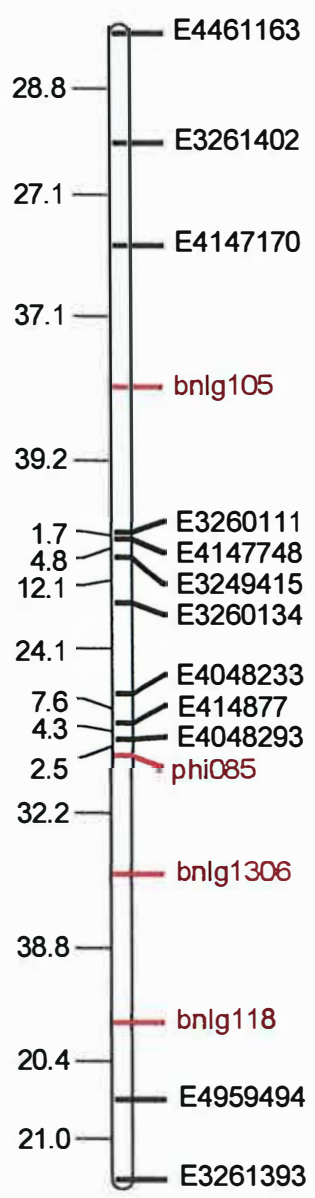

Grupo 1

(sem referência cromossômica)

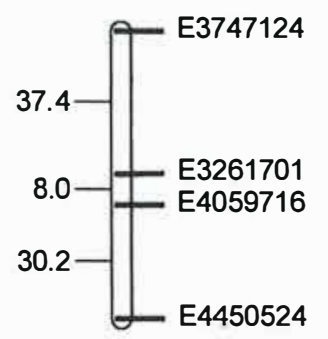

Figura 6 - Mapa genético composto de 10 grupos de ligação, gerado pelo programa Mapmaker. Acima do grupo está identificado o cromossomo do milho correspondente, a direita o nome dos marcadores (AFLP em preto e SSR em vermelho) e do lado esquerdo a distância em centimorgans obtida pela função de mapeamento de Haldane. 


\subsubsection{Identificação de marcadores moleculares associados a QRLs usando regressão linear múltipla}

Análises de regressão múltipla foram realizadas com os 196 marcadores não-distorcidos utilizando os valores de cada avaliação de doença (no florescimento, 15 e 30 dias após este) e para a AUDPC de cada experimento e também para as médias dos experimentos (Tabelas 16, 17 e18). A proporção da variação fenotípica explicada pelos modelos de regressão foi obtida pelo coeficiente de determinação $\mathrm{R}^{2}$ dos mesmos e a proporção da variação fenotípica explicada pelos marcadores individualmente pelo $R^{2}$ parcial. Esses modelos explicaram de $33 \%$ (primeira avaliação do ensaio de segunda época) a $45 \%$ (análise conjunta da terceira avaliação dos experimentos) da variação em resistência à mancha de Phaeosphaeria. Considerando os modelos das 3 avaliações e da AUDPC, foram identificados 10 marcadores associados a QRLs no primeiro experimento, 9 no segundo e 9 na análise conjunta dos mesmos. Dos marcadores associados a QRLs, 3 estão no cromossomo 1, 2 no cromossomo 2, 1 no cromossomo 4, 2 no cromossomo 5, 1 no cromossomo 6,1 no cromossomo 8 , e 1 não foi alocado a nenhum cromossomo.

$\mathrm{Na}$ análise de regressão para marcadores SSR, usou-se o código -1 para representar individuos homozigotos para o alelo marcador do genitor suscetível, 0 para indivíduos heterozigotos e 1 para homozigotos para 0 alelo do genitor resistente. Dessa forma, a origem parental do alelo de resistência no QRL foi determinada pelo sinal do coeficiente de regressão; sendo ele negativo (decréscimo de doença), infere-se que o alelo de resistência descende do genitor resistente e quando positivo, do genitor suscetível. Já os marcadores AFLPs foram codificados como 1 e 0 , representando presença ou ausência da banda, independente do genitor de origem. Neste caso, o sinal do coeficiente de regressão, se negativo, indica que a presença do marcador está associada com a redução da doença (marcador em associação com o alelo de resistência no QRL) ou, caso contrário, com o aumento (marcador em repulsão com o 
alelo de resistência no $Q R L)$. A origem parental do marcador foi obtida recorrendo-se aos dados de leitura dos géis.

Tabela 16. Resumos das análise de regressões múltiplas para reação a mancha de Phaeosphaeria, utilizando o processo de "Stepwise" para a seleção de marcadores. Ensaio de primeira época.

\begin{tabular}{|c|c|c|c|c|c|c|c|}
\hline Marcadores & $\begin{array}{l}\text { Estimativa } \\
\text { dos } \\
\text { parâmetros }\end{array}$ & $\begin{array}{l}\text { Erro } \\
\text { padrão }\end{array}$ & $F^{*}$ & $\mathrm{R}^{2}$ parcial & $c^{1}$ & $\begin{array}{c}\text { Origem do } \\
\text { marcador } \\
\text { AFLP } \\
\end{array}$ & $\begin{array}{l}\text { Fase de } \\
\text { ligação }\end{array}$ \\
\hline \multicolumn{8}{|c|}{ A1 } \\
\hline E3359162 & $-0,060$ & 0,016 & 14,05 & 0,084 & - & PR & A \\
\hline E4450999 & 0,042 & 0,014 & 8,51 & 0,038 & $8^{a}$ & PS & A \\
\hline E4461150 & $-0,044$ & 0,018 & 5,94 & 0,037 & $1^{a}$ & PS & $\mathbf{R}$ \\
\hline Bnlg249 & $-0,036$ & 0,009 & 16,01 & 0,129 & 6 & & A \\
\hline \multicolumn{8}{|c|}{$\mathrm{R}^{2}$ do modelo 0,4248} \\
\hline \multicolumn{8}{|c|}{ A2 } \\
\hline E445068 & 0,315 & 0,108 & 8,57 & 0,043 & $5^{a}$ & PS & A \\
\hline E4147204 & $-0,259$ & 0,093 & 7,83 & 0,064 & $2^{a}$ & PS & $\mathbf{R}$ \\
\hline E3260111 & 0,208 & 0,105 & 3,95 & 0,028 & 5 & PR & $\mathbf{R}$ \\
\hline Bnlg249 & $-0,215$ & 0,058 & 13,86 & 0,087 & 6 & & A \\
\hline Bnlg439 & $-0,251$ & 0,062 & 16,36 & 0,128 & 1 & & $A$ \\
\hline \multicolumn{8}{|c|}{$\mathrm{R}^{2}$ do modelo 0,3498} \\
\hline E4450999 & 0,459 & 0,209 & 4,85 & 0,030 & $8^{a}$ & PS & $A$ \\
\hline E445068 & 0,921 & 0,237 & 15,12 & 0,122 & $5^{a}$ & PS & A \\
\hline Phi021 & $-0,364$ & 0,144 & 6,37 & 0,048 & 4 & & A \\
\hline Umc1026 & 0,504 & 0,140 & 12,91 & 0,074 & 2 & & $\mathbf{R}$ \\
\hline Bnlg249 & $-0,434$ & 0,131 & 10,92 & 0,074 & 6 & & A \\
\hline Bnlg439 & $-0,567$ & 0,140 & 16,00 & 0,086 & 1 & & A \\
\hline \multicolumn{8}{|c|}{$\mathrm{R}^{2}$ do modelo 0,435} \\
\hline \multicolumn{8}{|c|}{ AUDPC1 } \\
\hline E4450999 & 0,323 & 0,146 & 4,89 & 0,031 & $8^{a}$ & PS & A \\
\hline E445068 & 0,607 & 0,166 & 13,42 & 0,067 & $5^{a}$ & PS & A \\
\hline Phi021 & $-0,236$ & 0,101 & 5,49 & 0,043 & 4 & & A \\
\hline Umc1026 & 0,335 & 0,098 & 11,67 & 0,075 & 2 & & $\mathbf{R}$ \\
\hline Bnlg249 & $-0,312$ & 0,092 & 11,53 & 0,084 & 6 & & A \\
\hline Bnlg439 & $-0,405$ & 0,098 & 16,98 & 0,127 & 1 & & A \\
\hline \multicolumn{8}{|c|}{$\mathrm{R}^{2}$ do modelo 0,427} \\
\hline
\end{tabular}


Tabela 17. Resumos das análise de regressões múltiplas para reação a mancha de Phaeosphaeria, utilizando o processo de "Stepwise" para a seleção de marcadores. Ensaio de segunda época.

\begin{tabular}{|c|c|c|c|c|c|c|c|}
\hline Marcadores & $\begin{array}{l}\text { Estimativa } \\
\text { dos } \\
\text { parâmetros }\end{array}$ & $\begin{array}{l}\text { Erro } \\
\text { padrão }\end{array}$ & $F^{*}$ & $\mathrm{R}^{2}$ parcial & $\begin{array}{l}\text { Cromos- } \\
\text { somo }\end{array}$ & $\begin{array}{c}\text { Origem do } \\
\text { marcador } \\
\text { AFLP }\end{array}$ & $\begin{array}{l}\text { Fase de } \\
\text { ligaçäo }\end{array}$ \\
\hline \multicolumn{8}{|c|}{ A1 } \\
\hline E4450999 & 0,209 & 0,068 & 9,48 & 0,060 & $8^{a}$ & PS & A \\
\hline E445068 & 0,219 & 0,076 & 8,28 & 0,086 & $5^{a}$ & PS & $A$ \\
\hline umc1026 & 0,105 & 0,047 & 5,26 & 0,038 & 2 & & $\mathbf{R}$ \\
\hline bnlg249 & $-0,155$ & 0,043 & 13,19 & 0,095 & 6 & & $A$ \\
\hline bnlg439 & $-0,134$ & 0,046 & 8,56 & 0,057 & 1 & & $A$ \\
\hline \multirow{2}{*}{\multicolumn{8}{|c|}{ R2 do modelo }} \\
\hline & & & & & & & \\
\hline E445068 & 0,791 & 0,231 & 11,77 & 0,090 & $5^{a}$ & PS & A \\
\hline E4147204 & $-0,605$ & 0,201 & 9,07 & 0,062 & $2^{a}$ & PS & $\mathbf{R}$ \\
\hline E4059147 & 0,420 & 0,208 & 4,06 & 0,027 & $1^{a}$ & PS & $A$ \\
\hline phi021 & $-0,311$ & 0,139 & 4,98 & 0,044 & 4 & & $A$ \\
\hline bnlg249 & $-0,352$ & 0,125 & 7,90 & 0,057 & 6 & & $A$ \\
\hline bnlg439 & $-0,564$ & 0,136 & 17,16 & 0,127 & 1 & & $A$ \\
\hline \multicolumn{8}{|c|}{$\begin{array}{c}\text { R2 do modelo } \\
\text { A3 }\end{array}$} \\
\hline E4450999 & 0,823 & 0,3132 & 6,90 & 0,051 & $8^{a}$ & PS & $A$ \\
\hline E445068 & 1,401 & 0,3557 & 15,51 & 0,083 & $5^{a}$ & PS & A \\
\hline phi021 & $-0,653$ & 0,2163 & 9,13 & 0,082 & 4 & & A \\
\hline umc1026 & 0,721 & 0,2105 & 11,75 & 0,054 & 2 & & $\mathbf{R}$ \\
\hline bnlg249 & $-0,495$ & 0,1971 & 6,31 & 0,039 & 6 & & A \\
\hline bnlg439 & $-0,892$ & 0,2109 & 17,92 & 0,139 & 1 & & A \\
\hline \multicolumn{8}{|c|}{$\begin{array}{c}\text { R2 do modelo } 0,442 \\
\text { AUDPC }\end{array}$} \\
\hline E4450999 & 0,436 & 0,189 & 5,31 & 0,028 & $8^{a}$ & PS & A \\
\hline E445068 & 0,826 & 0,216 & 14,69 & 0,088 & $5^{a}$ & PS & A \\
\hline E4147204 & $-0,503$ & 0,191 & 6,90 & 0,049 & $2^{a}$ & PS & $\mathbf{R}$ \\
\hline phi021 & $-0,333$ & 0,131 & 6,47 & 0,066 & 4 & & A \\
\hline bnlg249 & $-0,318$ & 0,119 & 7,13 & 0,052 & 6 & & A \\
\hline bnlg439 & $-0,558$ & 0,130 & 18,49 & 0,130 & 1 & & A \\
\hline E3747871 & 0,403 & 0,199 & 4,11 & 0,026 & 2 & PR & $\mathbf{R}$ \\
\hline \multicolumn{8}{|c|}{ R2 do modelo 0,438} \\
\hline
\end{tabular}


Tabela 18. Resumos das análise de regressões múltiplas das médias dos experimentos para reação a mancha de Phaeosphaeria, utilizando o processo de "Stepwise" para a seleção de marcadores.

\begin{tabular}{|c|c|c|c|c|c|c|c|}
\hline Marcadores & $\begin{array}{l}\text { Estimativa dos } \\
\text { parâmetros }\end{array}$ & $\begin{array}{l}\text { Erro } \\
\text { padrão }\end{array}$ & $F^{*}$ & $\mathrm{R}^{2}$ parcial & $\begin{array}{l}\text { Cromos- } \\
\text { somo }\end{array}$ & $\begin{array}{l}\text { Origem do } \\
\text { Marcador }\end{array}$ & $\begin{array}{l}\text { Fase de } \\
\text { ligação }\end{array}$ \\
\hline \multicolumn{8}{|c|}{ 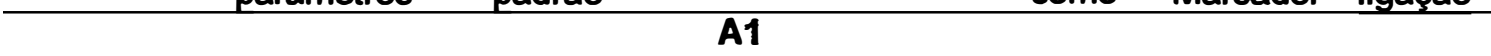 } \\
\hline E3359162 & $-0,110$ & 0,043 & 6,45 & 0,046 & - & PR & A \\
\hline E4450999 & 0,113 & 0,038 & 8,86 & 0,055 & $8^{a}$ & PS & $A$ \\
\hline E445068 & 0,106 & 0,044 & 5,90 & 0,061 & $5^{a}$ & PS & A \\
\hline E4147204 & $-0,078$ & 0,038 & 4,13 & 0,027 & $2^{a}$ & PS & $\mathbf{R}$ \\
\hline bnlg249 & $-0,095$ & 0,024 & 15,77 & 0,106 & 6 & & A \\
\hline bnlg439 & $-0,075$ & 0,026 & 8,37 & 0,103 & 1 & & A \\
\hline \multicolumn{8}{|c|}{$\begin{array}{c}\text { R2 do modelo } \\
\text { A2 }\end{array}$} \\
\hline E445068 & 0,579 & 0,161 & 13,02 & 0,082 & $5^{a}$ & PS & A \\
\hline E4147204 & $-0,432$ & 0,142 & 9,24 & 0,067 & $2^{a}$ & PS & $\mathbf{R}$ \\
\hline phi021 & $-0,235$ & 0,097 & 5,84 & 0,039 & 4 & & A \\
\hline bnlg249 & $-0,269$ & 0,088 & 9,30 & 0,063 & 6 & & A \\
\hline bnlg439 & $-0,385$ & 0,095 & 16,40 & 0,135 & 1 & & A \\
\hline \multicolumn{8}{|c|}{$\mathrm{R} 2$ do modelo 0,388} \\
\hline E4450999 & 0,641 & 0,254 & 6,36 & 0,038 & $8^{a}$ & PS & A \\
\hline E445068 & 1,161 & 0,288 & 16,20 & 0,087 & $5^{a}$ & PS & A \\
\hline phi021 & $-0,509$ & 0,175 & 8,42 & 0,076 & 4 & & $A$ \\
\hline umc1026 & 0,612 & 0,171 & 12,84 & 0,054 & 2 & & $\mathbf{R}$ \\
\hline bnlg249 & $-0,463$ & 0,160 & 8,42 & 0,060 & 6 & & $A$ \\
\hline bnlg439 & $-0,727$ & 0,171 & 18,07 & 0,135 & 1 & & A \\
\hline \multicolumn{8}{|c|}{$\begin{array}{c}\text { R2 do modelo } \\
\text { AUDPC3 }\end{array}$} \\
\hline E445068 & 0,657 & 0,192 & 11,75 & 0,086 & $5^{a}$ & PS & $A$ \\
\hline E4147204 & $-0,498$ & 0,167 & 8,89 & 0,065 & $2^{a}$ & PS & $\mathbf{R}$ \\
\hline E4059147 & 0,351 & 0,173 & 4,11 & 0,026 & $1^{a}$ & PS & A \\
\hline phi021 & $-0,276$ & 0,116 & 5,71 & 0,047 & 4 & & A \\
\hline bnlg249 & $-0,339$ & 0,104 & 10,63 & 0,066 & 6 & & A \\
\hline bnlg439 & $-0,491$ & 0,113 & 18,80 & 0,132 & 1 & & A \\
\hline \multicolumn{8}{|c|}{ R2 do modelo } \\
\hline
\end{tabular}

* significativo a $5 \%$ de probabilidade. ${ }^{2}$ somente agrupou, mas não foi ordenado no grupo de ligação. A (associação) e R (repulsão). - segregação independente. ${ }^{1}$ Refere-se a fase de ligação entre alelo marcador do PR e alelo de resistência no QRL. 
No primeiro experimento, a maior porcentagem da variação fenotípica explicada pela associação marcador-QRL (43\%) foi obtida para a avaliação realizada aos 30 dias após o florescimento (Tabela 16). Ainda considerando os quatro modelos do primeiro experimento, nota-se que nem todos os marcadores foram significativos em todas as avaliações, a exceção dos locos bnlg249 e bnlg439 que, por sua vez, foram os que explicaram as maiores proporções da variação fenotípica. Em quatro associações, notou-se ligação em fase de repulsão entre alelos marcadores do genitor resistente e alelos de resistência no QRL (Tabela 16).

A exemplo do primeiro experimento, o modelo baseado na terceira avaliação fenotípica foi o que explicou a maior proporção da variação fenotípica no ensaio de segunda época (Tabela 17). Dos marcadores associados a QRLs nesse experimento, somente um não foi identificado no primeiro experimento (E4059147). O marcador descende do genitor suscetível e está associado à redução da resistência, ou seja, está em fase de repulsão ao alelo de resistência no $Q R L$. Sua contribuição para a variação fenotípica foi de $2,7 \%$ na segunda avaliação, única na qual foi detectado. Por outro lado, 3 marcadores identificados no primeiro experimento não o foram no segundo (E3359162, E4461150 e E3260111). Os marcadores bnlg439 e bnlg249, assim como no primeiro experimento, entraram nos modelos das 3 avaliações e da AUDPC e apresentaram os maiores valores de $R^{2}$. O marcador E45068 também foi selecionado nos modelos das 3 avaliações e para a AUDPC e explicou de $8,3 \%$ a $9,0 \%$ da variação fenotípica. Em três diferentes associações, notou-se ligação em fase de repulsão entre alelos marcadores do genitor resistente e alelos de resistência no QRL.

$\mathrm{Na}$ análise de regressão usando as médias das avaliações dos 2 experimentos, o modelo baseado na terceira avaliação também foi o que explicou a maior proporção da variação fenotípica (45,1 \%) (Tabela 18). Todos os marcadores foram identificados nas análises individuais dos experimentos. A exemplo das análises anteriores, os marcadores que explicaram as maiores 
proporções da variação fenotípica foram o bnlg439, bnlg249 e E445068. Em duas diferentes associações, notou-se ligação em fase de repulsão entre alelos marcadores do genitor resistente e alelos de resistência no $Q R L$.

Embora com pequenos efeitos, foram identificados alelos de resistência oriundos da linhagem suscetivel, DAS21, nos cromossomos 1 (E445061150), 2 (E4147204, E3747871, umc1026) e 5 (E3260111). Isto vai ao encontro do trabalho de Silva (2002), que sugeriu a presença de genes de resistência nesta linhagem com base em análises de médias de gerações. A observação de progênies transgressivas nas avaliações fenotípicas do presente trabalho (item 4.1.1) também corrobora com estes resultados.

O procedimento "stepwise" seleciona as variáveis regressoras (marcadores) procurando o melhor modelo de regressão através da exclusão de marcadores com informação redundante, ou seja, que apresentam alta correlação (Silva \& Vencovsky, 2002). Assim, cada marcador que entra no modelo deve estar associado a um QRL diferente. Porém, em diferentes avaliações, as variáveis regressoras (marcadores) podem ser alteradas, seja porque existem QRLs com efeito importante apenas em determinados momentos (ex. retardando o progresso inicial da doença) ou porque a associação de um marcador que identificou um determinado QRL em uma determinada avaliação pode ser menos significativa do que a associação do mesmo QRL a outro marcador próximo em uma outra avaliação. Isto decorre do fato de que a associação do marcador é feita com uma região e não com um gene. Se cada marcador identifica um QRL então é possível inferir sobre a interação QRL x ambiente comparando o número de QRLs detectados.

$\mathrm{Na}$ segunda avaliação e para a AUDPC, foram identificados 5 e 6 QRLs no primeiro experimento e 6 e 7 no segundo experimento, respectivamente. Os QRLs ligados aos marcadores E3359162 (não agrupado) e E3260111 (cromossomo 5), foram identificados somente no primeiro experimento indicando interação desses QRLs com 0 ambiente. No cromossomo 1 foram identificados 2 QRLs, tanto no primeiro como no segundo 
experimento, um deles, o de maior efeito, identificado pelo mesmo marcador em ambos os experimentos (bnlg439), o marcador E4461150 identificado no primeiro experimento e o E4059147 no segundo experimento. $O$ fato de terem sido identificados marcadores diferentes ligados a QRLs do cromossomo 1 no primeiro e no segundo experimento não permite declarar a interação QRL por ambiente, embora também não exclua essa possibilidade, pois esses marcadores estão no mesmo cromossomo e podem estar ligados ao mesmo QRL. A ocorrência ou não da interação QRL por ambiente nesse caso só poderia ser feita com segurança se esses marcadores estivessem em posições distantes no cromossomo. No entanto, como os referidos marcadores não entraram no mapa de referência, essa análise não é possível. Da mesma maneira não podem ser tiradas conclusões seguras da interação QRL por ambiente no caso dos marcadores ligados a QRL no cromossomo 2. Em geral, observou-se uma concordância da distribuição das marcas associadas a QRLs nos grupos de ligação, para ambos os ensaios sugerindo que tratam-se dos mesmos QRLs.

Kernes et al. (1999) identificaram marcadores ligados a QRLs a ferrugem comum e ao carvão do milho usando regressão linear múltipla e seleção de variáveis regressoras pelo procedimento "stepwise". Os autores avaliaram a resistência à ferrugem comum em 3 ambientes e ao carvão em 2. Para resistência a ferrugem, os modelos de regressão para os ambientes explicaram 8,8 \% (4 QRLs), 11,6 \% (6 QRLs) e 19 \% (9 QRLs) da variação fenotípica, ao passo que na análise combinada dos 3 ambientes o modelo de regressão explicou 22,0 \% da variação fenotípica (12 QRLs). A proporção da variação fenotípica explicada individualmente pelos marcadores variou de 1,3 \% a $4,4 \%$. Para resistência a carvão, os modelos de regressão explicaram $13,4 \%$ (5QRLs) e 16,2 \% (6QRLs) da variação fenotípica. A proporção da variação fenotípica explicada individualmente pelos marcadores variou de 1,2 $\%$ a $6,0 \%$. Esses resultados, embora obtidos em patossistemas diferentes, podem ser usados como referência para concluir que no presente trabalho foi 
possivel explicar importante proporção da variação em resistência a este patógeno. No que concerne a magnitude da contribuição de cada loco, não foram encontrados QRLs de grande efeito fenotípico nessa população, o que vai ao encontro do caráter quantitativo da resistência.

Para que os marcadores tenham potencial de uso em programas de melhoramento eles devem ser estáveis e de efeito pronunciado. Nesse sentido, os marcadores bnlg439, bnlg249 e E445068, com associação significativa a QRLs na maioria das avaliações fenotípicas, são os mais promissores para uso no melhoramento. A análise da população com outros marcadores microssátelites e outras combinações de "primers" AFLPs é necessária para que sejam identificados outros QRLs e para que sejam saturadas as regiões onde estão localizados os QRLs identificados neste trabalho. O mapeamento de QRLs a partir de populações segregantes de outras fontes de resistência poderá contribuir para a identificação de QRLs que não estão presentes nas linhagens estudadas. Dessa maneira, alelos favoráveis poderão ser identificados e incorporados em germoplasma elite. Deve-se considerar que em muitos casos, a seleção nos programas de melhoramento genético é realizada na ausência da doença, o que, em geral, resulta na diminuição da freqüência de alelos de resistência. Se marcadores moleculares com forte associação a genes de resistência à Phaeosphaeria, assim como para outros patógenos, forem identificados, os melhoristas poderão identificar e seguir esses alelos durante a seleção, mesmo na ausência do patógeno, permitindo a seleção de genótipos superiores para outras características de interesse e ao mesmo tempo mantendo freqüências elevadas de genes de resistência. 
4.2.6 Mapeamento de QRLs utilizando a metodologia de intervalo composto (MIC)

O mapeamento por análise de intervalo composto (MIC) exige que os marcadores estejam ordenados em grupos de ligação. Desta maneira, apenas os marcadores ordenados no mapa participaram na análise de identificação por este método. A análise foi realizada para cada avaliação pontual (no florescimento, 15 e 30 dias após este) e para a AUDPC de cada experimento e também considerando as médias das avaliações pontuais e da AUDPC dos experimentos. Assim, foi possível analisar a contribuição fenotípica de cada QRL durante a epidemia e nos dois experimentos.

Considerando as avaliações pontuais e AUDPC de ambos os experimentos e das médias destes, foram detectados QRLs em 10 intervalos em 6 cromossomos. O número de QRLs variou de 3 a 7 nas análises das avaliações pontuais e AUDPC dos experimentos. Na primeira avaliação dos experimentos 1 e 2, foram identificados 3 e 7 QRLs, respectivamente. $\mathrm{Na}$ segunda e terceira avaliação de ambos os experimentos foram identificados 5 e 4 QRLs, respectivamente. Para a AUDPC foram identificados 7 QRLs no primeiro experimento e 4 no segundo. A partir da análise da média dos experimentos foram identificados 8 QRLs na primeira avaliação, 7 na segunda, 5 na terceira e 6 para a AUDPC. As estimativas das posições e dos efeitos aditivos e de dominância desses QRLs são apresentados na Tabela 19. Os gráficos dos valores do LOD score ao longo dos grupos de ligação nos quais foram identificados QRLs são apresentados nas Figuras 7, 8 e 9. 


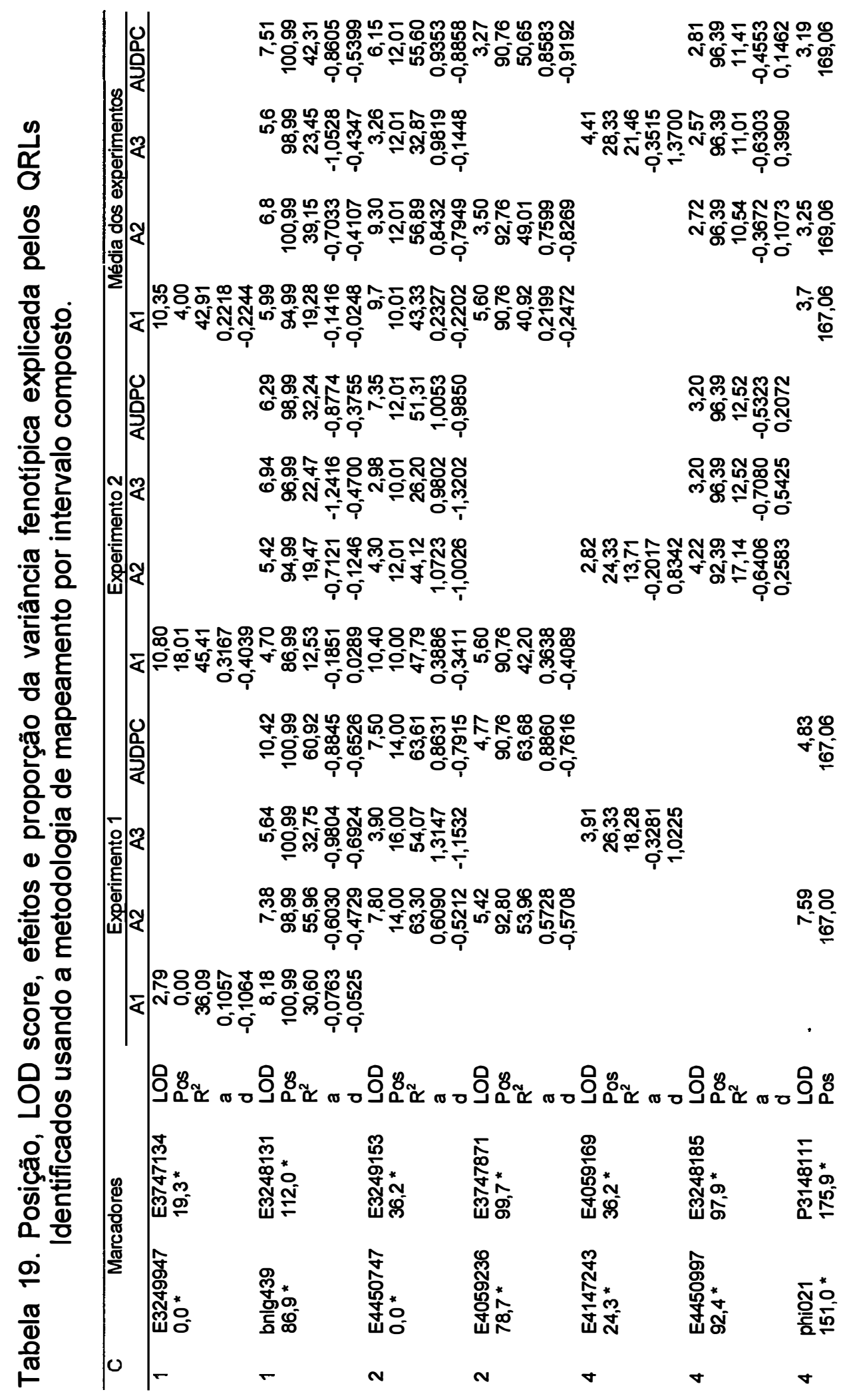




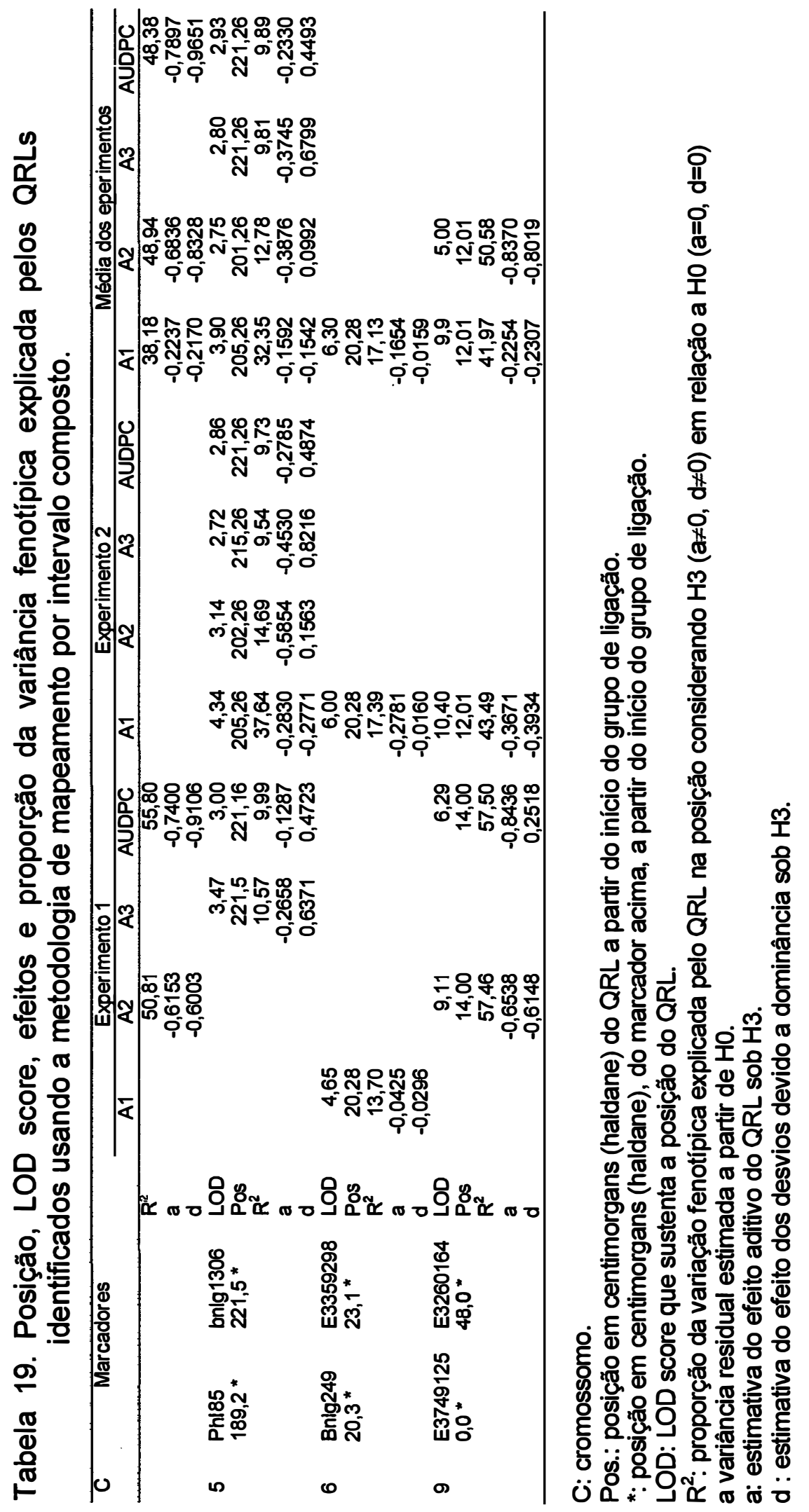




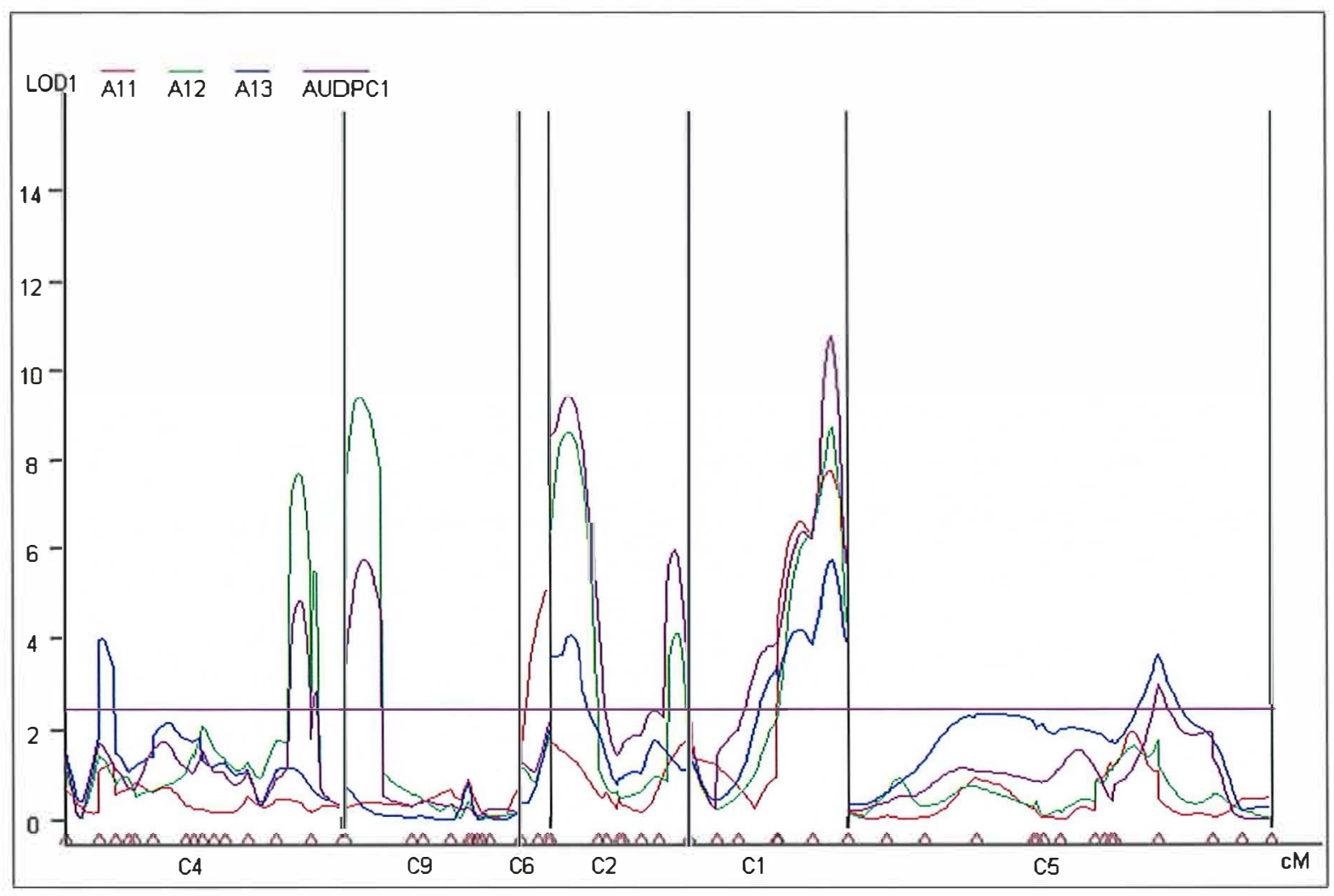

Figura 7 - Distribuição de LOD score ao longo dos cromossomos, separados pelas barras verticais, onde foram mapeados QRLs a mancha de Phaeosphaeria, no primeiro experimento, nas avaliaçōes 1 (A11), 2 (A12) e 3 (A13) e para a AUDPC (AUDPC1). No eixo das ordenadas é representado o grupo de ligação e no eixo das abcissas os valores de LOD score. 


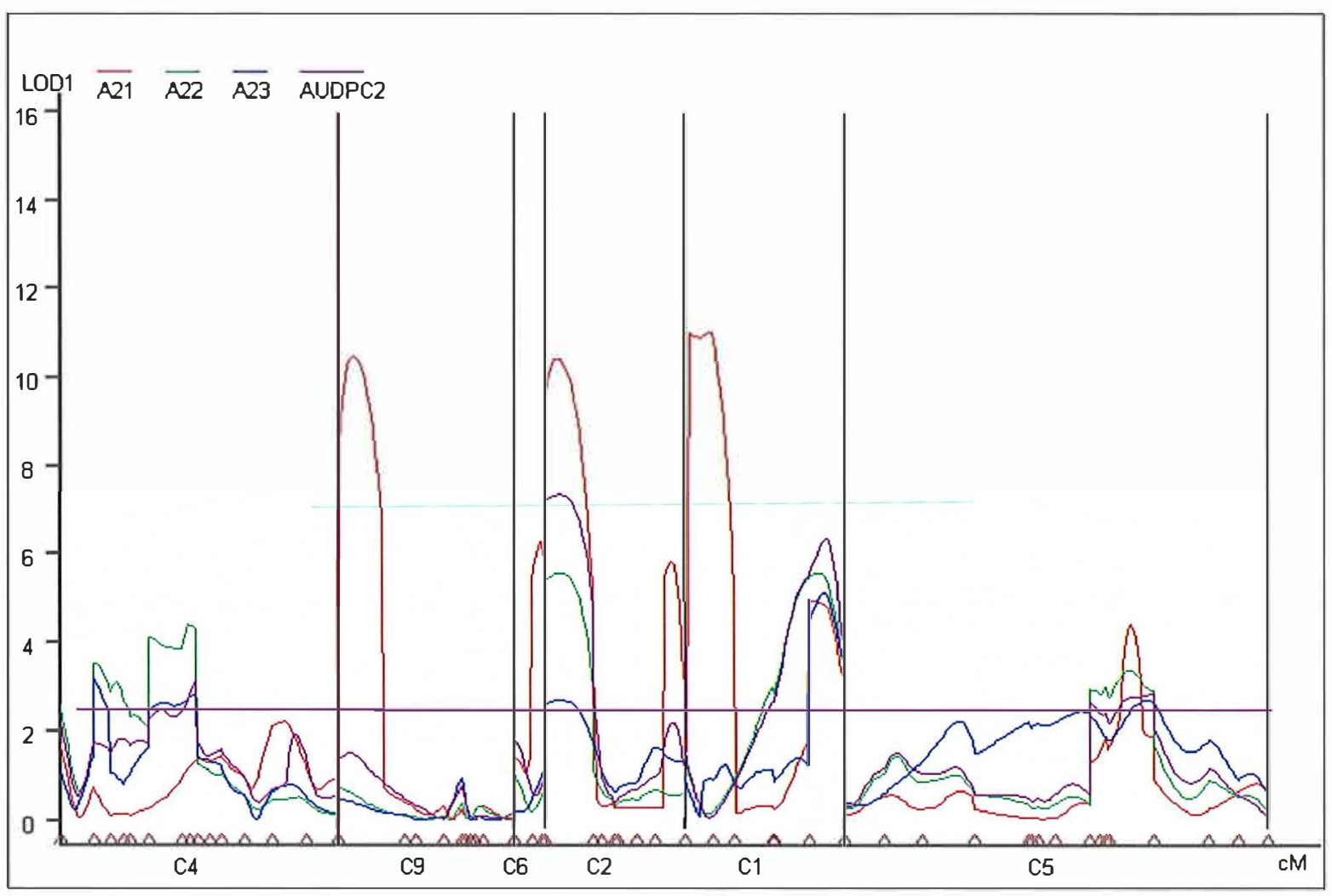

Figura 8 - Distribuição de LOD score ao longo dos cromossomos, separados pelas barras verticais, onde foram mapeados QRLs a mancha de Phaeosphaeria, no segundo experimento, nas avaliaçōes 1 (A21), 2 (A22) e 3 (A23) e para a AUDPC (AUDPC2). No eixo das ordenadas é representado o grupo de ligação e no eixo das abcissas os valores de LOD score. 


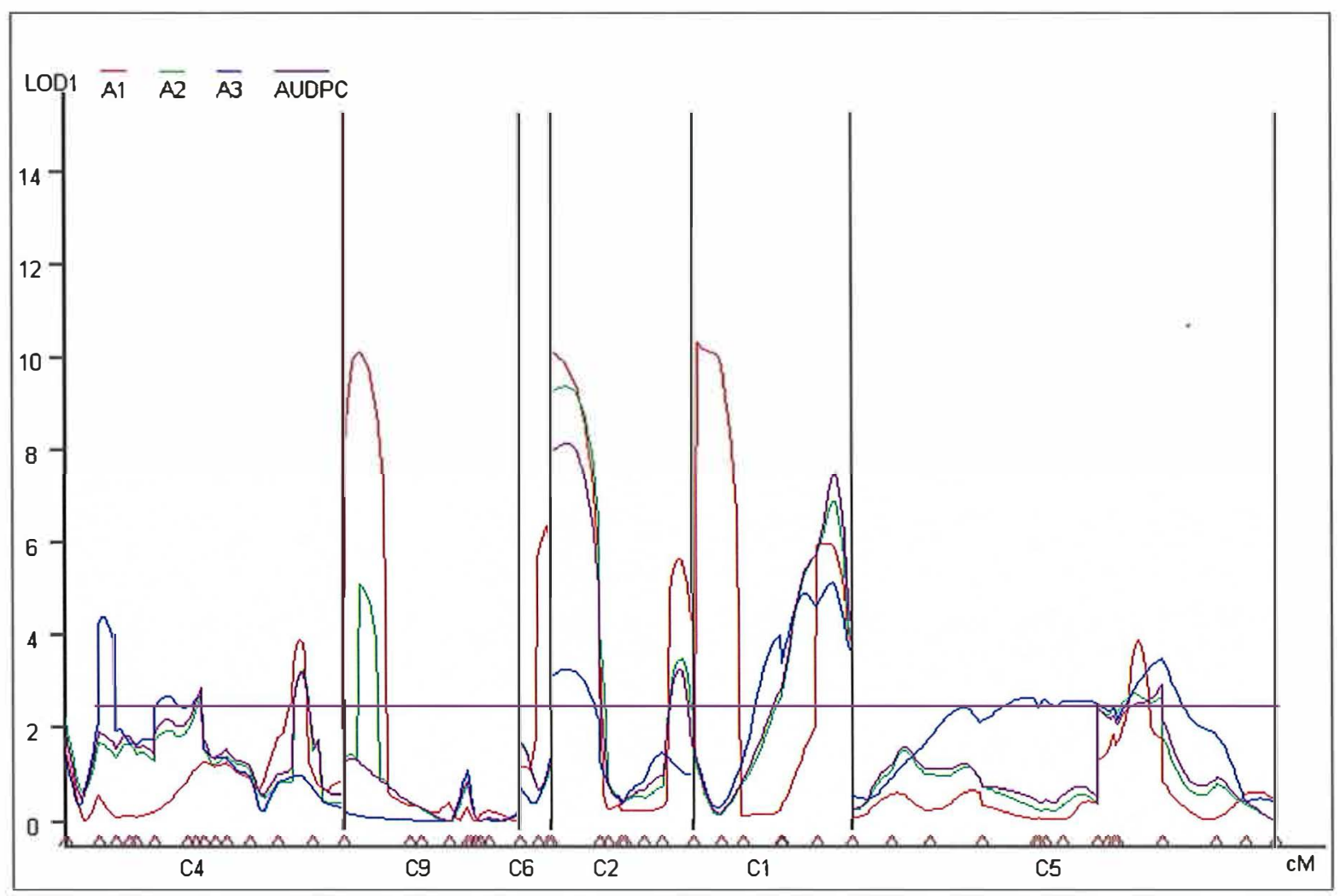

Figura 9 - Distribuição do LOD score ao longo dos cromossomos onde foram mapeados QRLs a mancha de Phaeosphaeria nas avaliações 1 (A1), 2 (A2) e 3 (A3) e para a AUDPC da média dos experimentos. No eixo das ordenadas é representado o grupo de ligação e no eixo das abcissas os valores de LOD score. 
No cromossomo 1, o QRL identificado no intervalo E3249947E3747134 apresenta efeito aditivo positivo e o alelo favorável é do genitor suscetível. O QRL localizado no intervalo bnlg439-E3248131 apresenta efeito aditivo negativo (contribui para aumentar a resistência) e o alelo favorável é do genitor resistente. Os 2 QRLs identificados no cromossomo 2 apresentam efeito aditivo positivo; os alelos favoráveis são do genitor suscetivel (DAS21). Os QRLs localizados nos cromossomos 4, 5, 6 e 9 apresentam efeito aditivo negativo, contribuem para reduzir a doença e os alelos favoráveis são do genitor resistente. Na análise de regressão (item 4.1.7), alelos favoráveis de QRLs do genitor suscetível foram encontrados nos cromossomos 2 e 5.

No primeiro experimento foram identificados QRLs em 9 diferentes intervalos (Tabela 19). Verificou-se que alguns QRLs só apresentaram efeito significativo em algumas avaliações e que somente o QRL localizado entre os marcadores bnlg439 e E3248131 (cromossomo 1) apresentou efeito significativo tanto nas 3 avaliações como para a AUDPC. Os QRLs localizados nos intervalos bnlg439-E3248131, E4059236-E3747871 (cromossomo 2), phi021-bnlg1306 (cromossomo 4) e bnlg249-E3359298 (cromossomo 6) foram identificados também na análise de regressão linear múltipla pelos marcadores bnlg439 (explicando em média 13,05 \% da variação fenotípica), E3747871 (explicando de 2,56 \% da variação fenotípica da AUDP do experimento 2), phi021 (explicando em média $5,54 \%$ da variação fenotípica) e bnig249 (explicando em média $7,6 \%$ da variação fenotípica), respectivamente. Os marcadores que flanqueiam os outros QRLs não foram identificados na análise de regressão linear múltipla. A proporção da variação fenotípica explicada pelos QRLs, considerando a hipótese alternativa $(a \neq 0, d \neq 0)$ em relação a nula $(a=0, d=0)$ e a variância residual estimada a partir de $\mathrm{HO}$, variou de $9,99 \%$ a $63,68 \%$.

No segundo experimento foram identificados QRLs em 9 diferentes intervalos (Tabela 19). Um dos QRLs identificado no primeiro experimento não foi identificado no segundo (phi021-bnlg1306, cromossomo 4) e, entre os 
identificados no segundo experimento um não foi identificado no primeiro (E4450997-E3248185, cromossomo 4). Somente os QRLs localizados nos intervalos bnlg439-E3248131 (cromossomo 1), E4450747-E3249153 (cromossomo 2) e phi85-bnlg1306 (cromossomo 5) apresentaram efeito significativo para as 3 avaliações e para a AUDPC, os demais foram identificados apenas em avaliações pontuais ou em avaliações pontuais e para a AUDPC. Os QRLs localizados nos intervalos bnlg439-E3248131, E4059236E3747871 e bnlg249-E3359298 também foram identificados na análise de regressão linear múltipla pelos marcadores bnlg439 (explicando em média $11,33 \%$ da variação fenotípica), E3747871 (explicando 2,60 \% da variação fenotípica da AUDP do experimento 2) e bnlg249 (explicando em média 6,08\% da variação fenotípica), respectivamente. Os marcadores que flanqueiam os outros QRLs não foram identificados na análise de regressão linear múltipla. A proporção da variação fenotípica explicada pelos QRLs, considerando a hipótese alternativa $(a \neq 0, d \neq 0)$ em relação a nula $(a=0, d=0)$ e a variância residual estimada a partir de $\mathrm{H} 0$, variou de $9,34 \%$ a $51,31 \%$.

Considerando as médias dos experimentos, foram identificados QRLs em 10 diferentes intervalos. Somente os QRLs localizados nos intervalos bnlg439-E3248131 (cromossomo 1), E4450747-E3249153 (cromossomo 2) e phi85-bnlg1306 (cromossomo 5) apresentaram efeitos significativos para as 3 avaliações e para a AUDPC; os demais foram identificados apenas em avaliações pontuais ou em avaliações pontuais e para a AUDPC. Os QRLs localizados nos intervalos bnlg439-E3248131, phi21-P3148111 e bnlg249E3359298 também foram identificados na regressão múltipla pelos marcadores bnlg439 (explicando em média 12,6 \% da variação fenotípica), phi021 (explicando em média 6,40 \% da variação fenotípica) e bnlg249 (explicando em média $7,38 \%$ da variação fenotípica), respectivamente. Os marcadores que flanqueiam os outros QRLs não foram identificados na análise de regressão linear múltipla. A proporção da variação fenotípica explicada pelos QRLs, 
considerando a hipótese alternativa $(a \neq 0, d \neq 0)$ em relação a nula $(a=0, d=0)$ e a variância residual estimada a partir de $\mathrm{HO}$, variou de $9,81 \%$ a $56,89 \%$.

Os QRLs localizados nos intervalos bnlg439-E3248131 (cromossomo 1) e E4450747-E3249153 (cromossomo 2), foram identificados nas avaliações pontuais e para a AUDPC de ambos os experimentos, indicando que seus efeitos foram estáveis frente as variações entre experimentos e épocas de avaliação. Já os QRLs localizados entre E324947-E3747134 (cromossomo1) e bngl249-E3359298 (cromossomo 6), só foram identificados na primeira avaliação dos experimentos, a qual foi realizada no período de pleno florescimento que coincide com o início do período de ocorrência da doença. Assim, é possível que este QRL seja estádio-específico, só sendo expresso no início da epidemia. No cromossomo 4, O QRL localizado entre os marcadores E4450997 e E3248185 só foi identificado no experimento de segunda época (avaliação 2, 3 e AUDPC), enquanto o QRL identificado no intervalo phi021P3148111 foi identificado apenas no experimento de primeira época (avaliação 2 e AUDPC), evidenciando interação desses QRLs com o ambiente.

Foram mapeados QRLs em 10 diferentes posições pelo MIC. O número de QRLs identificados é superior ao encontrado por Carson et al. (1996). Os autores mapearam QRLs para mancha de Phaeosphaeria em linhagens recombinantes derivadas do cruzamento B73 x Mo17, usando marcadores RFLPs, e concluíram que pelo menos seis QRLs estão envolvidos no controle genético da resistência na população derivada desse cruzamento. Os QRLs identificados pelo autor explicaram $23 \%$ da variação fenotípica, proporção inferior a explicada nesse trabalho. A localização de alguns QRLs identificados por Carson et. al. (1996) também diferiu em relação aos relatados nesse trabalho. Os autores identificaram QRLs no braço curto do cromossomo 7 e no braço longo dos cromossomos 8 e 10 . No presente trabalho, também foi identificado um QRL no cromossomo 8, porém nos cromossomos 7 e 10 nenhum QRL foi identificado. Além das diferenças experimentais (tipo de população, marcador e metodologia de análise) salienta-se que os genitores 
analisados neste trabalho têm origem tropical, diferente dos genitores usados no trabalho de Carson et al. (1996).

A partir das informações de que um "bin" corresponde a cerca de 20 cM (McMullen \& Sincox, 1995) e da localização conhecida dos marcadores microssatélites nos cromossomos do milho, foi possível inferir a posição dos QRLs com relação aos "bins". A posição do QRL identificado no intervalo entre os marcadores bnlg439 ("bin" 1.03) e E3248131, no cromossomo 1, sugere que este está localizado próximo ao "cluster" de genes de resistência situado na região 1.4, perto do centrômero (McMullen \& Sincox, 1995a), que abriga os genes de resistência msv1 a "maize streak vírus" (Kietere et al., 1995) e hm1, de resistência a raça 1 de Cochiobolus carbonum (Zaitlin et al., 1993). Ainda próximo desta região foi mapeado um QRL para Cercospora (LehmensieK et al., 2001). Para inferir a posição aproximada do QRL localizado no intervalo entre os marcadores E3249947 e E3747134, também no cromossomo 1, foi tomada a posição deste intervalo em relação ao marcador bnlg439, localizado no "bin" 1.03. Essa distância está entre $67,6 \mathrm{cM}$ e $86,9 \mathrm{cM}$, o que representa aproximadamente 3 a 4 "bins". De acordo com essas considerações, é possível que este QRL esteja localizado próximo aos "bins" 1.06 e 1.07 ou do "bin" 1.00, dependendo de sua posição em relação ao ponto de referência bnlg439. Pelo fato da análise de regressão linear simples do marcador bnlg149 (analisado na população mas não ordenado no mapa), localizado no "bin" 1.00 , não ter identificado associação desse marcador a QRL (dados não apresentados), pode-se inferir que é mais provável que o QRL esteja localizado próximo aos "bins" 1.06 e 1.07. Nesta região também foram mapeados QRLs a Cercospora (LehmensieK et al., 2001) e a Giberella (Pe et al.,1993).

Para inferir a posição aproximada do QRL localizado entre E4450747 e E3249153 (cromossomo 2), foi tomada a posição deste intervalo em relação ao marcador umc1026, localizado no "bin" 2.04. A distância do intervalo ao marcador umc1026 está entre 23,9 cM e 66,2 cM, o que representa aproximadamente 2 a 3 "bins". Portanto, o QRL está localizado próximo aos 
"bins" 2.01 e 2.02 ou dos "bins" 2.06 e 2.07. Para obter informação da posição do QRL identificado no intervalo entre os marcadores E4059236 e E3747871, também no cromossomo 2, foi tomada a posição deste intervalo em relação ao marcador umc1026. A distância entre o intervalo e o umc1026 está entre 12,6 cM e 33,5 cM, o que representa, aproximadamente, 1 a 2 "bins". De acordo com essas considerações, este QRL pode estar localizado ao redor dos "bins" 2.03 ou do "bin" 2.05. Os dois QRLs no cromossomo 2 estão em sentido oposto em relação ao ponto de referência, umc1026. No cromossomo 2 foram mapeados QRLs a Cercospora no "bin" 2.04/05 (Bubeck et. al., 1993), Puccinia sorghi, 2.03 (Kerns et al., 1999) e QRLs a Erwinia sem localização (Ming et al., 1995b), e QRLs a podridão da espiga por Aspergillus flavus, no braço curto e longo, (Forb et al., 1998).

A posição do $Q R L$ identificado no intervalo entre os marcadores phi021 (4.03) e P3148111, no braço curto do cromossomo 4, indica que ele esta próximo ou em um dos "bins", onde foram mapeados QRLs para Cercospora, 4.04 (Bubeck et al. 1993) e para Setosphaeria turcica,4.02/03 (Freymark et al., 1993). Nessa região, McMullen \& Sincox, (1995) relataram um "cluster" onde encontra-se também o gene rp4 (Puccinia sorghi). No braço curto do cromossomo 4 também foi mapeado um QRL para podridão da espiga causada por Aspergillus flavus (Forb et al., 1998). Para obter a posição aproximada do QRL localizado no intervalo entre os marcadores E4450997 e E3248185, também no cromossomo 4, considerou-se a distância desse intervalo em relação ao marcador mttgb02, localizado no "bin" 4.06/07. Essa distância está entre $23,9 \mathrm{cM}$ e $29,9 \mathrm{cM}$, o que representa aproximadamente 1 "bin". Assim, esse QRL está localizado ao redor dos "bins" 4.05 e 4.06 pois, além da distância ao mttgb02 ("bin" 4.06/07), sabe-se que ele está localizado entre esse marcador e o phi021 ("bin" 4.03). Outro QRL identificado no cromossomo 4, no intervalo entre os marcadores E4147243 e E4059169, está localizado entre $26,27 \mathrm{cM}$ e $38,2 \mathrm{cM}$ do marcador mttgb02, ou seja, aproximadamente 1 a 2 "bins" desse marcador. Considerando a distância 
desse QRL a mttgb02 e sua posição no grupo de ligação em relação aos outros microssatélites, ele está localizado ao redor dos "bins" 4.07/08, ou 4.08/09. Nos "bins" 4.07 e 4.08 foram mapeados QRLs para Cercospora (Bubeck et. al., 1993), ao passo que no 4.07 foram mapeados QRLs para Enwinia (Ming et al., 1995b) e antracnose do colmo causada por Colletotrichum graminicola (Jung et. al, 1994).

No cromossomo 5, O QRL identificado no intervalo entre os marcadores phi85 (5.07) e bngl1306 (5.07), indica que ele está no "bin" 5.07, próximo a região onde foram mapeados QRLs a Cercospora, (Lehmensiek et al., 2001) e a Setosphaeria turcica (Freymark et al., 1993).

O QRL localizado entre os marcadores bnlg249 (6.01) e E3359298, no cromossomo 6 , localiza-se próximo a um "cluster" de genes de resistência no "bin" 6.01 no braço curto desse cromossomo (McMullen \& Sincox, 1995). Nesse "cluster" foram mapeados genes de resistência aos virus "maize dwarf mosaic virus" (mdm1) (Sincox et al., 1995), "Wheat streak mosaic virus" (wsm1) (McMullen et.al., 1994), "Sugarcane mosaic virus" (Scm1) (Dussle, et al., 2000), "High plains" (Kaeppler et al., 1997) e o gene $\mathrm{hm} 1$, de resistência ao fungo Cochliobolus heterostrophus (Zaitlin et al., 1993).

No cromossomo 9, O QRL identificado no intervalo entre os marcadores E3749125 e E3260164, está a uma distância entre 40.7 cM e 88,7 cM do marcador phi016 (9.04), o que representa aproximadamente 2 a 4 "bins". Com base nessa distância e sabendo-se que esse QRL está do lado oposto ao marcador phi061 ("bin" 9.03) no cromossomo, considerando como ponto de referência o phi016, ele esta localizado ao redor dos "bins" 9.06 e 9.08 . No "bin" 9.05 foi mapeado um QRL para Setosphaeria turcica (Freymark et al., 1993). QRLs para podridão causada por Erwinia (Ming et al., 1995b) e ferrugem causada por Puccinia polysora Underw (no braço curto do cromossomo 9) (Brunelli et al. 2002) também foram mapeados no cromossomo 9, porém, sem a localização dos mesmos com relação aos "bins" do cromossomo. 
Embora o intervalo médio de um "bin" seja de aproximadamente, 20 cM (McMullen \& Sincox, 1995a), é sabido que seu tamanho pode variar de acordo com a população usada. Com isso, a posição dos QRLs mapeados com base na distância dos mesmos aos microssatélites localizados em "bins" conhecidos no genoma do milho é aproximada. Contudo, essa localização é importante para selecionar marcadores microssatélites para saturar as regiōes onde esses QRLs se encontram e obter marcadores mais próximos aos mesmos. Assim, pode-se obter estimativas mais precisas dos seus efeitos, aumentar a chance de sucesso na clonagem desses QRLs e também obter maior eficiência no caso da seleção assistida.

Comparando-se os resultados da análise de regressão linear múltipla (RLM) com o de MIC, apenas 4 QRLs foram detectados por ambas as análises, pois somente 4 dos marcadores que entraram nos modelos de regressão foram identificados pelo método de MIC. Isto não significa, no entanto, que os QRLs identificados somente por uma das técnicas são artefatos, pois deve-se considerar que na regressão múltipla não foram usados apenas os marcadores ordenados no mapa, mas sim todos aqueles que não apresentaram distorção de segregação, incluindo além de marcadores agrupados, aqueles que segregaram independentemente. Não obstante, considerando a distribuição dos QRLs nos cromossomos, verificou-se relativa concordância; ambas as metodologias identificaram QRLs no cromossomo 1 (RLM 3 e MIC 2), cromossomo 2 (RLM 3 e MIC 2), cromossomo 4 (RGL 1 e MIC 3), cromossomo 5 (RLM 2 e MIC 1) e cromossomo 6 (RLM 1 e MIC 1). $O$ método de MIC localizou 1 QRL no cromossomo 9 não identificado na regressão, enquanto que 1 QRL identificado no cromossomo 8 por RLM não foi identificado por MIC. Um QRL identificado na RLM pelo marcador E3359162, não foi considerado na análise por MIC uma vez que segregou independente dos demais. Isto indica a necessidade de construir um mapa com maior cobertura do genoma para que outros QRLs possam ser caracterizados mais precisamente. É possivel que os QRLs identificados pelas metodologias nos mesmos cromossomos mas por 
marcadores diferentes, sejam os mesmos uma vez que ambos métodos fornecem apenas um posicionamento mais provável de cada $Q R L$.

As estimativas da proporção da variação fenotípica explicada pelos QRLs obtidas a partir das análises de mapeamento por intervalo composto são bem superiores às obtidas pela análise de regressão múltipla. Isto pode ser devido ao fato de que o mapeamento por intervalo composto considera e compensa a recombinação entre marcadores e o QRL na estimativa de seu efeito (Zeng, 1993, Zeng, 1994). No entanto, ainda assim a diferença é muito relevante, o que leva a crer que os valores obtidos pelo método de mapeamento por intervalo composto estão superestimados. No presente trabalho, o mapeamento de QTLs usando população $F_{2}$ e marcadores dominantes é baseado em dados incompletos dos genótipos marcadores, pois das 9 classes possíveis da combinação de dois locos, somente 4 podem ser diferenciadas $\left(M_{1} M_{2}, M_{1} m_{2} m_{2}, m_{1} m_{1} M_{2}\right.$ e $\left.m_{1} m_{1} m_{2} m_{2}\right)$ (Liu, 1998). De acordo com Jiang \& Zeng (1997), o poder de detecção e a precisão das estimativas dos parâmetros do QTL decrescem com o aumento de genótipos com informação perdida ou informação parcial. Embora tenha sido possível detectar QRLs a mancha de Phaeosphaeria usando população $F_{2}$ e marcadores, em sua maioria dominantes, estimativas mais precisas dos efeitos dos QRLs nessa população poderão ser obtidas usando marcadores codominantes regularmente espaçados nas regiōes onde foram mapeados os QRLs. Outra alternativa seria usar gerações de retrocruzamento para o mapeamento, pois nesse caso os marcadores dominantes são tão informativos quanto os codominantes.

Para utilização de marcadores em larga escala na seleção assistida, é necessário que sua análise seja simples, rápida, de baixo custo e confiável. Embora marcadores AFLP sejam úteis para saturar rapidamente o genoma e identificar marcadores associados a características de interesse, a técnica não é prática o suficiente para uso em larga escala. Assim, uma estratégia interessante é a de utilizar marcadores AFLP na identificação de genes de 
interesse e, posteriormente, convertê-los em marcadores co-dominantes baseados em PCR (Bradeen \& Simon, 1998; Dussle et al., 2002; Paltridge et al., 1998). Esses marcadores PCR-específicos são mais informativos e adequados para uso em larga escala.

\subsubsection{Considerações finais}

Com base no coeficiente de variação experimental, pode-se inferir que as avaliações fenotípicas das gerações e das famílias foram realizadas com precisão, uma vez que estes foram inferiores aos relatados na literatura em trabalhos de avaliação de doenças por meio de escalas de notas. Avaliações fenotípicas precisas aumentam a confiabilidade dos resultados.

O número de genes envolvidos no controle genético da resistência a mancha de Phaeosphaeria estimado através do mapeamento foi maior do que o encontrado pela análise de médias de gerações. Isso se deve ao fato de que as expressões convencionais usadas para a estimar o número de genes ou blocos gênicos envolvidos no controle genético da característica são baseadas em uma série de pressuposições (os genes devem ter efeitos de igual magnitude e direção sobre o caráter e todos os alelos que diminuem a expressão do caráter devem estar em um dos pais) que em geral não são atendidas (Cruz e Regazzi, 1997).

O máximo de informação genética é obtido a partir da associação de marcadores co-dominantes e população $F_{2}$, entretanto, o custo. para saturar 0 genoma com esses marcadores a procura de genes de interesse é alto para os padrões de muitos laboratórios. Dessa forma, o uso associado de marcadores microssatélites em posições estratégicas (para serem usados como ancoras) e marcadores AFLP (marcador com baixo custo por loco e de maior rendimento de locos por reação) apresenta-se como uma alternativa interessante para saturar rapidamente o genoma e orientar a seleção de outros marcadores microssatélites para as regiões específicas onde se encontram os QRLs, 
diminuindo o número de locos microssatélites a serem analisados e, consequentemente 0 custo das análises.

O uso de marcadores moleculares na identificação de QRLs à mancha de Phaeosphaeria em diferentes fontes de resistência deverá colaborar para definir estratégias que aumentem a eficiência dos programas de melhoramento à doença, inclusive possibilitando a seleção na ausência da doença, o que evitaria a interferência na avaliação de outras características de importância para a cultura. Deve-se considerar ainda que, por não estar dominada a metodologia de inoculação do patógeno para avaliação da doença, o melhorista depende da ocorrência natural da mesma, o que pode causar transtornos em épocas atípicas em que a infestação natural for baixa.

A detecção de alelos de resistência em ambos os genitores abre a possibilidade de encontrar genótipos descendentes do cruzamento que reunam mais alelos favoráveis que 0 genitor resistente, o que pode ser feito com 0 auxílio de marcadores moleculares na população aqui estudada. 


\section{CONCLUSÕES}

1. De acordo com a análise de médias de gerações, a resistência a mancha de Phaeosphaeria é resultado de maior ação gênica aditiva comparada a dominante nas populações DAS95 x DAS21 e DAS72 x DAS21.

2. Existem pelo menos 12 QRLs à mancha de Phaeosphaeria segregando na população DAS95 x DAS21. Estes QRLs estão localizados em 7 cromossomos (cromossomo 1, 2, 4, 5, 6, 8 e 9),

3. A maioria do $Q R L s$ localizam-se em regiōes onde já existem QRLs mapeados para outras doenças.

4. Embora a maior parte dos QRLs detectados através da regressão linear múltipla e do mapeamento por intervalo composto tenham sido identificados em ambos os experimentos e por ambas as metodologias foram também identificados QRLs que apresentaram interação com o ambiente, isso indica a importância da avaliação das populações em diferentes ambientes para identificar o maior número de QRLs possível.

5. Ambos os genitores contribuíram com alelos de resistência, embora a contribuição do genitor suscetível tenha sido inferior a do genitor resistente. 
ANEXO 
Tabela 10. Resultado do agrupamento realizado pelo teste Scott Knott nas médias ajustadas do primeiro experimento de avaliação da severidade da doença em três períodos (A1, $A 2, A 3)$ e da AUDPC para progênies $F_{3}$, linhagens genitoras (DAS21 e DAS95 e híbrido $\left(F_{1}\right)$.

\begin{tabular}{|c|c|c|c|c|c|c|c|}
\hline \multicolumn{2}{|l|}{ A1 } & \multicolumn{2}{|c|}{$\mathrm{A} 2$} & \multicolumn{2}{|c|}{ A3 } & \multicolumn{2}{|c|}{ AUDPC } \\
\hline Trat ament o & Médi a & Trat ament o & Médi a & Trat ament o & Médi a & Trat ament o & Médi a \\
\hline 65 & $1,63 a$ & 77 & $3,27 a$ & 65 & $5,76 a$ & 65 & $4,49 a$ \\
\hline 75 & $1,43 \mathrm{~b}$ & 48 & $3,23 a$ & 77 & $5,57 a$ & 77 & $4,42 a$ \\
\hline 103 & $1,27 \mathrm{c}$ & 65 & 3,22 a & 48 & $5,54 a$ & 48 & $4,38 a$ \\
\hline 95 & $1,25 \mathrm{c}$ & 103 & $2,64 \mathrm{~b}$ & 111 & $5,10 a$ & 111 & $3,80 \mathrm{~b}$ \\
\hline 13 & $1,25 \mathrm{c}$ & 75 & $2,62 \mathrm{~b}$ & 33 & 4,72 b & 33 & $3,54 \mathrm{~b}$ \\
\hline 57 & $1,24 \mathrm{c}$ & DAS21 & $2,58 \mathrm{~b}$ & 100 & 4,62 b & DAS21 & $3,53 \mathrm{~b}$ \\
\hline 48 & $1,24 \mathrm{c}$ & 111 & $2,50 \mathrm{~b}$ & 46 & 4,62 b & 103 & $3,51 \mathrm{~b}$ \\
\hline 111 & $1,22 \mathrm{c}$ & 46 & $2,38 \mathrm{~b}$ & 105 & $4,58 \mathrm{~b}$ & 46 & $3,50 \mathrm{~b}$ \\
\hline 46 & $1,19 \mathrm{c}$ & 105 & $2,37 \mathrm{~b}$ & 97 & $4,55 \mathrm{~b}$ & 105 & $3,47 \mathrm{~b}$ \\
\hline 98 & $1,18 \mathrm{c}$ & 95 & $2,37 \mathrm{~b}$ & 108 & $4,52 \mathrm{~b}$ & 75 & $3,44 \mathrm{~b}$ \\
\hline 58 & $1,18 \mathrm{c}$ & 33 & $2,36 \mathrm{~b}$ & DAS21 & $4,48 \mathrm{~b}$ & 100 & $3,34 \mathrm{~b}$ \\
\hline 16 & $1,17 \mathrm{c}$ & 100 & $2,07 \mathrm{c}$ & 103 & $4,38 \mathrm{~b}$ & 97 & $3,30 \mathrm{~b}$ \\
\hline 112 & $1,16 \mathrm{c}$ & 97 & $2,05 \mathrm{c}$ & 58 & $4,28 \mathrm{~b}$ & 108 & $3,21 \mathrm{c}$ \\
\hline 100 & $1,16 \mathrm{c}$ & 58 & $1,93 \mathrm{c}$ & 75 & 4,26 b & 58 & $3,11 \mathrm{c}$ \\
\hline DAS21 & $1,15 \mathrm{c}$ & 108 & $1,91 \mathrm{c}$ & 98 & $3,95 \mathrm{c}$ & 95 & $2,93 \mathrm{c}$ \\
\hline 55 & $1,15 \mathrm{c}$ & 88 & $1,90 \mathrm{c}$ & 88 & $3,79 \mathrm{c}$ & 98 & $2,87 \mathrm{c}$ \\
\hline 107 & $1,13 \mathrm{c}$ & 59 & $1,89 \mathrm{c}$ & 74 & $3,74 \mathrm{c}$ & 88 & $2,84 \mathrm{c}$ \\
\hline 74 & $1,13 \mathrm{c}$ & 98 & $1,79 \mathrm{c}$ & 20 & $3,53 \mathrm{c}$ & 74 & $2,74 d$ \\
\hline 77 & $1,12 d$ & 57 & $1,78 \mathrm{c}$ & 95 & $3,49 \mathrm{c}$ & 59 & $2,65 d$ \\
\hline 97 & $1,11 d$ & 89 & $1,76 \mathrm{c}$ & 112 & $3,47 \mathrm{c}$ & 112 & $2,57 d$ \\
\hline 88 & $1,11 d$ & 74 & $1,75 \mathrm{c}$ & 59 & 3,41 C & 57 & $2,57 d$ \\
\hline 33 & $1,11 d$ & 112 & $1,68 d$ & 57 & $3,35 \mathrm{c}$ & 89 & $2,55 d$ \\
\hline 59 & $1,09 d$ & 13 & $1,67 d$ & 89 & $3,34 \mathrm{c}$ & 20 & $2,48 d$ \\
\hline 53 & $1,08 d$ & 92 & $1,59 d$ & 101 & $3,32 \mathrm{c}$ & 55 & $2,30 \mathrm{e}$ \\
\hline 14 & $1,08 d$ & 16 & $1,54 d$ & 36 & $3,27 \mathrm{c}$ & 36 & $2,30 \mathrm{e}$ \\
\hline 89 & $1,07 d$ & 3 & $1,51 \mathrm{~d}$ & 55 & $3,15 c$ & 101 & $2,29 e$ \\
\hline 26 & $1,07 d$ & 55 & $1,45 d$ & 107 & $2,77 d$ & 92 & $2,17 \mathrm{e}$ \\
\hline 64 & $1,06 \mathrm{~d}$ & 87 & $1,44 d$ & 64 & $2,77 d$ & 87 & $2,09 e$ \\
\hline 24 & $1,06 d$ & 20 & $1,43 d$ & 92 & $2,76 d$ & 64 & $2,09 e$ \\
\hline 105 & $1,05 d$ & 14 & $1,43 d$ & 87 & $2,74 d$ & 13 & $2,08 \mathrm{e}$ \\
\hline 90 & $1,05 d$ & 64 & $1,42 d$ & 15 & $2,69 d$ & 107 & $2,05 \mathrm{e}$ \\
\hline 87 & $1,05 d$ & 26 & $1,39 d$ & 67 & $2,65 d$ & 16 & $2,05 \mathrm{e}$ \\
\hline 11 & $1,05 d$ & 116 & $1,38 d$ & 2 & $2,63 d$ & 3 & $2,04 \mathrm{e}$ \\
\hline 101 & $1,04 d$ & 60 & $1,38 d$ & 3 & $2,57 \mathrm{~d}$ & 60 & $1,95 \mathrm{e}$ \\
\hline 45 & $1,04 d$ & 81 & $1,36 \mathrm{~d}$ & 16 & $2,56 \mathrm{~d}$ & 15 & $1,95 \mathrm{e}$ \\
\hline 39 & $1,04 d$ & 11 & $1,36 d$ & 68 & $2,55 \mathrm{~d}$ & 26 & $1,92 \mathrm{e}$ \\
\hline 81 & $1,03 d$ & 25 & $1,35 d$ & 60 & $2,51 d$ & 2 & $1,92 \mathrm{e}$ \\
\hline 63 & $1,03 d$ & 36 & $1,34 d$ & 13 & $2,50 d$ & 67 & 1,91 e \\
\hline 35 & $1,03 d$ & 107 & $1,33 d$ & 51 & $2,48 d$ & 51 & $1,88 \mathrm{e}$ \\
\hline 118 & $1,02 d$ & 118 & $1,30 \mathrm{~d}$ & 113 & $2,45 d$ & 68 & $1,84 f$ \\
\hline 108 & $1,02 d$ & 94 & $1,30 d$ & 26 & $2,45 d$ & 11 & $1,82 f$ \\
\hline
\end{tabular}


Tabela 10. Resultado do agrupamento realizado pelo teste Scott Knott nas médias ajustadas do primeiro experimento de avaliação da severidade da doença em três períodos (A1, A2, A3) e da AUDPC para progênies $F_{3}$, linhagens genitoras (DAS21 e DAS95 e híbrido $\left(F_{1}\right)$.

\begin{tabular}{|c|c|c|c|c|c|c|c|}
\hline \multicolumn{2}{|l|}{ A1 } & \multicolumn{2}{|c|}{ A2 } & \multicolumn{2}{|c|}{ A3 } & \multicolumn{2}{|c|}{ AUDPC } \\
\hline Tratamento & Média T & Tratamento & Média & Tratamento & Média & Tratamento & Média \\
\hline 99 & $1,02 d$ & 93 & $1,29 d$ & 39 & $2,38 \mathrm{~d}$ & 39 & $1,80 f$ \\
\hline 92 & $1,02 d$ & 51 & $1,28 d$ & 11 & $2,29 d$ & 14 & $1,80 \mathrm{f}$ \\
\hline 78 & $1,02 d$ & 101 & $1,26 \mathrm{~d}$ & 17 & $2,20 \mathrm{e}$ & 113 & $1,73 f$ \\
\hline 56 & $1,02 d$ & 17 & $1,26 d$ & 79 & $2,17 \mathrm{e}$ & 17 & $1,73 f$ \\
\hline 49 & $1,02 d$ & 53 & $1,23 d$ & 14 & $2,16 \mathrm{e}$ & 94 & $1,72 \mathrm{f}$ \\
\hline 47 & $1,02 d$ & 39 & $1,23 d$ & 18 & $2,15 \mathrm{e}$ & 79 & $1,69 f$ \\
\hline 41 & $1,02 d$ & 63 & $1,22 \mathrm{e}$ & 94 & $2,13 \mathrm{e}$ & 118 & $1,68 \mathrm{f}$ \\
\hline 32 & $1,02 d$ & 15 & $1,22 \mathrm{e}$ & 44 & $2,11 \mathrm{e}$ & 25 & $1,68 \mathrm{f}$ \\
\hline 29 & $1,02 d$ & 79 & $1,21 \mathrm{e}$ & 118 & $2,06 \mathrm{e}$ & 93 & $1,65 \mathrm{f}$ \\
\hline 28 & $1,02 d$ & 2 & $1,20 \mathrm{e}$ & 25 & $2,02 \mathrm{e}$ & 18 & $1,65 f$ \\
\hline 19 & $1,02 d$ & 52 & $1,19 e$ & 115 & $2,01 \mathrm{e}$ & 44 & $1,64 \mathrm{f}$ \\
\hline 3 & $1,02 d$ & 4 & $1,17 \mathrm{e}$ & 93 & $2,00 \mathrm{e}$ & 116 & $1,61 \mathrm{f}$ \\
\hline DAS95 & $1,01 d$ & 67 & $1,16 \mathrm{e}$ & 106 & $1,98 e$ & 63 & $1,60 \mathrm{f}$ \\
\hline 114 & $1,01 d$ & 44 & $1,16 e$ & 63 & $1,98 \mathrm{e}$ & 106 & $1,56 \mathrm{f}$ \\
\hline 113 & $1,01 d$ & 18 & $1,16 e$ & 4 & $1,94 \mathrm{e}$ & 53 & $1,56 \mathrm{f}$ \\
\hline 94 & $1,01 d$ & 35 & $1,15 \mathrm{e}$ & 41 & $1,90 \mathrm{e}$ & 4 & $1,56 \mathrm{f}$ \\
\hline 91 & $1,01 d$ & 24 & $1,15 e$ & 53 & $1,89 e$ & 115 & $1,54 \mathrm{f}$ \\
\hline 86 & $1,01 d$ & 106 & $1,13 e$ & 45 & $1,87 e$ & 41 & $1,52 \mathrm{f}$ \\
\hline 80 & $1,01 d$ & 68 & $1,13 e$ & 116 & $1,85 e$ & 52 & $1,50 \mathrm{~g}$ \\
\hline 73 & $1,01 d$ & 41 & $1,13 e$ & 71 & $1,84 e$ & 45 & $1,49 \mathrm{~g}$ \\
\hline 72 & $1,01 d$ & 102 & $1,12 e$ & 24 & $1,81 e$ & 24 & $1,48 \mathrm{~g}$ \\
\hline 68 & $1,01 d$ & 61 & $1,12 \mathrm{e}$ & 52 & $1,80 \mathrm{e}$ & 81 & $1,47 \mathrm{~g}$ \\
\hline 66 & $1,01 d$ & 22 & $1,12 \mathrm{e}$ & 117 & $1,78 \mathrm{e}$ & 71 & $1,47 \mathrm{~g}$ \\
\hline 52 & $1,01 d$ & 45 & $1,11 \mathrm{e}$ & 110 & $1,78 \mathrm{e}$ & 117 & $1,42 \mathrm{~g}$ \\
\hline 42 & $1,01 d$ & 71 & $1,10 e$ & 5 & $1,77 \mathrm{e}$ & 102 & $1,42 \mathrm{~g}$ \\
\hline 36 & $1,01 d$ & 27 & $1,10 e$ & 7 & $1,76 \mathrm{e}$ & 5 & $1,42 \mathrm{~g}$ \\
\hline 22 & $1,01 d$ & 12 & $1,10 e$ & 102 & $1,72 f$ & 110 & $1,40 \mathrm{~g}$ \\
\hline 17 & $1,01 d$ & DAS95 & $1,09 e$ & 10 & $1,68 f$ & 7 & $1,40 \mathrm{~g}$ \\
\hline 7 & $1,01 d$ & 49 & $1,09 e$ & 62 & $1,67 f$ & 49 & $1,38 \mathrm{~g}$ \\
\hline 2 & $1,01 d$ & 73 & $1,08 \mathrm{e}$ & 49 & $1,67 \mathrm{f}$ & 10 & $1,35 \mathrm{~g}$ \\
\hline F1 & $1,00 d$ & 23 & $1,08 \mathrm{e}$ & 81 & $1,58 \mathrm{f}$ & 62 & $1,33 \mathrm{~g}$ \\
\hline 116 & $1,00 d$ & 1 & $1,08 \mathrm{e}$ & 54 & $1,55 f$ & 61 & $1,32 \mathbf{g}$ \\
\hline 115 & $1,00 d$ & 43 & $1,07 e$ & 61 & $1,51 \mathrm{f}$ & 54 & $1,29 \mathrm{~g}$ \\
\hline 102 & $1,00 d$ & 115 & $1,06 \mathrm{e}$ & F1 & $1,49 f$ & 70 & $1,27 \mathbf{g}$ \\
\hline 71 & $1,00 d$ & 72 & $1,06 \mathrm{e}$ & 70 & $1,49 f$ & F1 & $1,25 \mathrm{~g}$ \\
\hline 70 & $1,00 d$ & 37 & $1,06 \mathrm{e}$ & 42 & $1,46 f$ & 43 & $1,25 \mathrm{~g}$ \\
\hline 69 & $1,00 \mathrm{~d}$ & 28 & $1,06 \mathrm{e}$ & 43 & $1,43 f$ & 37 & $1,25 \mathrm{~g}$ \\
\hline 61 & $1,00 \mathrm{~d}$ & 8 & $1,06 \mathrm{e}$ & 37 & $1,43 f$ & 23 & $1,25 \mathrm{~g}$ \\
\hline 60 & $1,00 \mathrm{~d}$ & 5 & $1,06 \mathrm{e}$ & 23 & $1,42 f$ & 12 & $1,23 \mathrm{~g}$ \\
\hline 54 & $1,00 d$ & 117 & $1,05 e$ & 90 & $1,40 \mathrm{f}$ & 90 & $1,22 \mathrm{~g}$ \\
\hline 40 & $1,00 d$ & 31 & $1,05 \mathrm{e}$ & 29 & $1,40 \mathrm{f}$ & 42 & $1,22 \mathrm{~g}$ \\
\hline 34 & $1,00 d$ & 7 & $1,05 \mathrm{e}$ & 8 & $1,38 \mathrm{f}$ & 8 & $1,22 \mathrm{~g}$ \\
\hline
\end{tabular}


Tabela 10. Resultado do agrupamento realizado pelo teste Scott Knott nas médias ajustadas do primeiro experimento de avaliação da severidade da doença em três períodos (A1, A2, A3) e da AUDPC para progênies $F_{3}$, linhagens genitoras (DAS21 e DAS95 e híbrido $\left(F_{1}\right)$.

\begin{tabular}{|c|c|c|c|c|c|c|c|}
\hline \multicolumn{2}{|l|}{ A1 } & \multicolumn{2}{|c|}{ A2 } & \multicolumn{2}{|c|}{ A3 } & \multicolumn{2}{|c|}{ AUDPC } \\
\hline Tratamento & Média & Tratamento & Média & Tratamento & Média & Tratamento & Média \\
\hline 27 & $1,00 d$ & 99 & $1,04 \mathrm{e}$ & 12 & $1,36 f$ & 29 & $1,21 \mathrm{~g}$ \\
\hline 25 & $1,00 d$ & 90 & $1,04 \mathrm{e}$ & 114 & $1,35 f$ & 72 & $1,20 \mathrm{~g}$ \\
\hline 23 & $1,00 d$ & 84 & $1,04 \mathrm{e}$ & 91 & $1,34 \mathrm{f}$ & 35 & $1,20 \mathrm{~g}$ \\
\hline 20 & $1,00 d$ & 78 & $1,04 \mathrm{e}$ & 72 & $1,34 \mathrm{f}$ & 114 & $1,19 \mathrm{~g}$ \\
\hline 18 & $1,00 d$ & 70 & $1,04 \mathrm{e}$ & 21 & $1,33 f$ & 78 & $1,18 \mathrm{~g}$ \\
\hline 12 & $1,00 d$ & 114 & $1,03 \mathrm{e}$ & 78 & $1,32 f$ & 22 & $1,18 \mathrm{~g}$ \\
\hline 10 & $1,00 d$ & 76 & $1,03 \mathrm{e}$ & 83 & $1,30 \mathrm{f}$ & 91 & $1,17 \mathrm{~g}$ \\
\hline 9 & $1,00 d$ & 54 & $1,03 e$ & 84 & $1,29 f$ & 84 & $1,17 \mathrm{~g}$ \\
\hline 6 & $1,00 d$ & 47 & $1,03 e$ & 69 & $1,29 f$ & 28 & $1,16 \mathrm{~g}$ \\
\hline 5 & $1,00 d$ & F1 & $1,02 \mathrm{e}$ & 28 & $1,27 \mathrm{f}$ & 83 & $1,15 \mathrm{~g}$ \\
\hline 110 & $0,99 d$ & 110 & $1,02 e$ & 35 & $1,26 f$ & 69 & $1,15 \mathrm{~g}$ \\
\hline 109 & $0,99 d$ & 85 & $1,02 \mathrm{e}$ & 22 & $1,24 f$ & 21 & $1,12 \mathrm{~g}$ \\
\hline 106 & $0,99 d$ & 69 & $1,02 \mathrm{e}$ & 82 & $1,23 f$ & 82 & $1,11 \mathrm{~g}$ \\
\hline 104 & $0,99 d$ & 50 & $1,02 \mathrm{e}$ & 80 & $1,17 f$ & 27 & $1,11 \mathrm{~g}$ \\
\hline 93 & $0,99 d$ & 10 & $1,02 \mathrm{e}$ & 19 & $1,17 f$ & 19 & $1,09 \mathrm{~g}$ \\
\hline 85 & $0,99 d$ & 113 & $1,01 \mathrm{e}$ & 85 & $1,12 f$ & 80 & $1,08 \mathrm{~g}$ \\
\hline 84 & $0,99 d$ & 91 & $1,01 \mathrm{e}$ & 27 & $1,11 f$ & 85 & $1,07 \mathrm{~g}$ \\
\hline 83 & $0,99 d$ & 29 & $1,01 \mathrm{e}$ & 34 & $1,09 f$ & 1 & $1,07 \mathrm{~g}$ \\
\hline 82 & $0,99 d$ & 19 & $1,01 \mathrm{e}$ & 30 & $1,09 f$ & 31 & $1,06 \mathrm{~g}$ \\
\hline 76 & $0,99 d$ & 83 & $1,00 \mathrm{e}$ & 109 & $1,08 f$ & 50 & $1,05 \mathrm{~g}$ \\
\hline 51 & $0,99 d$ & 66 & $1,00 \mathrm{e}$ & 86 & $1,08 f$ & 34 & $1,04 \mathrm{~g}$ \\
\hline 50 & $0,99 d$ & 56 & $1,00 \mathrm{e}$ & 50 & $1,08 f$ & DAS95 & $1,03 \mathrm{~g}$ \\
\hline 44 & $0,99 d$ & 38 & $1,00 \mathrm{e}$ & 32 & $1,08 f$ & 104 & $1,03 \mathrm{~g}$ \\
\hline 43 & $0,99 d$ & 6 & $1,00 e$ & 31 & $1,08 f$ & 86 & $1,03 \mathrm{~g}$ \\
\hline 38 & $0,99 d$ & 82 & $0,99 \mathrm{e}$ & 104 & $1,07 f$ & 47 & $1,03 \mathrm{~g}$ \\
\hline 31 & $0,99 d$ & 80 & $0,99 e$ & 1 & $1,07 f$ & 32 & $1,03 \mathrm{~g}$ \\
\hline 15 & $0,99 d$ & 40 & $0,99 \mathrm{e}$ & 9 & $1,05 f$ & 30 & $1,02 \mathrm{~g}$ \\
\hline 8 & $0,99 d$ & 34 & $0,99 e$ & 47 & $1,03 f$ & 109 & $1,01 \mathrm{~g}$ \\
\hline 1 & $0,99 d$ & 104 & $0,98 \mathrm{e}$ & 6 & $1,03 f$ & 56 & $1,01 \mathrm{~g}$ \\
\hline 117 & $0,98 d$ & 62 & $0,98 \mathrm{e}$ & 56 & $1,02 f$ & 6 & $1,01 \mathrm{~g}$ \\
\hline 96 & $0,98 d$ & 42 & $0,98 \mathrm{e}$ & 96 & $1,01 \mathrm{f}$ & 9 & $1,00 \mathrm{~g}$ \\
\hline 79 & $0,98 d$ & 32 & $0,98 \mathrm{e}$ & DAS95 & $0,97 \mathrm{f}$ & 76 & $0,99 \mathrm{~g}$ \\
\hline 67 & $0,98 d$ & 86 & $0,97 \mathrm{e}$ & 66 & $0,97 f$ & 73 & $0,99 \mathrm{~g}$ \\
\hline 62 & $0,98 d$ & 109 & $0,95 \mathrm{e}$ & 76 & $0,95 f$ & 66 & $0,99 \mathrm{~g}$ \\
\hline 37 & $0,98 d$ & 30 & $0,95 \mathrm{e}$ & 40 & $0,95 f$ & 96 & $0,98 \mathrm{~g}$ \\
\hline 30 & $0,98 d$ & 96 & $0,94 \mathrm{e}$ & 99 & $0,91 \mathrm{f}$ & 99 & $0,97 \mathrm{~g}$ \\
\hline 21 & $0,98 d$ & 9 & $0,94 \mathrm{e}$ & 73 & $0,89 f$ & 40 & $0,97 \mathrm{~g}$ \\
\hline 4 & $0,98 d$ & 21 & $0,91 \mathrm{e}$ & 38 & $0,86 f$ & 38 & $0,93 \mathrm{~g}$ \\
\hline
\end{tabular}


Tabela 11. Resultado do agrupamento realizado pelo teste Scott-Knott nas médias ajustadas do segundo experimento de avaliação da severidade da doença em três períodos (A1, A2, A3) e da AUDPC para progênies $F_{3}$, linhagens genitoras (DAS21 e DAS95 e híbrido (F1).

\begin{tabular}{|c|c|c|c|c|c|c|c|}
\hline \multicolumn{2}{|c|}{ A1 } & \multicolumn{2}{|l|}{ A2 } & \multicolumn{2}{|l|}{ A3 } & \multicolumn{2}{|c|}{ AUDPC } \\
\hline Tratamento & Médi a & Tratamento & Médi a & Tratamento & Médi a & Tratamento & Médi a \\
\hline 77 & $2,58 a$ & 48 & $5,60 a$ & 77 & $8,14 a$ & 77 & $5,30 a$ \\
\hline 65 & $2,58 a$ & 77 & $5,24 a$ & 48 & $7,54 a$ & 48 & $5,23 a$ \\
\hline 75 & $2,51 a$ & 65 & $5,09 a$ & 65 & $7,43 a$ & 65 & $5,05 a$ \\
\hline 48 & $2,17 \mathrm{~b}$ & 100 & $4,88 a$ & 100 & 7,18 a & 100 & $4,70 \mathrm{~b}$ \\
\hline 105 & $2,09 \mathrm{~b}$ & 33 & $4,67 \mathrm{~b}$ & 58 & $7,11 a$ & 108 & $4,58 \mathrm{~b}$ \\
\hline 97 & $2,05 \mathrm{~b}$ & 108 & $4,62 \mathrm{~b}$ & 33 & $7,09 \mathbf{a}$ & 33 & $4,58 \mathrm{~b}$ \\
\hline 111 & $2,02 \mathrm{~b}$ & 58 & $4,61 \mathrm{~b}$ & 108 & $7,07 \mathbf{a}$ & 58 & $4,54 \mathrm{~b}$ \\
\hline 108 & $2,02 \mathrm{~b}$ & 75 & $4,39 \mathrm{~b}$ & 111 & 6,99 a & 111 & $4,41 \mathrm{C}$ \\
\hline 46 & $1,98 \mathrm{~b}$ & 111 & $4,32 \mathrm{~b}$ & 105 & $6,00 \mathrm{~b}$ & 75 & $4,27 \mathrm{c}$ \\
\hline 88 & $1,94 \mathrm{~b}$ & 46 & $3,99 \mathrm{~b}$ & 75 & 5,81 b & DAS21 & $4,13 \mathrm{c}$ \\
\hline DAS21 & $1,93 \mathrm{~b}$ & DAS21 & $3,79 \mathrm{c}$ & 88 & 5,75 b & 46 & $3,86 \mathrm{~d}$ \\
\hline 33 & $1,90 \mathrm{c}$ & 88 & $3,78 \mathrm{c}$ & 97 & $5,71 \mathrm{~b}$ & 97 & $3,83 d$ \\
\hline 100 & $1,85 \mathrm{c}$ & 97 & $3,77 \mathrm{c}$ & 20 & $5,70 \mathrm{~b}$ & 88 & $3,81 \mathrm{~d}$ \\
\hline 95 & $1,83 \mathrm{c}$ & 55 & $3,50 \mathrm{c}$ & 55 & $5,50 \mathrm{~b}$ & 105 & $3,58 \mathrm{e}$ \\
\hline 58 & $1,82 \mathrm{c}$ & 36 & $3,50 \mathrm{c}$ & 46 & $5,48 \mathrm{~b}$ & 55 & $3,48 e$ \\
\hline 103 & $1,75 \mathrm{c}$ & 57 & $3,43 \mathrm{c}$ & DAS21 & 5,34 b & 103 & $3,47 \mathrm{e}$ \\
\hline 16 & $1,70 \mathrm{c}$ & 103 & $3,40 \mathrm{c}$ & 103 & $5,32 \mathrm{~b}$ & 36 & $3,30 \mathrm{e}$ \\
\hline 15 & $1,57 d$ & 95 & $3,15 \mathrm{~d}$ & 98 & 5,17 b & 20 & $3,30 \mathrm{e}$ \\
\hline 112 & $1,56 d$ & 64 & $3,14 \mathrm{~d}$ & 68 & $5,13 \mathrm{~b}$ & 57 & $3,24 e$ \\
\hline 74 & $1,56 d$ & 105 & $3,12 \mathrm{~d}$ & 59 & $5,03 \mathrm{~b}$ & 64 & $3,15 \mathrm{e}$ \\
\hline 67 & $1,52 d$ & 2 & $3,09 \mathrm{~d}$ & 89 & $4,83 \mathrm{c}$ & 68 & $3,14 \mathrm{e}$ \\
\hline 26 & $1,52 d$ & 20 & $3,08 \mathrm{~d}$ & 64 & $4,81 \mathrm{c}$ & 89 & $3,10 \mathrm{e}$ \\
\hline 64 & $1,51 d$ & 68 & $3,06 \mathrm{~d}$ & 57 & $4,77 \mathrm{c}$ & 2 & $3,09 \mathrm{e}$ \\
\hline 2 & $1,50 d$ & 89 & $3,05 d$ & 13 & 4,76 c & 59 & $3,06 \mathrm{e}$ \\
\hline 36 & $1,49 d$ & 59 & $3,03 \mathrm{~d}$ & 36 & $4,70 \mathrm{c}$ & 98 & $3,05 e$ \\
\hline 98 & $1,46 d$ & 51 & $2,89 d$ & 2 & $4,68 \mathrm{c}$ & 95 & $3,05 \mathrm{e}$ \\
\hline 89 & $1,46 d$ & 13 & $2,89 d$ & 92 & $4,34 \mathrm{c}$ & 13 & $2,95 \mathrm{f}$ \\
\hline 51 & $1,45 d$ & 98 & $2,79 d$ & 112 & $4,27 \mathrm{c}$ & 74 & $2,78 f$ \\
\hline 3 & $1,44 d$ & 67 & $2,79 d$ & 79 & $4,21 \mathrm{c}$ & 112 & $2,72 f$ \\
\hline 55 & $1,42 d$ & 115 & $2,77 d$ & 95 & $4,09 \mathrm{c}$ & 115 & $2,70 \mathrm{f}$ \\
\hline 87 & $1,38 \mathrm{e}$ & 74 & $2,76 d$ & 101 & $4,07 \mathrm{c}$ & 16 & $2,68 f$ \\
\hline 39 & $1,34 \mathrm{e}$ & 15 & $2,72 d$ & 115 & $4,06 \mathrm{c}$ & 15 & $2,68 f$ \\
\hline 20 & $1,34 \mathrm{e}$ & 26 & $2,70 d$ & 87 & $4,03 \mathrm{c}$ & 51 & $2,67 \mathrm{f}$ \\
\hline 63 & $1,32 \mathrm{e}$ & 16 & $2,70 d$ & 45 & $4,03 \mathrm{c}$ & 67 & $2,66 \mathrm{f}$ \\
\hline 57 & $1,31 \mathrm{e}$ & 87 & $2,53 \mathrm{e}$ & 74 & $4,02 \mathrm{c}$ & 26 & $2,65 f$ \\
\hline 14 & $1,30 \mathrm{e}$ & 112 & $2,52 \mathrm{e}$ & 15 & $3,69 \mathrm{~d}$ & 92 & $2,64 f$ \\
\hline 110 & $1,28 \mathrm{e}$ & 92 & $2,52 e$ & 26 & $3,68 d$ & 87 & $2,62 f$ \\
\hline 68 & $1,28 \mathrm{e}$ & 3 & $2,43 e$ & 116 & $3,67 \mathrm{~d}$ & 101 & $2,44 \mathrm{~g}$ \\
\hline 60 & $1,28 \mathrm{e}$ & 110 & $2,38 \mathrm{e}$ & 16 & $3,61 d$ & 45 & $2,40 \mathrm{~g}$ \\
\hline 53 & $1,27 \mathrm{e}$ & 39 & $2,35 \mathrm{e}$ & 67 & $3,53 \mathrm{~d}$ & 3 & $2,37 \mathrm{~g}$ \\
\hline 10 & $1,27 e$ & 17 & $2,35 \mathrm{e}$ & 44 & $3,51 \mathrm{~d}$ & 17 & $2,33 \mathrm{~g}$ \\
\hline
\end{tabular}


Tabela 11. Resultado do agrupamento realizado pelo teste Scott-Knott nas médias ajustadas do segundo experimento de avaliação da severidade da doença em três períodos (A1, A2, A3) e da AUDPC para progênies $F_{3}$, linhagens genitoras (DAS21 e DAS95 e híbrido (F1).

\begin{tabular}{|c|c|c|c|c|c|c|c|}
\hline \multicolumn{2}{|c|}{ A1 } & \multicolumn{2}{|c|}{ A2 } & \multicolumn{2}{|c|}{ A3 } & \multicolumn{2}{|c|}{ AUDPC } \\
\hline Tratamento & Média & Tratamento & Média & Tratamento & Média & Tratamento & Média \\
\hline 13 & $1,26 e$ & 101 & $2,29 e$ & 17 & $3,50 \mathrm{~d}$ & 110 & $2,30 \mathrm{~g}$ \\
\hline 102 & 1,24 e & 45 & $2,26 \mathrm{e}$ & 107 & $3,47 d$ & 79 & $2,30 \mathrm{~g}$ \\
\hline 79 & $1,24 \mathrm{e}$ & 44 & $2,25 \mathrm{e}$ & 51 & $3,45 d$ & 44 & $2,28 \mathrm{~g}$ \\
\hline 21 & $1,23 \mathrm{e}$ & 94 & $2,22 \mathrm{e}$ & 29 & $3,43 d$ & 116 & $2,25 \mathrm{~g}$ \\
\hline 8 & $1,21 \mathrm{f}$ & 102 & $2,19 \mathrm{e}$ & 8 & $3,31 \mathrm{~d}$ & 39 & $2,25 \mathrm{~g}$ \\
\hline 115 & $1,20 \mathrm{f}$ & 14 & $2,10 e^{-}$ & 69 & $3,16 d$ & 94 & $2,16 \mathrm{~g}$ \\
\hline 92 & $1,20 \mathrm{f}$ & 116 & $2,08 \mathrm{e}$ & 3 & $3,16 \mathrm{~d}$ & 102 & $2,10 \mathrm{~g}$ \\
\hline 11 & $1,19 \mathrm{f}$ & 11 & $2,06 \mathrm{e}$ & 110 & $3,15 d$ & 11 & $2,10 \mathrm{~g}$ \\
\hline 41 & $1,18 \mathrm{f}$ & 63 & $2,02 \mathrm{e}$ & 34 & $3,11 \mathrm{~d}$ & 14 & $2,07 \mathrm{~g}$ \\
\hline 107 & $1,17 f$ & 60 & $1,99 e$ & 11 & $3,10 \mathrm{~d}$ & 63 & $2,06 \mathrm{~g}$ \\
\hline 116 & $1,16 f$ & 25 & $1,99 \mathrm{e}$ & 94 & $3,08 \mathrm{~d}$ & 60 & $2,04 \mathrm{~g}$ \\
\hline 59 & $1,16 f$ & 7 & $1,98 \mathrm{e}$ & 18 & $3,07 d$ & 29 & $2,04 \mathrm{~g}$ \\
\hline 18 & $1,16 \mathrm{f}$ & 70 & $1,96 \mathrm{e}$ & 24 & $3,00 \mathrm{e}$ & 18 & $2,04 \mathrm{~g}$ \\
\hline 24 & $1,14 \mathrm{f}$ & 18 & $1,96 \mathrm{e}$ & 39 & $2,96 \mathrm{e}$ & 107 & $2,00 \mathrm{~h}$ \\
\hline 101 & $1,13 \mathrm{f}$ & 4 & $1,95 \mathrm{e}$ & 114 & $2,95 e$ & 7 & $2,00 \mathrm{~h}$ \\
\hline 90 & $1,13 f$ & 79 & $1,88 \mathrm{e}$ & 113 & $2,95 \mathrm{e}$ & 25 & $1,95 \mathrm{~h}$ \\
\hline 81 & $1,13 \mathrm{f}$ & 81 & $1,85 \mathrm{e}$ & 93 & $2,91 \mathrm{e}$ & 69 & $1,94 \mathrm{~h}$ \\
\hline 7 & $1,13 \mathrm{f}$ & 72 & $1,85 e$ & 60 & $2,90 \mathrm{e}$ & 81 & $1,90 \mathrm{~h}$ \\
\hline 94 & $1,12 f$ & 41 & $1,84 \mathrm{e}$ & 7 & $2,90 \mathrm{e}$ & 4 & $1,90 \mathrm{~h}$ \\
\hline 23 & $1,12 f$ & 29 & $1,82 \mathrm{e}$ & 63 & $2,88 \mathrm{e}$ & 70 & $1,89 h$ \\
\hline 44 & $1,10 \mathrm{f}$ & 69 & $1,80 \mathrm{e}$ & 117 & $2,82 \mathrm{e}$ & 41 & $1,89 h$ \\
\hline 40 & $1,10 \mathrm{f}$ & 10 & $1,74 \mathrm{e}$ & 118 & $2,79 e$ & 24 & $1,88 h$ \\
\hline 37 & $1,10 \mathrm{f}$ & 21 & $1,72 \mathrm{e}$ & 53 & $2,79 e$ & 8 & $1,87 \mathrm{~h}$ \\
\hline 17 & $1,10 \mathrm{f}$ & 24 & $1,70 \mathrm{e}$ & 102 & $2,77 \mathrm{e}$ & 72 & $1,86 h$ \\
\hline 5 & $1,10 \mathrm{f}$ & 107 & $1,69 e$ & 25 & $2,77 e$ & 53 & $1,83 \mathrm{~h}$ \\
\hline 70 & $1,09 f$ & 93 & $1,67 \mathrm{e}$ & 81 & $2,76 \mathrm{e}$ & 93 & $1,82 \mathrm{~h}$ \\
\hline 29 & $1,09 f$ & 53 & $1,64 \mathrm{e}$ & 14 & $2,76 e$ & 34 & $1,81 \mathrm{~h}$ \\
\hline 56 & $1,08 \mathrm{f}$ & 113 & $1,62 \mathrm{e}$ & 52 & $2,70 \mathrm{e}$ & 113 & $1,80 \mathrm{~h}$ \\
\hline 72 & $1,07 \mathrm{f}$ & 117 & $1,54 f$ & 41 & $2,70 \mathrm{e}$ & 10 & $1,79 h$ \\
\hline 61 & $1,07 \mathrm{f}$ & 34 & $1,54 f$ & 4 & $2,69 e$ & 118 & $1,73 \mathrm{~h}$ \\
\hline 118 & $1,06 \mathrm{f}$ & 118 & $1,53 \mathrm{f}$ & 72 & $2,67 e$ & 117 & $1,71 \mathrm{~h}$ \\
\hline 114 & $1,06 \mathrm{f}$ & 71 & $1,51 \mathrm{f}$ & 70 & $2,54 \mathrm{e}$ & 114 & $1,71 \mathrm{~h}$ \\
\hline 71 & $1,06 \mathrm{f}$ & 52 & $1,49 \mathrm{f}$ & 10 & $2,41 e$ & 21 & $1,71 \mathrm{~h}$ \\
\hline 49 & $1,06 \mathrm{f}$ & 8 & $1,49 \mathrm{f}$ & 78 & $2,38 \mathrm{e}$ & 52 & $1,65 \mathrm{~h}$ \\
\hline 27 & $1,06 \mathrm{f}$ & 5 & $1,49 f$ & 106 & $2,36 \mathrm{e}$ & 71 & $1,60 i$ \\
\hline 25 & $1,06 f$ & 106 & $1,48 f$ & 71 & $2,31 \mathrm{e}$ & 78 & $1,59 i$ \\
\hline 104 & $1,05 f$ & 78 & $1,48 f$ & 35 & $2,23 \mathrm{e}$ & 106 & 1,57 i \\
\hline 93 & $1,05 f$ & 62 & $1,46 \mathrm{f}$ & 37 & $2,21 \mathrm{e}$ & 5 & $1,55 \mathbf{i}$ \\
\hline 62 & $1,05 f$ & 23 & $1,45 f$ & 43 & $2,16 \mathrm{f}$ & 62 & $1,51 \mathbf{i}$ \\
\hline 34 & $1,05 f$ & 90 & $1,44 \mathrm{f}$ & 42 & $2,16 \mathrm{f}$ & 42 & $1,47 \mathrm{i}$ \\
\hline 28 & $1,05 f$ & 114 & $1,42 f$ & 21 & $2,16 \mathrm{f}$ & 37 & $1,45 i$ \\
\hline 12 & $1,05 f$ & 42 & $1,35 f$ & 5 & $2,10 \mathrm{f}$ & 35 & $1,45 i$ \\
\hline
\end{tabular}


Tabela 11. Resultado do agrupamento realizado pelo teste Scott-Knott nas médias ajustadas do segundo experimento de avaliação da severidade da doença em três periodos (A1, A2, A3) e da AUDPC para progênies $F_{3}$, linhagens genitoras (DAS21 e DAS95 e híbrido (F1).

\begin{tabular}{|c|c|c|c|c|c|c|c|}
\hline \multicolumn{2}{|c|}{ A1 } & \multicolumn{2}{|c|}{ A2 } & \multicolumn{2}{|c|}{ A3 } & \multicolumn{2}{|c|}{ AUDPC } \\
\hline Tratamento & Média & Tratamento & Média & Tratamento & Média & Tratamento & Média \\
\hline 109 & $1,04 f$ & 40 & $1,35 f$ & 62 & $2,08 \mathrm{f}$ & 90 & $1,44 i$ \\
\hline 91 & $1,04 f$ & 91 & $1,31 \mathrm{f}$ & 84 & $1,95 f$ & 23 & $1,43 i$ \\
\hline 31 & $1,04 f$ & 83 & $1,31 f$ & 83 & $1,90 \mathrm{f}$ & 84 & 1,39 \\
\hline 83 & $1,03 f$ & 35 & $1,30 \mathrm{f}$ & 12 & $1,88 \mathrm{f}$ & 83 & 1,39 $\mathbf{i}$ \\
\hline 82 & $1,03 f$ & 84 & $1,29 f$ & 82 & $1,86 f$ & 91 & $1,37 \mathrm{i}$ \\
\hline 45 & $1,03 f$ & 12 & $1,28 \mathrm{f}$ & 91 & $1,83 f$ & 40 & $1,37 \mathbf{i}$ \\
\hline 96 & $1,02 f$ & 82 & $1,26 \mathrm{f}$ & 90 & $1,78 \mathrm{f}$ & 12 & 1,37 i \\
\hline 86 & $1,02 f$ & 37 & $1,25 f$ & 19 & $1,77 \mathrm{f}$ & 82 & $1,35 i$ \\
\hline 85 & $1,02 f$ & 61 & $1,23 f$ & F1 & $1,74 f$ & F1 & $1,31 i$ \\
\hline 84 & $1,02 f$ & 109 & $1,22 f$ & 28 & $1,71 \mathrm{f}$ & 43 & $1,30 i$ \\
\hline 78 & $1,02 f$ & 50 & $1,18 f$ & 23 & $1,70 \mathrm{f}$ & 19 & $1,28 i$ \\
\hline 66 & $1,02 f$ & 19 & $1,17 f$ & 40 & $1,68 \mathrm{f}$ & 54 & $1,22 j$ \\
\hline 50 & $1,02 f$ & 56 & $1,16 f$ & 54 & $1,66 f$ & 61 & $1,21 \mathrm{j}$ \\
\hline 47 & $1,02 f$ & F1 & $1,13 f$ & 38 & $1,49 f$ & 28 & $1,21 \mathrm{j}$ \\
\hline 43 & $1,02 \mathrm{f}$ & 99 & $1,12 f$ & 49 & $1,40 \mathrm{~g}$ & 109 & $\mathbf{1 , 1 8} \mathbf{j}$ \\
\hline 113 & $1,01 \mathrm{f}$ & 85 & $1,11 \mathrm{f}$ & 85 & $1,31 \mathrm{~g}$ & 56 & $1,17 \mathbf{j}$ \\
\hline 42 & $1,01 \mathrm{f}$ & 54 & $1,11 \mathrm{f}$ & 61 & $1,30 \mathrm{~g}$ & 50 & $1,16 j$ \\
\hline 38 & $1,01 \mathrm{f}$ & 27 & $1,09 f$ & 56 & $1,29 \mathrm{~g}$ & 38 & $1,16 j$ \\
\hline 22 & $1,01 \mathrm{f}$ & 66 & $1,08 \mathrm{f}$ & 1 & $1,28 \mathrm{~g}$ & 85 & $1,14 j$ \\
\hline 1 & $1,01 \mathrm{f}$ & DAS95 & $1,07 \mathrm{f}$ & 50 & $1,26 \mathrm{~g}$ & 49 & $1,14 j$ \\
\hline 19 & $1,00 \mathrm{f}$ & 38 & $1,07 \mathrm{f}$ & 109 & $1,25 \mathrm{~g}$ & 27 & $1,10 j$ \\
\hline F1 & $0,99 \mathrm{f}$ & 30 & $1,06 \mathrm{f}$ & 31 & $1,22 \mathrm{~g}$ & 104 & $1,08 \mathbf{j}$ \\
\hline 99 & $0,99 \mathrm{f}$ & 104 & $1,05 f$ & 104 & $1,18 \mathrm{~g}$ & 31 & $1,08 j$ \\
\hline 69 & $0,99 \mathrm{f}$ & 28 & $1,05 \mathrm{f}$ & 27 & $1,15 \mathrm{~g}$ & 99 & $\mathbf{1 , 0 7} \mathbf{j}$ \\
\hline 54 & $0,99 f$ & 86 & $1,04 f$ & 22 & $1,11 \mathrm{~g}$ & 22 & $1,05 j$ \\
\hline 35 & $0,98 \mathrm{f}$ & 49 & $1,04 f$ & 86 & $1,07 \mathrm{~g}$ & 1 & $1,05 j$ \\
\hline 9 & $0,98 \mathrm{f}$ & 31 & $1,04 f$ & 47 & $1,07 \mathrm{~g}$ & 86 & $1,04 j$ \\
\hline 4 & $0,98 \mathrm{f}$ & 22 & $1,04 \mathrm{f}$ & 99 & $1,04 \mathrm{~g}$ & 66 & $1,04 j$ \\
\hline 106 & $0,97 \mathrm{f}$ & 43 & $1,00 \mathrm{f}$ & 66 & $0,98 \mathrm{~g}$ & 30 & $1,01 \mathrm{j}$ \\
\hline DAS95 & $0,96 \mathrm{f}$ & 76 & $0,96 \mathrm{f}$ & 30 & $0,97 \mathrm{~g}$ & 47 & $1,00 \mathrm{j}$ \\
\hline 80 & $0,96 \mathrm{f}$ & 6 & $0,96 \mathrm{f}$ & 80 & $0,96 \mathrm{~g}$ & DAS95 & $0,99 \mathbf{j}$ \\
\hline 30 & $0,95 \mathrm{f}$ & 1 & $0,96 \mathrm{f}$ & 96 & $0,94 \mathrm{~g}$ & 96 & $0,95 \mathbf{j}$ \\
\hline 117 & $0,94 \mathrm{f}$ & 47 & $0,95 f$ & DAS95 & $0,88 \mathrm{~g}$ & 76 & $0,92 \mathbf{j}$ \\
\hline 76 & $0,94 \mathrm{f}$ & 96 & $0,92 \mathrm{f}$ & 6 & $0,84 \mathrm{~g}$ & 6 & 0,92 j \\
\hline 52 & $0,94 \mathrm{f}$ & 9 & $0,89 f$ & 76 & $0,83 \mathrm{~g}$ & 80 & $0,89 \mathbf{j}$ \\
\hline 6 & $0,93 \mathbf{f}$ & 73 & $0,84 \mathrm{f}$ & 32 & $0,79 \mathrm{~g}$ & 9 & $0,84 \mathbf{j}$ \\
\hline 73 & $0,92 f$ & 80 & $0,82 f$ & 73 & $0,71 \mathrm{~g}$ & 73 & $0,83 \mathbf{j}$ \\
\hline 32 & $0,92 \mathrm{f}$ & 32 & $0,75 \mathrm{f}$ & 9 & $0,61 \mathrm{~g}$ & 32 & $0,80 \mathrm{j}$ \\
\hline
\end{tabular}




\section{REFERÊNCIAS BIBLIOGRÁFICAS}

AGROCERES. Guia Agroceres de sanidade. São Paulo: Sementes Agroceres SIA, 1996. 72p.

AJMONE-MARSAN, P.; GORNI, C.; CHITTÓ, A.; RADAELLI, R.; VAN VIJK, R.; STAM, P.M. Identification of QTLs for grain yield and grain-related traits of maize (Zea mays L.) using AFLP map, different testers, and cofactor analysis. Theoretical and Applied Genetics, v.102, p.230-243, 2001.

AJMONE-MARSAN, P.; MONFREDINI, G.; LUDWIG, W.F.; MELCHINGER, A.E.; FRANCESCHINI, P. Identification of genomic regions affecting plant height and their relationship with grain yield in na elite maize cross. Maydica, v.39, p.133-139, 1994.

AJMONE-MARSAN, P.; MONFREDINI, G.; LUDWIG, W.F.; MELCHINGER, A.E.; FRANCESCHINI, P.; PAGNOTTO, G.; MOTTO, M. In an elite cross of maize a major quantitative trait locus controls one-fourth of the genetic variation for grain yield. Theoretical and Applied Genetics, v.90, p.415424, 1995.

AMORIM, L. Avaliação de doenças. In: BERGAMIN FILHO, A.; KIMATI, H.; AMORIM, L. (Ed.). Manual de fitopatologia. 3.ed. São Paulo: Agronômica Ceres, 1995. v.1, cap.32, p.647-671. 
BALMER, E.; PEREIRA, O.A.P. Doenças do milho. In: PATERNIANI, E.; VIEGAS, G.P. Melhoramento e produção de milho. 2.ed. Campinas: Fundação Cargill, 1987. v.2, cap.14, p.595-634.

BASTEN, C.J.; WEIR, B.S.; ZENG, B.Z. QTL cartographer, version 1.21. (software). Raleig: North Carolina State University, Department of Statistics, 2000.

BEARZOTI, E. Mapeamento de QTL. In: PINHEIRO, J.B.; CARNEIRO, I.F. Análise de QTL no melhoramento de plantas. Goiânia: FUNAPE, 2000. p.63-223.

BEAVIS, W.D.; GRANT, D.A. Linkage map based on information from four $F_{2}$ populations of maize (Zea mays L.). Theoretical and Applied Genetics, v.82, p.636-644, 1991.

BENTOLILA, S.; GUITTON, C.; BOUVET, N.; SAILLAND, A.; NYKAZA, S. FREYSSIENT, G. Identification of an RFLP marker tightly linked to the Ht1 gene in maize. Theoretical and Applied Genetics, v.82, p.393-398, 1991.

BERGAMIN FILHO, A. Curvas de progresso da doença. In: BERGAMIN FILHO; A.; KIMATI, H.; AMORIM, L. (Ed.). Manual de fitopatologia. São Paulo: Editora Agronômica Ceres, 1995. v.1, p.602-625.

BERGAMIN FILHO, A.; AMORIM, L. Manejo de fitopatossistemas: conceitos básicos. In: Doenças de plantas tropicais: epidemiologia e controle econômico. São Paulo: Agronômica Ceres, 1996. cap.9, p.189-228. 
BRADEEN, J.M.; SIMON, P.W. Conversion of an AFLP fragment linked to the carrot $Y_{2}$ locus to a simple, codominant, PCR-based marker form. Theoretical and Applied Genetics, v.97, p.960-967, 1998.

BRUNELLI, K.R.; SILVA, H.P.; CAMARGO, L.E.A. Mapeamento de genes de resistência a Puccinia polysora em milho. Fitopatologia Brasileira, v.27, n.2, p.134-140, 2002.

BUBECK, D.M.; GOODMAN, M.M.; BEAVIS, W.D.; GRANT, D. Quantitative trait loci controlling resistance to gray leaf spot in maize. Crop Science, v.33, p.838-847, 1993.

BURR, B.; BURR, F.A.; THOMPSON, K.H.; ALBERTSEN, M.C.; STUBER, C. W. Gene mapping with recombinant imbreds in maize. Genetics, v.118, p.519-526, 1988.

CAMARGO, L.E.A. Mapeamento de QRLs: contribuições e perspectivas. In: PINHEIRO, J.B.; CARNEIRO, I.F. (Org.). Análise de QTL no melhoramento de plantas. Goiânia: FUNAPE, 2000. p.49-62.

CAMPBELL, C.L.; MADDEN, L.V. Introduction to plant disease epidemiology. New York: John Wiley \& Sons, 1990. 532p.

CARSON, M.L. Inheritance of resistance to Phaeosphaeria leaf spot of maize. Plant Disease, v.85, n.7, p.798-800, 2001.

CARSON, M.L.; GOODMAN, M.M.; GLAWE, D.A. Phaeosphaeria leaf spot of maize in Florida. Plant Disease, v.75, n.9, p.968, 1991. 
CARSON, M.L.; STUBER, C.W.; SENIOR, M.L. Identification of quantitative trait loci (QTLs) for resistance to two foliar diseases in a mapping population of recombinant inbred (RI) lines of maize. Phytopathology, v.86, p.59, 1996. Abstract.

CARVALHO, G.A.; PAULA JÚNIOR, T.J.; ALZATE-MARIN, A.L.; NIETSCHE, S.; BARROS, E.G.; MOREIRA, M.A. Herança da resistência da linhagem And-277 de feijoeiro comum à raça 63-23 de Phaeoisariopsis griseola e identificação de marcador RAPD ligado ao gene de resistência. Fitopatologia Brasileira, v.23, n.4, p.482-485, 1998.

CASTIGLIONI, P.; AJMONE-MARSAN, P.; VAN WIJK, R.; MOTTO, M. AFLP markers in a molecular linkage map of maize: codominant scoring and linkage group distribuition. Theoretical and Applied Genetics, v.99, p.425431, 1999.

CASTLE, W.E. An improved method of estimating the number of genetics factors concerned in cases of blending inheritance. Science, v.54, p.223, 1921.

CHIN, E.C.L.; SENIOR, M.L.; SMITH, J.S.C. Maize simple repetitive DNA sequences: abundance and allele variation. Genome, v.39, p.866-873. 1996.

COCHRAN, W.G.; COX, G.M. Experimental design. 2.ed. New York: John Wiley \& Sons, 1966. 611p.

COE, E.H.; HOISINGTON, D.A.; NEUFFER, M.G. Linkage map of corn (maize) (zea mays L.). Maize Genetics Cooperation Newsletter, v.61, p.116-147, 1987. 
COELHO, A.S.G. Considerações gerais sobre a análise de QTL's. In: PINHEIRO, J.B.; CARNEIRO, I.F. Análise de QTL no melhoramento de plantas. Goiânia: FUNAPE, 2000. p.1-36.

CRESTE, S.; TULMANN NETO, A.; FIGUEIRA, A. Detection of single sequence repeat polymorfisms in denaturing polyacrylamide sequencing gels by silver staining. Plant Molecular Biology Reporter, v.19, p.299-306, 2001.

CRUZ, C.D.; REGAZZI, A. J. Modelos biométricos aplicados ao melhoramento genético. Viçosa: UFV, 1997. 390p.

DAS, S.N.; PRODHAN, H.S.; KAISER, SA, K.M. Further studies on the inheritance of resistance to Phaeosphaeria leaf spot of maize. Indian Journal of Mycology Research, v.27, n.2, p.127-130, 1989a.

DAS, S.N.; SINHAMAHAPATRA, S.P.; BASAK, S.L. Inheritance of resistance to Phaeosphaeria leaf spot of maize. Annual of Agricultural Research, v.10, n.2, p.182-184, 1989 b.

DAVIS, G.L.; MCMULLEN, M.D.; BAYSDORFER, C.; MUSKET, T.; GRANT, D.; STAEBELL, M.; XU, G.; POLACCO, M.; KOSTER, L.; MELIAHANCOCK, S.; HOUCHINS, K.; CHAO, S.; COE, E.H. A maize map standard with sequenced core markers, grass genome reference points and 932 expressed tagged sites (ESTs) in a 1736-locus map. Genetics, v.152, p.1137-1172, 1999.

DRAPER, J.M.; SMITH, H. Applied regression analysis. 2.ed. New York: John Wiley \& Sons, 1981. 709p. 
DUSSLE, C.M.; MELCHINGER, A.E.; XIA, X.C.; LÜBBERSTEDT, T. Molecular mapping and gene action of Scm1 and Scm2, two major QTL contributing to SCMV resistance in maize. Plant Breeding, v.119, p.299-303, 2000.

DUSSLE, C.M.; QUINT, M.; XU, M.L.; MELCHINGER, A.E.; LÜBBERSTEDT, T. Conversion of AFLP fragments tightly linked to SCMV resistance genes Scmv1 and Scmv2 into simple PCR-based markers. Theoretical and Applied Genetics, v.105, p.1190-1195, 2002.

EDWARDS, M.D.; STUBER, C.W.; WENDEL, J.F. Molecular-marker-facilitated investigations of quantitative trait loci in maize. Numbers, genomic distribuition and typs of genes action. Genetics, v.116, p.113-125, 1987.

FANTIN, G.M. Mancha de Phaeosphaeria, doença do milho que vem aumentando sua importância. Biológico, v.56, n.1, p.39, 1994.

FANTIN, G.M.; BALMER, E. Método de inoculação e evolução de sintomas da mancha foliar de Phaeosphaeria maydis em milho. Summa Phytopathologica, v.23, n.1, p.64, 1997. /Resumo/

FERNANDES, F.T.; OLIVEIRA, E. de. Principais doenças da cultura do milho. Sete Lagoas: EMBRAPA, CNPMS, 1997. 80p. (Circular técnica, 26)

FERNANDES, F.T.; SANS, L.M.A.; PINTO, N.F.J.A. Influência de fatores climáticos na ocorrência de Phyllosticta sp em milho. Fitopatologia Brasileira, v.20, p.309, 1995. /Resumo/

FERREIRA, M.E.; GATTAPAGLIA, D. Introdução ao uso de marcadores moleculares em análise genética. 2.ed. Brasília: EMBRAPA, CENARGEN, 1996. 220p. 
FORBES, A.; KAUFMAN, B.; HAMBLIN, A.M.; WHITE, D.G.; ROCCHEFORD, T.R. Mapping QTL associated with resistance to Aspergillus flavus ear rot and inhibition of aflatoxin production in different genetic backgrounds of maize. In: MAIZE GENETICS CONFERENCE, 40., 1998. Abstracts. http://www.agron.missouri.edu (20 Jan. 2003)

FREYMARK, P.J.; LEE, M.; WOODMAN, W.L.; MARTISON, C.A. Quantitative and qualitative trait loci affecting host-plant response to Exserohilum turcicum in maize (Zea mays L.). Theoretical and Applied Genetics, v.87, p.537-544, 1993.

FUTREL, M.C. Puccinia polysora epidemics on maize associated with cropping practice and genetic homogeneity. Phytopathology, v.65, p.1040-1042, 1975.

GODOY, C.V.; AMORIM, L.; BERGAMIN FILHO, A.; SILVA, W.J.; SOLFERINO, O.B.; SILVA, H.P; PEREIRA, O.A.P. Avaliação do progresso de doenças do milho em diferentes localidades e épocas de plantio. Summa Phytopathologica, v.24, n.1, p.80, 1998. /Resumo/

GOMES, F.P. Curso de estatística experimental. São Paulo: Livraria Nobel, 1990. 430p.

HALDANE, J.B.S. The combinantion of linkage values, and the calculation of distance between the loci of linked factors. Journal of Genetics, v.8, p.299$309,1919$.

HENNINGS, P. Fungi S. paulenses II a cl. Puttemans collecti. Hedwigia, v.41, p.295-311, 1902. 
HOISINGTON, D.; KHAIRALLAH, M.; GONZÄLEZ DE LEON, D. Laboratory protocols: CIMMYT applied molecular genetics laboratory. 2.ed. Mexico: CIMMYT, 1994. 51p.

HOLLAND, J.B.; UHR, D.V.; JEFFERS, D.; GOODMAN, M.M. Inheritance of resistance to southern corn rust in tropical-by-corn-belt maize populations. Theoretical and Applied Genetics, v.96, p.232-241, 1998.

JANSEN, R.C. Maximum likelihood in a generalized linear finite mixture model by using the EM algorithm. Biometrics, v.49, n.1, p.227-231, 1993.

JANSSEN, P.; COOPMAN, R.; HUYS, G.; SWINGS, J.; BLEEKER, M.; VOS, P.; ZABEAU, M.; KERSTERS, K. Evaluation of the DNA fingerprint method AFLP as a new tool in bacterial taxonomy. Microbiology, v.142, p.18811893, 1996.

JIANG, C.; ZENG, Z.B. Mapping quantitative trait loci with dominant and missing markers in various crosses from two inbred lines. Genetica, v.101, p.47-58, 1997.

JUNG, M.; WELDEKIDAN, T.; SCHAFF, D.; PATERSON, A.; TINGEY, S.; HAWK, J. Generations-means analysis and quantitative trait.locus mapping of anthracnose stalk rot genes in maize. Theoretical and Applied Genetics, v.89, p.413-418, 1994.

KAEPPLER, S.M.; MARCON, A.; JENSEN, S. Genetic mapping of resistance to high plains virus in maize. In: PLANT \& ANIMAL GENOME CONFERENCE, 5., San Diego, 1997. Abstracts. http://uww.intl-pag.org/pag/5/abstract/p-5d192.html (20 Jan. 2003) 
KAO, C.H.; ZENG, Z.B.; TEASDALE, R.D. Multiple interval mapping of quantitative trait loci. Genetics, v.152, p.1203-1216, 1999.

KERNS, M.R.; DUDLEY, J.W.; RUFENER II, G.K. QTL for resistance to common rust and smut in maize. Maydica, n.44, p.37-45, 1999.

KYETERE, D.; MING, R.; MCMULLEN, M.; PRATT, R.; BREWBAKER, J.; MUSKET, T.; PIXLEY, K.; MOON, H. Monogenic resistance to maize streak virus maps to the short arm of cromosome 1. Maize Genetics Cooperation Newsletter, v.69, p.136-137, 1995.

LANDER , E.; BOTSTEIN, D. Mapping mendelian factors underlying quantitaive traits using RFLP linkage maps. Genetics, v.121, p.185-199, 1989.

LANDER, E.S.; GREEN, P.; ABRAHAMSON, J.; BARLOW, A.; DALY, M.J.; LINCOLN, E.E.; NEWBURG, L. Mapmaker: an interactive computer package for constructing primary genetic linkage maps of experimental and natural populations. Genomics, v.1, p.174-181, 1987.

LEHMENSIEK, A.; ESTERHUIZEN, A.M.; VAN STADEN, D.; NELSON, S.W.; RETIEF, A.E. Genetic mapping of gray leaf spot (GLS) resistance genes in maize. Theoretical and Applied Genetics, v.103, p.797-803, 2001.

LIU, B.H. Statistical genomics. New YorK: CRC, 1998. 610p.

LIMA, M.; DUDIENAS, C.; PATERNIANI, M.E.A.G.Z.; DUARTE, A.P. Cruzamentos dialélicos parciais entre linhagens de milho com ênfase na produtividade e doenças foliares. In: CONGRESSO NACIONAL DE MILHO E SORGO, 22., Recife, 1998. Anais. Recife: ABMS, 1998. p.38. 
LINCH, M.; WALSH, B. Genetics and analysis of quantitative traits. Sunderland: Sinauer Associates, 1998. 980p.

LITT, M.; LUTY, J.A. A hipervariable microssatellite revealed by in vitro amplification of a dinucleotide repeat within the cardiac muscle actin gene. American Journal of Human Genetics, v.44, p.398-401, 1989.

MARTIN, G.B.; WILLIAMS, C.G.K., TANKSLEY, S.D. Rapid identification of markers linked to a Pseudomonas resistance gene in tomato by using random primers and near-isogenic lines. Proceedings of the National Academy of Sciences of the United States of America, v.88, p.23362340, 1991.

MATHER, K.; JINKS, J.L. Biometrical genetics. Ithaca: Cornell University Press, 1971. 382p.

McMULLEN, M.D.; JONES, M.W.; SIMCOX, K.D.; LOUIE, R. Three genetic loci control resistance to wheat streak mosaic virus in the maize imbred Pa405. Molecular Plant-Microbe Interactions, v.7, p.708-712, 1994.

McMULLEN, M.D.; SIMCOX, K.D. Clustering of disease resistance loci in the maize genome. Newsletter, n.69, p.52-53, 1995b.

MCMULLEN, M.D.; SIMCOX, K.D. Genomic organization of disease and insect resistance genes in maize. Molecular Plant-Microbe Interactions, v.8, p.811-815, 1995a.

MELO, L.C. Mapeamento de QTLs em feijoeiro, por meio de marcadores RAPD, em diferentes ambientes. Lavras: UFLA, 2000. 148p. 
MICHELMORE, R.W.; PARAN, I.; KESSELI, R.V. Identification of markers linked to disease resistance genes by bulked segregant analysis: a rapid method to detect markers in specific genomic regions using segregating populations. Proceedings of the National Academy of Science of the United States of America, v.88, p.9828-9832, 1991.

MILACH, S.C.K. Marcadores moleculares em plantas. Porto Alegre: UFRGS, 1998. 187p.

MING, R.; McMULLEN, M.D.; BREWBAKER, J.L.; PRATT, R.C.; MOON, H.G.; MUSKET, T.; HOLLEY, R. RFLP mapping of genes confering resistance to Erwinia stewartii. Maize Genetics Cooperation Newsletter, v.69, p.60, 1995b.

MING, R.; MCMULLEN, M.D.; BREWBAKER, J.L.; PRATT, R.C.; MOON, H.G.; MUSKET, T.; HOLLEY, R. RFLP mapping of maize mosaic virus resistance genes. Maize Genetics Cooperation Newsletter, v.69, p.60-61, 1995a.

MIRANDA FILHO, J.B. Quantitative analysis of a cross between populations and their derived generations. Revista Brasileira de Genética, v.14, n.2, p.547$561,1991$.

MUELLER, U.G.; WOLFENBARGER, L.L. AFLP genotiping and fingerprinting. Trends in Ecology \& Evolution, v.14, n.10, p.389-394, 1999.

OGLIARI, J.B. Identificação e localização de um gene de resistência de milho a Exserohilum turcicum (Pass) Leonard \& Suggs através do uso de marcadores moleculares microssatélites. Piracicaba, 1999. 114p. Tese (Doutorado) - Escola Superior de Agricultura "Luiz de Queiroz", Universidade de São Paulo. 
PACCOLA-MEIRELLES, L.D.; FERREIRA, A.S.; MEIRELLES, W.F.; MARRIEL, I.E.; CASELA, C.R. Detection of a bacterium associated with a leaf spot disease of maize in Brazil. Journal of Phytopathology, v.149, p.275-279, 2001.

PALTRIDGE, N.G.; COLLINS, N.C.; BENDAHMANE, A.; SYMONS, R.H. Development of YLM, a codominant PCR marker closely linked to the Yd2 gene for resistance to barley Yellow dwarf disease. Theoretical and Applied Genetics, v.96, p.1170-1177, 1998.

PARLEVLIET, J.E. Components of resistance that reduce the rate of epidemic development. Annual Review of Phytopathology, v.17, p.203-222, 1979.

PATERNIANI, M.E.A.G.Z; SAWAZAKI, E.; DUDIENAS, C.; DUARTE, A .P GALLO, P.B. Cruzamentos dialélicos entre linhagens de milho com diferentes niveis de resistência a moléstias foliares. In: CONGRESSO NACIONAL DE MILHO E SORGO, 22., Recife, 1998. Anais. Recife: ABMS, 1998. p.98.

PE, M.E.; GIANFRANCESCHI, L.; TARAMINO, G.; TARCHINI, R.; ANGELINI, P.; DANI, M.; BINELLI, G. Mapping quantitative trait loci (QTL) for resistance to Gibberella zeae infection in maize. Molecular General Genetics, v.241, p.11-16, 1993

PEGORARO, D.G.; BARBOSA NETO, J.F.; DAL SOGLIO, F.K.; VACARO, E.; NUSS, C.; CONCEIÇÃO, L.D.H. Genética da resistência à mancha foliar de feosféria em milho. In: REUNIÃO TÉCNICA ANUAL DO MILHO, 45., Pelotas, 2000. Anais. Pelotas: EMBRAPA, CNPC, 2000. p.232. 
PEGORARO, D.G.; BARBOSA NETO, J.F.; VACARO, E.; NUSS, C.; DAL SOGLIO, F.K. Incidência da mancha foliar causada pelo fungo Phaeosphaeria maydis em milho: efeito de épocas de semeadura e doses de nitrogênio. In: CONGRESSO NACIONAL DE MILHO E SORGO, 22. Londrina, 1998. Anais. Londrina: ABMS, 1998. p.122.

RANE, M.S.; PAYAK, M.M.; RENFRO, B.L.A. Phaeosphaeria leaf spot of maize. Indian Phytopathology Society Bulletin, v.3, p.7-10, 1965.

REGINATO NETO, A. Incorporação de germoplasma exótico de milho (Zea mays L.). Piracicaba, 1998. 133p. Tese (Doutorado) - Escola Superior de Agricultura "Luiz de Queiroz", Universidade de São Paulo.

SAWAZAKI, E.; DUDIENAS, C.; PATERNIANI, M.E.A.G.Z.; GALVÃO, J.C.C.; CASTRO, J.L.; PEREIRA, J. Reação de cultivares de milho à mancha de Phaeosphaeria no estado de São Paulo. Pesquisa Agropecuária Brasileira, v.32, n.6, p.585-589, 1997.

SCHUSTER, I. Identificação de QTL para resistência de nematóide de cisto da soja e capacidade de combinação de genitores. Viçosa, 1999. 85p. Tese (Doutorado) - Universidade Federal de Viçosa.

SENIOR, M.L.; CHIN, E.; AUSTIN, D.; LEE, M.; SMITH, S. Mapping simple sequence repeats in maize. Maize Newsletter, v.70, p.50-54, 1996.

SHURTLEFF, M.C. (Ed.). Compendium of corn diseases. 2.ed. St. Paul: American Phytopathological Press, 1992.105p.

SILVA, H.D.; VENCOVSKY, R. Testes múltiplos e associação de marcas associadas a QTL's. Scientia Agricola, v.99, n.4, p.755-762, 2002. 
SILVA, H.P. Análise genética da resistência a Puccinia polysora Underw em milho ( Zea mays L.). Piracicaba, 2001. 87p. Tese (Doutorado) - Escola Superior de Agricultura "Luiz de Queiroz", Universidade de São Paulo.

SILVA, H.P. Genética da resistência a Phaeosphaeria maydis em milho. Jaboticabal, 2002. 105p. Tese (Doutorado) - Universidade Estadual de São Paulo.

SINCOX, K.D.; MCMULLEN, M.D.; LOUISE, R. Co-segregation of the maize dwarf mosaic virus resistnace gene, $m d m 1$, With the nucleolus organizer region in maize. Theoretical and Applied Genetics, v.90, p.341-346, 1995.

TANKSLEY, S.D. Mapping polygenes. Annual Review of Genetics, v.27, p.205-33, 1993.

THODAY, J. M. Location of polygenes. Nature, v.191, p.368-370, 1961.

VAN DER VOORT, J.N.A.M.; VAN ECK, H.J.; VAN ZANDVOORT, P.M.; OVERMARS, H.; HELDER, J.; BAKKER, J. Linkage analysis by genotyping of sibling populations: a genetic map for the potato cyst nematode constructed using a "pseudo-F2" mapping strategy. Molecular and General Genetics, v.261, n.6, p.1021-1031, 1999.

VELDBOOM, L.R.; LEE, M.; WOODMAN, W.L. Molecular-marker-facilited studies in na ellite maize population. 1. Linkage analysis and determination of QTL for morphological traits. Theoretical and Applied Genetics, v.88, p.7-16, 1994.

VENCOVSKY, R.; BARRIGA, P. Genética biométrica no fitomelhoramento. Ribeirão Preto: Sociedade Brasileira de Genética, 1992. 469p. 
VON PINHO, R.G. Metodologias de avaliação, quantificação de danos e controle genético da resistência do milho á Puccinia polysora e Physopella zeae. Lavras, 1998. 140p. Tese (Doutorado) - Universidade Federal de Lavras.

VOS, P.; HOGERS, R.; BLEEKER, M.; REIJANS, M.; VAN DE LEE, T.; HORNES, M.; FRIJTERS, A.; POT, J.; PELEMAN, J.; KUIPER, M.; ZABEAU, M. AFLP: a new technique for DNA fingerprinting. Nucleic Acids Research, v.23, n.21, p.4407-4414, 1995.

VUYLSTEKE, M.; MANK, R.; ANTONISE, R.; BASTIAANS, E.; SENIOR, M.L.; STUBER, C.W.; MELCHINGER, A.E.; LUBBERSTEDT, T.; XIA, X.C.; STAM, P.; ZABEAU, M.; KUIPER, M.; AFLP: two hight-density AFLP linkage maps of Zea mays L.: analysis of distribuition of AFLP markers. Theoretical and Applied Genetics, v.99, p.921-935, 1999.

WRIGHT, S. Systems of mating. the biometric relations between parent and offspring. Genetics, v.6, p.111-178, 1921.

XIA, X.C.; MELCHINGER, A.E.; KUNTZE, L.; LÜBBERSTEDT, T. QTL mapping of resistance to sugarcane mosaic virus in maize. Phytopathology, v.89, p.660-667, 1999.

XU, M.L., MELCHINGER, A.E., XIA, X.C.; LUBBERSTEDT, T. High-resolution mapping of loci conferring resistance to sugarcane mosaic virus in maize using RFLP, SSR and AFLP markers. Molecular and General Genetics, v.261, n.3, p.574-581, 1999.

YOUNG, N.D. QTL mapping and quantitative disease resistance in plants. Annual Review of Phytopathology, v.34, p.479-501, 1996. 
ZAITLIN, D.; DEMARS, S.; GUPTA, M. Linkage of a second gene for NCLB resistance to molecular markers in maize. Maize Genetics Cooperation Newsletter, v.66, p.69-70, 1992.

ZAITLIN, D.; DEMARS, S.; GUPTA, M. Linkage of $r h m$, a recessive gene for resistance to southern corn leaf blight, to RFLP marker loci in maize (Zea mays) seedlings. Genome, v.36, p.555-564, 1993.

ZENG, Z.B. Precision mapping of quantitative trait loci. Genetics, v.136, n.9, p.1457-1468, 1994.

ZENG, Z.B. Theoretical basis for separation of multiple linked gene effect in maping quantitative trait loci. Proceedings of the National Academy of Sciences of the United States of America, v.90, p.10972-10976, 1993. 
